\title{
Program Director's Report for the Office of Health and Environmental Research
}

\section{August 1996}

\section{Prepared for}

Office of Health and Environmental Research

Office of Energy Research

U.S. Department of Energy

Prepared by

Ernest Orlando Lawrence Berkeley National Laboratory

Berkeley, California 94720

operated by

University of California

for

U.S. Department of Energy

under Contract No. DE-AC03-76SF00098

PUB-778 


\section{DISCLAIMER}

This report was prepared as an account of work sponsored by an agency of the United States Government. Neither the United States Government nor any agency thereof, nor any of their employees, make any warranty, express or implied, or assumes any legal liability or responsibility for the accuracy, completeness, or usefulness of any information, apparatus, product, or process disclosed, or represents that its use would not infringe privately owned rights. Reference herein to any specific commercial product, process, or service by trade name, trademark, manufacturer, or otherwise does not necessarily constitute or imply its endorsement, recommendation, or favoring by the United States Government or any agency thereof. The views and opinions of authors expressed herein do not necessarily state or reflect those of the United States Government or any agency thereof. 


\section{DISCLAMMER}

Portions of this document may be illegible in electronic image products. Images are produced from the best available original document. 
1.0 OHER Program Summary

1.1 Director's Overview 1

Program Integration.................................................... 5

Center for Environmental Biotechnology ............... 6

2.0 Program Organization, Facilities, and Resources ... 9

2.1 Organization and Management of OHER Programs

Figure 1:LBNL and Division Org, Charts .............. 9

2.2 Budget Information

Table 1\&2: Budget Data \& Staff ............................. 12

Figure 2: Sponsoring Agencies Pie Chart............. 12

2.3 Personnel

OHER Investigator List ......................................... 13

2.4

Table 3: Facilities and Resources ...........................15

Advanced Light Source ........................................ 15

Imaging Facilities ....................................................16

National Tritium Labeling Facility .........................16

Biomedical Isotope Facility .....................................16

Resource for Molecular Cytogenetics ................... 17

Transgenic Resource .................................................... 17

Life Sciences Microscope Resource ........................ 17

Yeast Genetic Stock Center .......................................17

3.0 Research Management Practices ................................19

3.1 Advisory Committees and Program Reviews ..... 19

President's Council on the National Laboratories-

3.2 Institutional Program Development Funds .......... 22

Table 5: Summary of Major Discretionary Funding Investements (OHER-related LDRD) .22

3.3 Compliance with Animal Welfare and Human ......

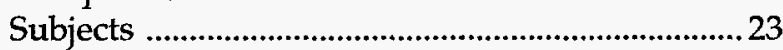

Waste Minimization and Pollution Prevention ... 23

Safety Committees ....................................................23

4.0 Research in Progress \& Major Accomplishments .. 25

Analytical Technology

New Instrumentation \& Detection Methods....... 25 


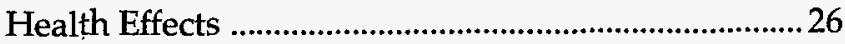

Tumor Biology ...............................................................26

Radiation Damage and Genetic Toxicology ….....27

Stem Cell Biology ......................................................... 28

General Life Sciences ................................................... 28

Structural Biology-Proteins ...................................28

Structural Biology-Nucleic Acids .........................29

Structural Biology-Uses of the ALS.....................29

Modeling Human Pathology in Transgenic Mice30

Human Genome Center ...........................................30

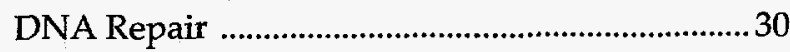

Medical Applications ........................................................32

The Center for Functional Imaging ....................... 32

Imaging of Apolipoprotein E-Binding Receptors In Vivo

Table 6: Significant Science and Technology

Achievements 33

Table 7: Major Examples of Collaborative Research...... 47

Table 8: Patents, Licenses, CRADAs (FY 95-96) ............. 49

Work for Others ...................................................... 51

Table 9: Summary of Work for Others ............................... 55

5.0 Program Orientation/Future Directions (FY97-99) 63

Analytical Technology ..................................................... 63

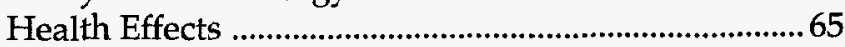

General Life Sciences .......................................................67

Medical Applications ..................................................73

Table 10: Facility Construction and Modification .............74

Table 11: Major Equipment Requirements .........................75

6.0 Contemporary Issues .................................................. 78

7.0 Appendices ......................................................................... 82

7.1 Information Transfer .............................................. 82

7.2 Conferences. Workshops, \& Training Programs . 92

7.3 Extramural Activities ................................................ 92

7.4 OHER-Supported Publications ............................. 102

7.5 Selected Research Highlights ............................... 114 


\section{Acknowledgments}

I am very grateful for the assistance I received in preparing this document. In particular, I would like to thank the following people for their extraordinary contributions:

Huber Warner, Assistant Deputy Director;

Adele Sylar;

Kati Markowitz;

Tony Linard;

of Life Sciences Division...

...as well as all of the fine scientists and engineers at "Berkeley Lab" whose research provided the inspiration for this document.

David Gilbert-Editor

(please call 510-486-6096 with your questions or comments, or contact me through the Internet at degilbert@lbl.gov) 


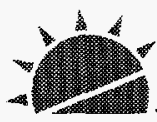

\section{OHER Program Summary}

\subsection{Director's Overview:}

Since its establishment, the Department of Energy's Office of Health and Environmental Research (OHER) has had responsibility for conducting biological research to develop the knowledge needed to identify, understand, and anticipate the long-term health consequences of energy use and development, including the potential health impacts of radiation. The Health Effects Research Program has established the basis for understanding the health consequences of radiation for humans, developed radiation dosimetry methodology, characterized and evaluated the health impacts of fossil fuels, and developed and conducted research to determine the health impacts of inhaled toxicants. The results of this research have provided input for setting genetic standards for radiation and chemical exposure.

During the ensuing years the Ernest Orlando Lawrence Berkeley National Laboratory ("Berkeley Lab" or "LBNL") has emerged as one of the premier Biosciences research venues in the national laboratory system. LBNL performs unclassified basic and applied research and develops technologies in support of OHER. OHER's mission is to explore and mitigate the long-term health and environmental consequences of energy use and to advance solutions to major medical challenges. The ability of the Laboratory to engage in this mission depends upon the strength of its core competencies. In addition, there are several key capabilities that are crosscutting, or underlie, many of the core competencies. We refer to these as foundations in order to distinguish them from the core competencies.

Core Competencies

Bioscience and Biotechnology: Structural biology; Genome research; Bioinstrumentation; Cell and molecular biology, Molecular cytogenetics; Medical imaging; Biology of human diseases; Radiation biology and; Biomolecular design. 
Environnental Assessment and Remediation: Advanced instrumentation and methods for environmental characterization and monitoring; Human health and ecological risk assessment; Indoor air quality; Subsurface remediation of contaminants; Geologic isolation of high-level nuclear waste; Actinide chemistry.

Advanced Detector Systems: Major detectors for highenergy physics, nuclear science, and astrophysics; Scientific conception and project leadership; Advances in particle and photon detection; Implementation of new concepts in detector technology.

Materials Characterization and Synthesis: Advanced spectroscopies and microscopies based on photons, electrons, and scanning probes; Ceramics; Alloys; Heterostructures; Superconducting, magnetic, and atomically structured materials; Bio-organic synthesis.

Chemical Dynamics, Catalysis, and Surface Science: Reactiondynamics; Photochemistry of molecules and free radicals; Surface structures and functions; Heterogeneous, homogeneous, and enzymatic catalysis.

Advanced Technologies for Energy Supply and Energy Efficiency: Subsurface resources and processes; Building technologies; Electrochemistry; Fossil-fuel technologies; Energy analysis.

Particle and Photon Beams: Analysis and design of accelerators; Beam dynamics; High-brightness ion and photon sources; Advanced magnet design and R\&D; High-frequency RF technology; X-ray optics and lithography; Induction linacs and neutral beams for fusion energy.

LBNL has identified four foundations; they are listed below together with descriptive subheadings.

\section{FouNDATIONS}

National Research Facilities: The development, construction and operation of major research facilities: Advanced Light Source; National Center for Electron Microscopy; 88-Inch Cyclotron; National Tritium Labeling Facility.

Computation and Information Management: Highspeed networking and distributed computing; Processing and analysis of scientific images; Data-acquisition and -analysis systems; Scientific-information systems; Database technology.

Engineering Design and Fabrication Technologies: Custom integrated circuits; Integrated accelerator systems; Superconducting-magnet assemblies; In- sertion devices for synchrotron radiation; Large-volumesemiconductor-detector technology; Laboratory automation; Advanced CAD/CAM facilities for large systems; Facilities for materials processing and fabrication.

Education of Future Scientists and Engineers: Undergraduate, graduate, postdoctoral, and faculty involvement in scientific and engineering research through close ties with the University of California (UC) system; Educational programs for elementary schools, high schools, and colleges.

The following areas bear most significantly on the role that LBNL plays in furthering the mission of OHER.

\section{BioscienCes AND BioteCHNOLOGY}

LBNL's bioscience and biotechnology competency focuses on structural biology; genome research; bioinstrumentation; molecular cytogenetics; medical imaging; the biology of human diseases; and biomolecular design. New recruits in the areas of genomic instability and chromatin structure will provide added cohesiveness to the on-going studies under the newly established Department of Cancer Biology. In the area of Radiation Biology, radiation is used as a probe to delineate the structure of DNA in chromatin and chromosomes. Also, fundamental research is conducted from molecules to cells, animals and humans, to develop better methods for radiation risk asessment. LBNL has pioneered the use of such techniques as electron crystallography, and has strong programs in x-ray crystallography, NMR spectroscopy, and chemical probe analysis to study biological problems. Recent programs have accelerated the capability to evaluate molecular complexes and the function of biological molecules, particularly proteins and DNA, from the perspective of their specific threedimensional structure. The LBNL Human Genome Center excels in genomic DNA sequencing, genetic mapping, physical mapping, and DNA isolation and analysis. Several major facilities serve as areas of intellectual and technical cross-fertilization. The Advanced Light Source offers dramatic new scientific opportunities for biosciences, especially in the fields of $x$-ray crystallography, $x$-ray spectroscopy, and $x$-ray microscopy.

One of LBNL's most ambitious partnerships, the Resource for Molecular Cytogenetics, a joint venture with the University of California, San Francisco, funded by the Department of Energy and Vysis, a diagnotics subsidiary of Amoco, was created to facilitate the application of molecular cytogenetics in clinical and 
biological studies. Work is being pursued in three areas: development and application of improved hybridization technology, selection of probes optimized for the use in in situ hybridization (FISH), and development of digital imaging microscopy. One of the missions of the Resource is the generation of physically mapped probes for use in in situ hybridization cancer studies. The probes have large inserts $(50-100 \mathrm{~kb})$, are cloned in a stable vector (typically cosmids, P1s or PACs) and will be distributed at $\sim 5 \mathrm{Mb}$ intervals over the entire human genome. A public database showing the currently available probes, along with a request form, can be accessed on the world wide web (WWW) using the Mosaic interface at (http://rmc-www.LBNL.gov/).

\section{ENVIRONMENTAL SCIENCE AND REMEDIATION TECHNOLOGIES}

LBNL scientists and engineers working in a range of disciplines from life sciences to geosciences address the bread th of issues outlined above and form a core competency in environmental assessment and remediation. This competency at LBNL includes: advanced instrumentation and methods for environmental characterization and monitoring; human health and ecological risk assessment; indoor air quality; subsurface remediation of contaminants; geologic isolation of high-level nuclear waste; and actinide chemistry. LBNL researchers study non-invasive methods for describing the subsurface, new methods for collecting samples and for measuring contaminant concentrations and identifying their chemical form, methods for assessing the biological toxicity of mixtures of contaminants, and methods toeliminate the exposure pathways and monitor the effectiveness of remediation schemes. LBNL has defined key scientific issues for locating a nuclear waste repository and provided the computational tools used throughout the DOE laboratory system, and is developing techniques and characterizations of complex agents that specifically and effectively sequester actinide ions (e.g., plutonium). LBNL has capabilities for improving risk assessments by developing assays to elucidate the chronic and sublethal effects of exposure to toxic substances in aquatic and terrestrial ecosystems. LBNL is preeminentin conducting research on the nature, sources, transport, transformation, and deposition of indoor air pollutants, including radon and combustion emissions. In addition, LBNL's strengths in reaction dynamics, combustion chemistry, and photochemistry of molecules and free radicals will lead to better understanding and control of the environmental impact of fossil fuel combustion.
Advanced Materials Synthesis, Characterization, and Processing-This competency draws its strength at LBNL from expertise in physics, chemistry, traditional materials science and theoretical modeling, combined with the development and application of many types of advanced spectroscopies and microscopies. An important aspect of LBNL's strength in materials research is its expertise in the synthesis of advanced ceramics and alloys; multilayer heterostructures; superconducting, magnetic, and atomically structured materials and devices; and materials made by bioorganic synthesis. In addition, new materials for heterogeneous catalysis and surface structures and functions are also an integral part of the materials research effort, which are in the LBNL competency on Chemical Dynamics, Catalysis, and Surface Science. LBNL employs and develops a unique array of techniques for spectroscopy and microscopy based on photons, electrons, and scanning probes. The Laboratory draws upon two national research facilitiesthe Advanced Light Source and the National Center for Electron Microscopy, as well as a broad spectrum of novel and unique characterization techniques.

\section{National EnERgy Research Scientific ComputTng Center}

From its location adjacent to the University of California campus in Berkeley, the National Energy Research Scientific Computing Center (NERSC) at Berkeley Lab represents the largest unclassified scientific computing resource on the West Coast.

In November, 1995, the Department of Energy selected Berkeley Lab as the site for the High-Performance Computing Access Center. A staff of 100 and a $\$ 40$ million budget from the DOE's Office of Energy Research enables NERSC to serve over 4,500 researchers from national laboratories across the United States, as well as from universities and industry as they work to solve a wide variety of technological and scientific problems. Five Cray Research supercomputer systems, with over two trillion bits of data storage capability, make up the heart of NERSC computer hardware capability.

NERSC is called upon to assist with a variety of national programs. For example, improved ocean and atmosphere computer models are being developed to better understand and predict the impact of global warming on climate and other aspects of our environment. Other programs combine high resolution nuclear magnetic resonance, much like a medical MRI exam, with supercomputing to study the effects of cancer causing agents on human DNA; use computer simulation to 
help develop new and refined materials that could ultimately save industry billions of dollars; and apply computer technology to the study of various pollutants to help develop effective environmental cleanup programs.

NERSC also includes the High Performance Computing Access Center, the Energy Sciences Network (ESNET--ahigh speed, fiber optic computer network), and the Center for Computational Sciences and Engineering (CCSE).

Research scientists in the U.S., Germany and Japan use ESNET as a global Internet to work both remotely and cooperatively on energy-related issues. Ultimately, researchers will be able to transmit as many as 8,000 pages of information a second on ESNET between locations, significantly expanding the cooperative research data base. Supporting this effort is the work of the 30 person CCSE staff who develop and use leading edge computer technology to solve very large scientific and engineering problems in energy, the environment and industrial technology.

NERSC, with its proximity to the Berkeley campus, the Mathematical Sciences Research Institute, and major computer/data communications companies in the Bay Area, is uniquely positioned to serve as a rich center of research synergy in the computational sciences for years to come.

\section{Advanced Manufacturing and Process TECHNOLOGY}

LBNL maintains unique capabilities in the area of engineering design and fabrication technologies. The integrated capability at LBNL includes: Laboratory and process automation; Advanced CAD/CAM facilities for large systems; Facilities for materials processing and fabrication; and Engineering Design and Fabrication Technologies. The laboratory and process automation is represented by engineering in the Human $\mathrm{Ge}$ nome Project while the advanced CAD/CAM capability is represented through design efforts of major facilities such as theKeck Telescope, Advanced Light Source, and Sudbury Neutrino Observatory detector assembly. The laaboratory is also coordinating the process automation team for the AMTEX (American Textile Industry) partnership.

\section{LaRge Scale Research and Development Factirties}

LBNL has an underlying capability for designing, build- ing and operating large shared research facilities for the benefit of the national scientific community. LBNL operates four such research facilities: the Advanced Light Source (ALS), the 88-Inch Cyclotron, the National Center for Electron Microscopy (NCEM), and the National Tritium Labeling Facility. The ALS is a thirdgeneration synchrotron radiation source optimized for the use of insertion devices to produce very high brightness tunable radiation in the XUV spectral range. The 88-Inch Cyclotron is a versatile and reliable accelerator of beams from hydrogen to uranium which has unique capabilities for multiply-charged ion beams with variable energy for research in nuclear structure, nuclear astrophysics and fundamental symmetries. The NCEM is an electron microscopy user facility for materials characterization at high spatial resolution which operates advanced high voltage and high resolution transmission electron microscopes for atomic resolution imaging and electron beam microanalysis of materials. The National Tritium Labeling Facility produces compounds with high specific activities of tritium to serve as tracers in chemical and biomedical research, and provides them to biomedical researchers in North America. The resource contains a unique combination of labeling equipment alongside analytical equipment dedicated to radiochemical analyses.

\section{SCIENCE AND ENGINEERING EXCELLENCE AND INTEGRATION}

LBNL maintains an underlying capability for engineering excellence and systems integration in many technical areas. Examples include: custom integrated circuits; integrated accelerator systems; integrated superconducting-magnet assemblies; insertion devices for synchrotron radiation; and large-volume semiconductor-detector technology. In addition to an extensive infrastructure of engineering and technical staff together with supporting mechanical and electronic shop facilities, the Laboratory maintains a number of unique, excellent and highly specialized functions that constitute the fundamental capability. These include facilities for the design of custom integrated circuits together with a capability to fabricate and test prototype devices, experience in the design and evaluation of superconducting magnet assemblies, a unique collection of experts in the area of permanent magnet insertion devices for synchrotron applications, and advanced CAD/CAM facilities for the design of large systems and corresponding expertise in managing large engineering projects. 


\section{AdVANCED ENERGY TECHNOLOGIES AND END USE APPLICATIONS}

LBNL has a strong core competency in energy technologies that integrates scientific, engineering, architectural, information and other capabilities for end use applications to address national needs in building technology, electrochemical energy storage, combustion, and energy use and subsurface energy resources.

\section{Program Integration}

Biosciences at LBNL, and the Health Effects area in particular, are being transformed into an integrated program that emphasizes the links between genome, structural biology, and health effects research. Complex biological problems are indeed appropriate for National Laboratories where multifaceted teams could be brought together to address them. Such problems require the latest knowledge about genes, protein structure, subcellular structure, tissue structure and gene expression and entail collaboration and cooperation between biologists, biophysicists, engineers, chemists and computer scientists.

Vertical support of a given problem should be encouraged. Protein structure should be used to understand function in the context of the higher organization of the cells and tissues. Functional human culture models should be developed in parallel with transgenic and knockout studies. Support for higher order structures should be considered. As such, molecular and nuclear medicine as well as imaging need to be integrated with cell and molecular biology and informatics.

The genome and structural biology programs will continue to emphasize technology development and support of user facilities, respectively, aimed at the rapid and cost-effective determination of DNA sequences and protein structures. Priority will be given, when choices need to be made, to the analysis of gene sequences and protein structures of interest to DOE, including genes and proteins that affect individual susceptibility to energy-related materials or that are related to energy production, energy utilization, and environmental cleanup.

Technologies and information developed in the genome and structural biology programs will be utilized in the health effects research program to understand the function of genes of interest to DOE. In particular, efforts will be focused on:
- determining the relationship between susceptibility genes and adverse health effects from exposure to energy-related materials;

- developing diagnostic tools that can be used to characterize low level environmental and occupational exposures to energy-related agents and to identify at-risk individuals;

- characterizing the relationship between the structure and function of proteins with potential uses in energy production, energy utilization and environmental cleanup; and re-engineering these proteins to improve their utility for achieving DOE's mission in these areas;

- understanding the function of these proteins and their regulation in the context of tissues and organisms, with additional emphasis on human cells and systems.

\section{Scientific Strategy}

The major focus of the health effects research program at LBNL is directed to understanding, at the molecular and structural levels, the function of genes of interest to DOE. This effort will require a coordinated, multidisciplinary research effort that takes advantage of the resources and technologies generated from OHER's genome, structural biology, and health effects programs.

The components of a scientific program to understand the function of a particular gene of interest to DOE are:

\section{Gene Isolation}

Human or microbial genome program libraries and technologies will be used to isolate clones containing genes of interest.

Clone physical characterization

Fine structure maps and sequence information useful in studying gene expression and genetic variability will be developed.

Interspecies comparison

Homologous genes will be identified, isolated, and characterized from different species enabling more rapid determination of gene function. Specific examples could include human and mouse genes for susceptibility or genes from different microbial species that could be useful in bioremediation.

Genetic variation at the sequence level 
Genetic variation will be determined on the genes of interestenabling an association of known sequence variation with biological effects. Specific genes/effects of interest will include susceptibility to disease in people or effectiveness of waste degradation in microbes.

Protein structure and function

The function and/or structure of proteins will be characterized using both biological and molecular approaches. For example, the function of potential human susceptibility genes could be characterized in vivo using transgenic mice and antisense methods. In contrast, the structure of microbial genes of potential use in bioremediation could be characterized using structural biology approaches.

Development of biological tools

Biological tools that address critical DOE needs are being developed from understanding gene function. Functional culture models will be created and studied. Additional examples would include cost-effective diagnostic tools for identifying at-risk individuals working at DOE clean-up sites. Similarly, microbial enzymes could be re-engineered for use in bioremediation or energy production.

This approach represents large scale, multidisciplinary science that requires appropriate coordination among DOE-funded research programs at national laboratories and universities. It makes use of the unique laboratory strengths in genomics, structural biology, cell and molecular biology, mouse genetics, and biomedical engineering. As outlined above, this approach is applicable to Departmental issues in health and the environment. These range from the identification of individuals with increased susceptibility to health risks from exposure to energy-related materials to the development of more efficient and cost-effective methods for cleaning up DOE waste sites or producing energy.

\section{Center for Environmental Biotechnology}

In the course of LBNL's strategic planning effort, Environmental Biotechnology has been identified as a major area for growth and development. While LBNL has several core competencies in this area, we now need to integrate these areas and add additional expertise. We therefore have embarked on the creation of a center and have attracted a highly productive and imaginative coordinator.

Ongoing environmental research at the Lawrence Berkeley National Laboratory is focused in several key areas:
- pollution prevention

- bioremediation

- waste site characterization and monitoring

- hazardous waste treatment

- human exposure and comparative risk assessment

- ecological risk assessment and restoration

The research approach is multi-disciplined and involves diverse departments within several divisions. Hence, it was decided to establish a Center for Environmental Biotechnology under a Director's Initiative. Programs are being established under key focus areas that bring together not only the capabilities at LBNL, but also link those established within academic institutions, industry, and government research institutions. Our goal is not to be redundant but rather to build bridges that link different capabilities within the DOE laboratories and associated universities and to focus on key environmental clean-up problems by enhancing synergy rather than competition between the various institutions.

There is also an educational component to the Center in that is directly linked to the BEST (Bioremediation, Education, Science and Technology) program which offers the opportunity for academic students to obtain hands on experience in the laboratory and field operations.

Another important link is to the community within the Bay Area. The Alameda Center for Environmental Technology (ACET) is being established and the Center for Environmental Biotechnology will help facilitate collaborative CRADAs with ACET.

The Center for Environmental Biotechnology will also collaborate with CAL-EPA in setting up a program to validate and certify new environmental biotechnologies for field application. In addition an Advisory Council has been organized to guide our research efforts to meet the demands of the market. The members of the Council are well known in the area of environmental technology and represent industry, academia and government sectors.

Currently, funds are being sought for establishing a central microbiology working laboratory and several proposals are being written in collaboration with UC Berkeley, Oregon State, CYTEC, General Electric, Idaho National Engineering Laboratory, Oak Ridge National 
Laboratory, and Los Alamos National Laboratory.

Both basic and applied research programs are being established within the Center for Environmental Biotechnology. These programs are:

\section{Ecotoxicity:}

This program focuses on determining the effect of pollution on small animals such as nematodes, worms, shellfish and amphibians. Studies include the monitoring of reproductive cycles and DNA damage as a result of being exposed to different levels and types of pollution in the Bay Area. This program, linked to the Health Risk Assessment program, works with cell biologists on developing more sensitive assays and a better understanding of the regulation system involved in having DNA damage and a negative cascade effect on normal metabolic functions.

\section{Health Risk Assessment:}

Research is concentrating on the development of assays using primary human cells and measurement of enzyme levels to determine how pollutants are actively metabolized. The EPA has a list of potential carcinogenic pollutants. However, most of the work done in this area has been done on rats and mice. We are assessing the health risk to humans by determining which pollutants, if ingested, inhaled, or absorbed, can be deleterious to our body cells by causing abnormalities in cell structure and function.

\section{Molecular Evolution and Ecology:}

California has many contaminated sites due to activities performed by the armed forces and industries such as oil refineries, metal electroplate shops, mining industry and agriculture. Nature has the ability to deal with some of the contamination by genetically altering certain microbial and plant species to either completely mineralize the contaminant or detoxify the pollutant. Our research will focus on how microorganisms and plants evolve through genetic mutations either spontaneously or by induction, to accommodate the pollutant in a toxic environment. By better understanding the regulation and expression systems of specific organisms, we can metabolically or genetically engineer "super organisms" such as microorganisms with more active enzymes or plants with better absorption capacity that can be used in bioremediation efforts.

\section{Structure-Function Relationships:}

One of the barriers to using microorganisms more effectively in the field for remediation has been the lack of understanding of the cell's physiology in a natural environment. Microorganisms grown under laboratory conditions such as on agar (solid) media or in submerged culture (fermentors) may exhibit a different structure and function than what is found in nature in soil, in water, and on plant surfaces. The research focus will be on linking engineering with microbiology to design bioreactors that would function more closely to what goes on within the subsurface or water column. This technology will improve soil treatment methods for field applications. In addition, physiological studies will yield information about what are the limits for optimization in field treatments. For example, microorganisms are notorious for developing biofilms that stick and clog soil pores. Finding a way to inhibit that formation yet enable the microorganism to bind to soil particles would improve the bioremediation treatment for certain soil matrixes.

\section{Natural Augmentation:}

In many instances microbial populations have been exposed to pollutants over time within a given site, natural selection occurs and enables these microorganisms to use the pollutant as a food substrate. Augmenting this population would have an advantage in that more biomass would require more food to survive. However, in some cases, this approach backfires, and the population dies out or can no longer metabolize the pollutant. Studies will center on optimizing biophysical parameters such as moisture, $\mathrm{pH}$, and salinity. Redox potential will improve and stabilize microbial metabolic processes occurring in soil or water systems. In addition competition factors will be evaluated, such as waste products, soil binding properties, gas-water interface effect on nutrient transport and those that may affect establishment of the desired population.

\section{In situ Microbial Monitoring:}

Bioremediation has been described as a black box by engineers because we do not have the technology to verify "balancing the equation." Therefore, improved systems to monitor microbial activity in the soil is needed. Research has begun on use of cold radioisotopes to monitor carbon metabolism and applications of this technology is being studied for metal uptake and detoxification. We need to focus on developing improved systems of biomarkers and biosensors for use in the field. One possibility is to integrate biopolymers with 
engineering knowledge to create semi-organic sensors.

The descriptions above make it clear that the Center for Environmental Biotechnology is integrating all existing capabilities related to environmental biotechnology within LBNL and establishing key synergistic links with outside laboratories. We feel that by using this approach, resources will be saved in solving several key environmental pollution problems in $D O E, D O D$, and in California, including those critical pollution problems created by the agriculture, oil, and mining industries.

Partnership Integration

LBNL maintains an underlying capability for utilizing a multiprogram energy research laboratory as a national resource in partnership with industry, universities and other government agencies. An excellent example of interagency partnership for the advancement of technology is a new Cooperative Research and Development Agreement (CRADA), funded by the National Institute of Standards and Technology. Led by Dr. Daniel Pirkel of the LBNL/UC SF Resource for Molecular Cytogenetics, this collaboration with Vysis, (a subsidiary of $A M O C O$ ) entails the development and evaluation of techniques and DNA reagents for performing comparative genomic hybridization to arrays of DNA on a microchip. The resulting technology will be configured so that it will be applicable to clinical genetic testing in a wide range of health problems including cancer and developmental abnormalities.

One of the most productive forms of technology partnerships, the direct exchange of personnel and ideas through the educational process, is strongly supported through LBNL's fundamental capability of Education of Future Scientists and Engineers. LBNL supports undergraduate, graduate, postdoctoral, and faculty involvement in scientific and engineering research through close ties with the University of California system and with educational programs for elementary schools, high schools, and colleges.

\section{CENTER fOR SCIENCE AND ENGINEERING}

\section{EDUCATION}

Ernest Orlando Lawrence Berkeley National Laboratory's Center for Science and Engineering Education (CSEE) was established in 1987 to bring together many of the laboratory's educational programs. Since its inception, CSEE programs have grown to include new pre-college, undergraduate, graduate, and faculty programs that support the Center's goals to: (i) promote equal access to scientific and technical careers for all students, including women, minorities, the handicapped, and the economically disadvantaged; (ii) improve the quality of science and engineering teaching by supporting increased classroom emphasis on the scientific process and exposure to frontier science and technology; (iii) increase the number of U.S. students who become scientists and engineers by developing and implementing strategies to provide continuity of opportunity from elementary through graduate school; and (iv) promote scientific literacy, including an understanding of relationships among frontier science and technology. 


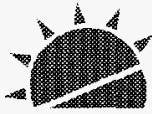

\subsection{Program Organization, Facilities, and Resources}

\section{Figure 1: Organizational Charts}

\section{ERNEST ORLANDO LAWRENCE BERKELEY NATIONAL LABORATORY • UNIVERSITY OF CALIFORNIA}

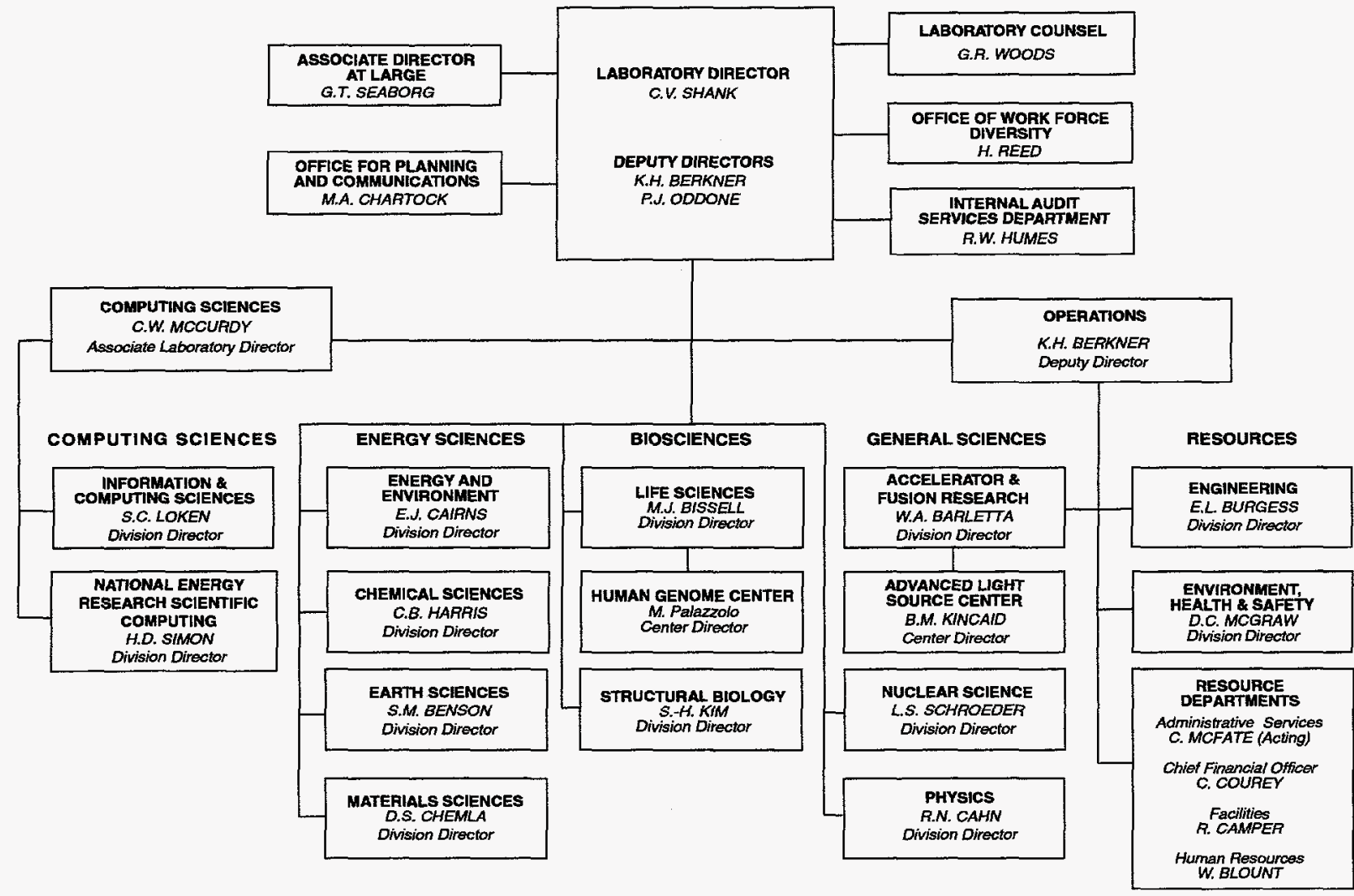

EARTH SCIENCES DIVISION ORGANIZATIONAL CHART

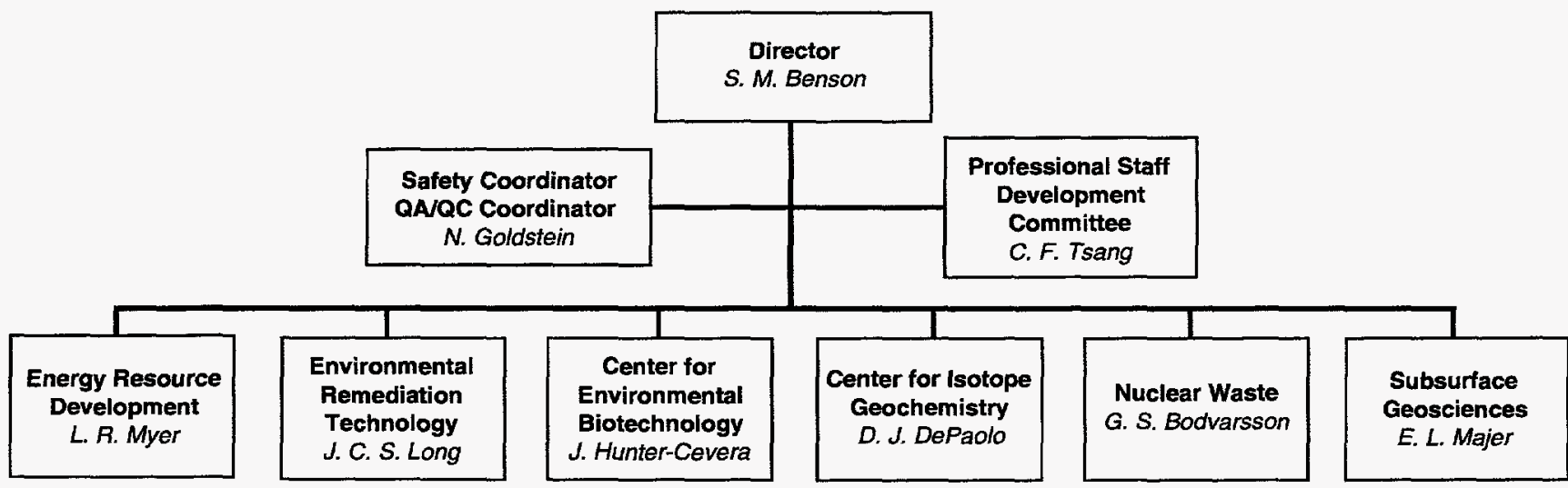




\section{LIFE SCIENCES DIVISION ORGANIZATIONAL CHART}

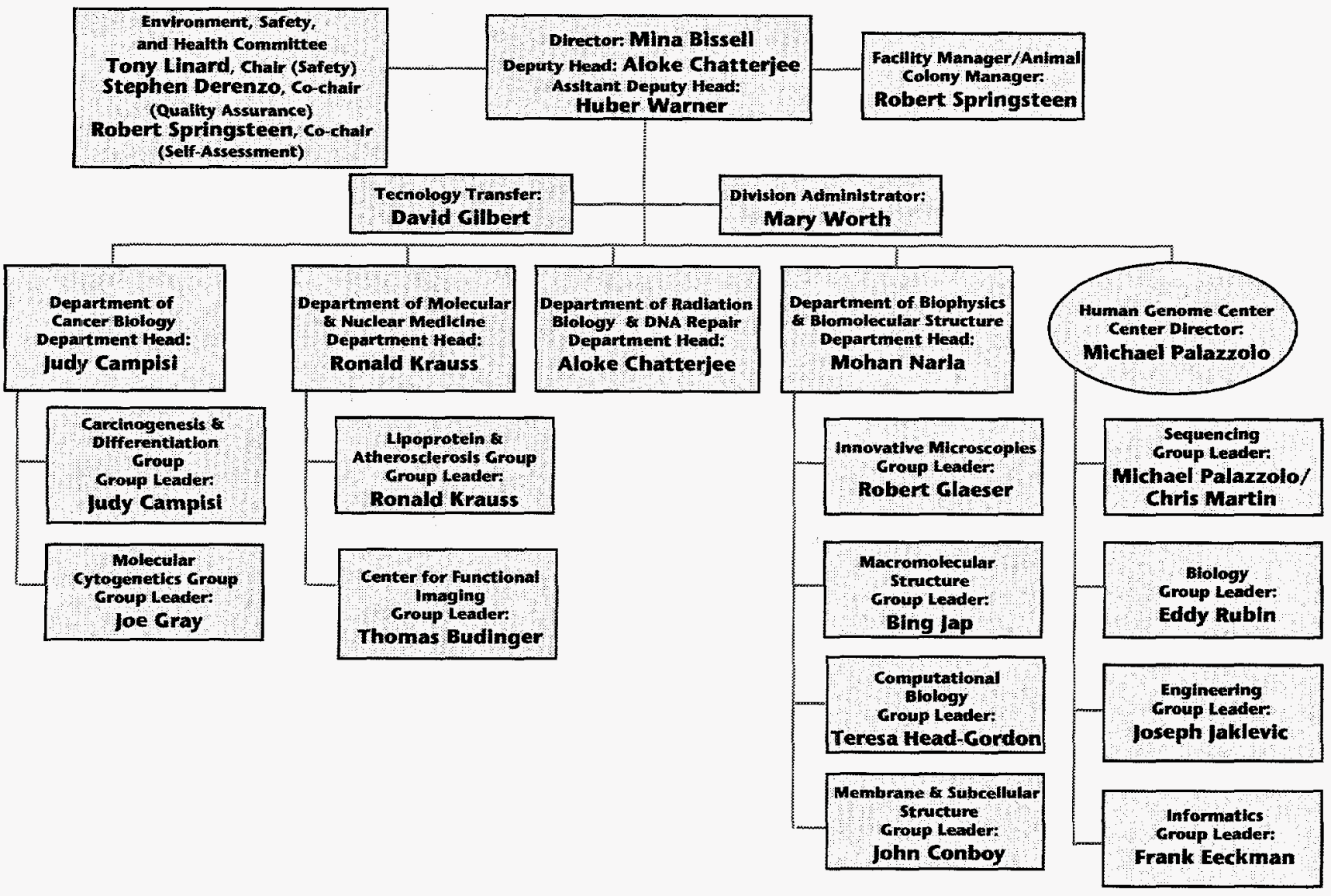

STRUCTURAL BIOLOGY DIVISION ORGANIZATIONAL CHART

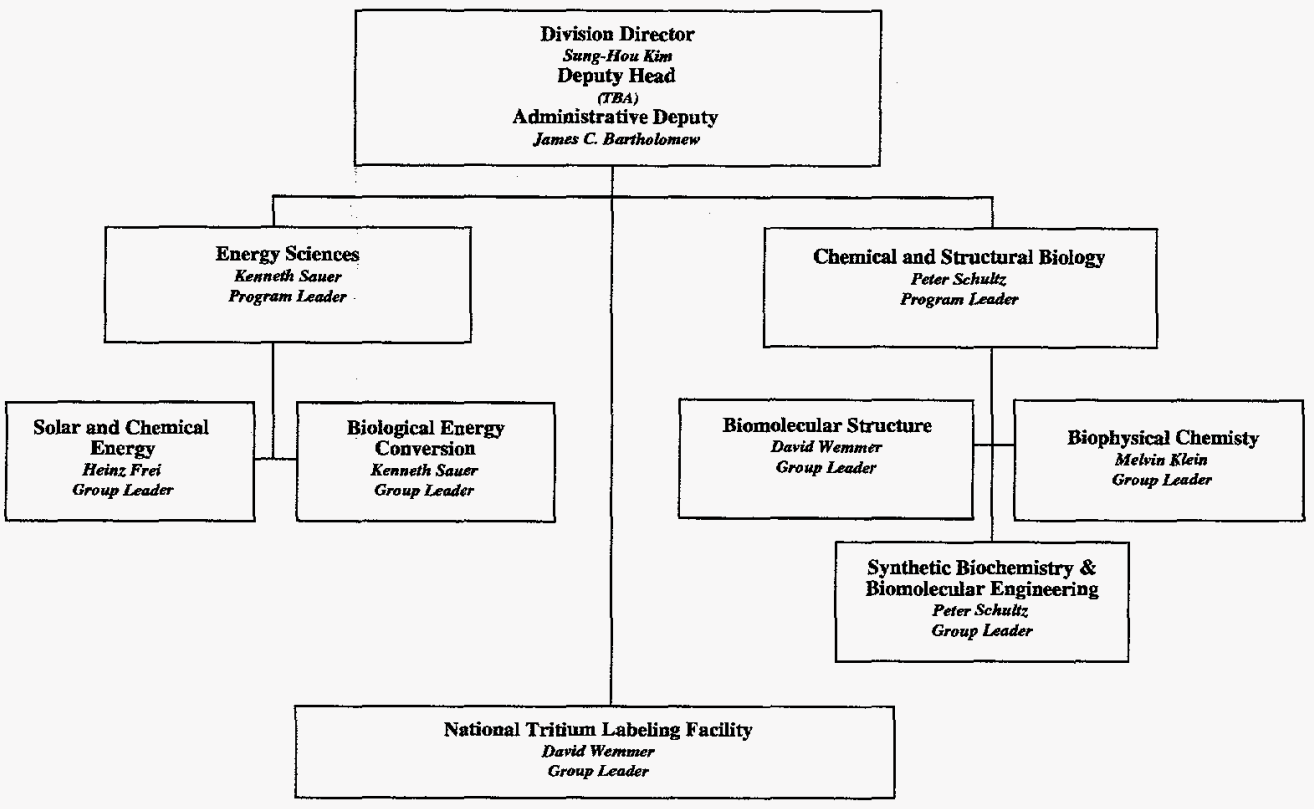




\section{ENGINEERING DIVISION ORGANIZATIONAL CHART}

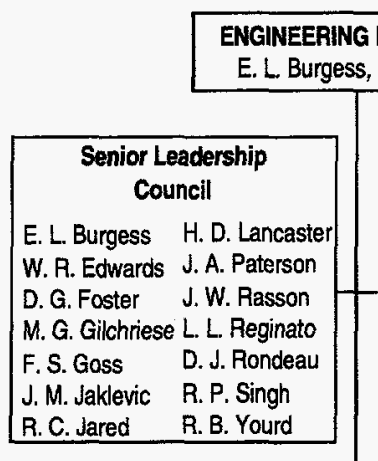

Administrative Support

L. G. Cobb, Tech. Dept.

J. A. Magee, Eng. Depts. M. E. St. Hill, Budget

\begin{tabular}{|c|c|}
\hline $\begin{array}{c}\text { New Initiatives and } \\
\text { Partnerships } \\
\text { D. G. Foster }\end{array}$ & $\begin{array}{c}\text { Division } \\
\text { Technical Resources } \\
\text { D. J. Rondeau }\end{array}$ \\
\cline { 2 - 3 }
\end{tabular}

\begin{tabular}{|c|}
\hline $\begin{array}{l}\text { Electronic \& Software } \\
\text { Engineering }\end{array}$ \\
\hline $\begin{array}{l}\text { Accelerator Electronics } \\
\text { Engineering Dept. } \\
\text { H. D. Lancaster, Head } \\
\text { L. L. Reginato, Deputy }\end{array}$ \\
\hline $\begin{array}{l}\text { Detector Instrumentation } \\
\text { Dept. } \\
\text { M. G. Gilchriese, Acting Head } \\
\text { R. C. Jared, Deputy }\end{array}$ \\
\hline $\begin{array}{l}\text { Software } \\
\text { Engineering Dept. } \\
\text { R. P. Singh, Head } \\
\text { A. K. Biocca, Deputy }\end{array}$ \\
\hline
\end{tabular}

\begin{tabular}{|c|}
$\begin{array}{c}\text { Mechanical } \\
\text { Engineering }\end{array}$ \\
\hline $\begin{array}{c}\text { Accelerator Mechantical } \\
\text { Engineering Dept. } \\
\text { R. B. Yourd, Head }\end{array}$ \\
\hline ALS Mechanical \\
Engineering Dept. \\
J. A. Paterson, Head \\
E. H. Hoyer, Deputy \\
\hline Detector Mechanical \\
Engineering Dept. \\
J. A. Rasson, Acting Head \\
W. R. Edwards, Act. Deputy \\
\hline
\end{tabular}

\section{ENERGY AND ENVIRONMENT DIVISION ORGANIZATIONAL CHART}

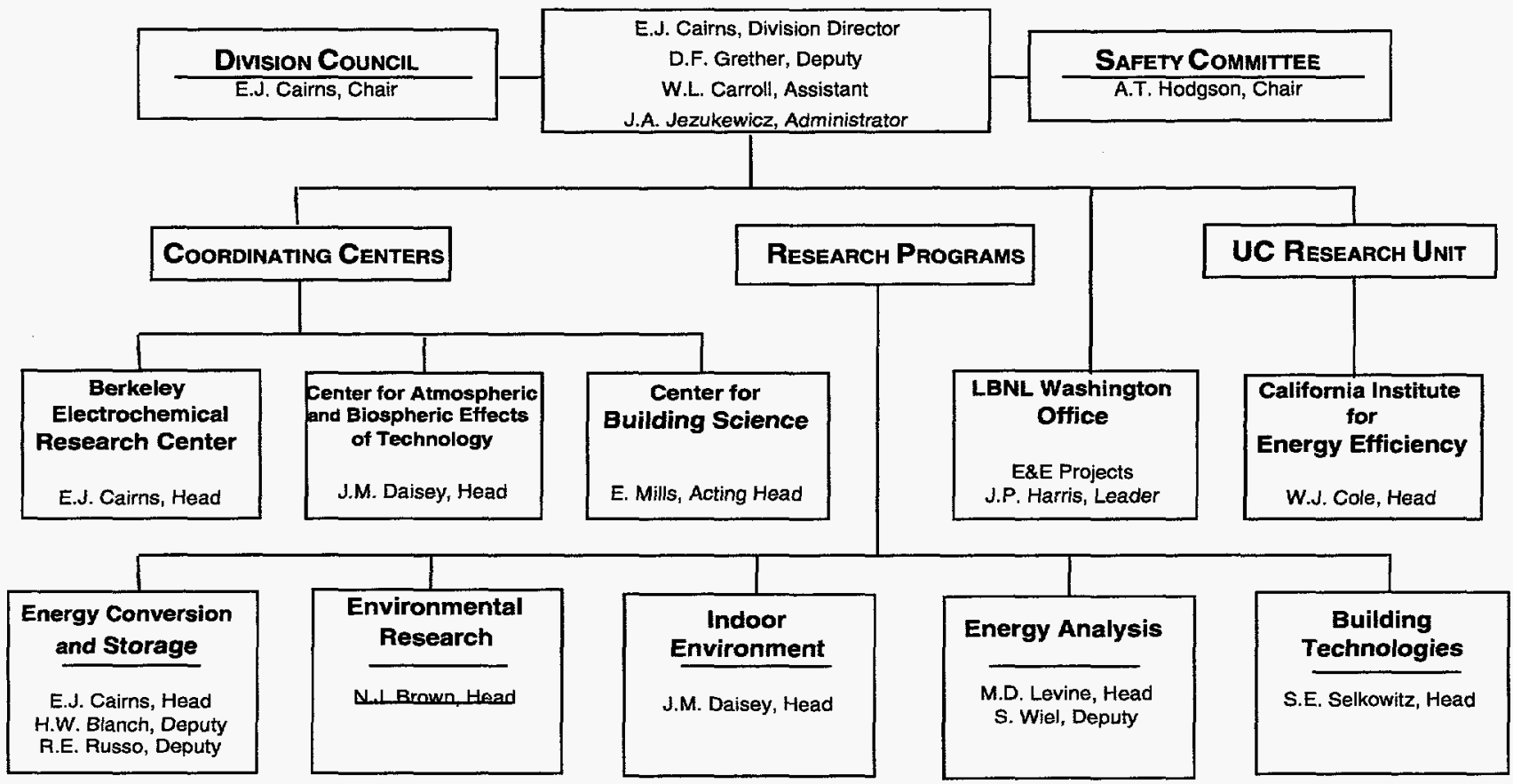


Table 1:

Budget Data FY 1993, 1994, 1995, \& 1996

Laboratory Funding (millions of dollars)

Source

$\underline{1993} \quad \underline{1994} \quad \underline{1995} \quad \underline{1996}$

OHER

$\begin{array}{lrrrr}\text { Operating } & 17.9 & 21.2 & 22.3 & 23.6 \\ \text { Capital equip. } & 1.4 & 2.6 & 3.8 & 3.2 \\ \text { Construction } & 1.2 & 2.7 & 20.5 & 12.4 \\ \text { TOTAL } & 20.5 & 26.5 & 41.2 & 39.2\end{array}$

Other OER

$\begin{array}{lrrrr}\text { Operating } & 115.1 & 104.2 & 106.9 & 155.7 \\ \text { Capital equip } & 15.0 & 20.8 & 12.2 & 27.5 \\ \text { Construction } & 24.8 & 19.9 & 13.1 & 19.1 \\ \text { TOTAL } & 154.9 & 144.9 & 132.2 & 202.2\end{array}$

Other DOE

$\begin{array}{lrrrr}\text { Operating } & 49.2 & 59.5 & 54.0 & 44.5 \\ \text { Capital equip. } & 0.5 & 1.6 & 6.0 & 4.6 \\ \text { Construction } & 1.2 & 0.0 & 3.4 & 2.3 \\ \text { TOTAL } & 50.9 & 61.1 & 63.4 & 51.4 \\ & 35.4 & 44.1 & 48.0 & 48.0\end{array}$

$\begin{array}{lllll}\text { WFO } & 35.4 & 44.1 & 48.0 & 48.0\end{array}$

Total Lab Funding $\quad \underline{261.7} \quad \underline{276.6} \quad \underline{290.2} \quad \underline{340.9}$
Table 2:

Staff Working on OHER-Sponsored Projects

Laboratory Personnel $\underline{1993} \quad \underline{1994} \quad \underline{1995} \quad \underline{1996}$ (FTEs)

\begin{tabular}{lrrrr} 
OHER direct & 115 & 102 & 104 & 140 \\
Other DOE direct & 1415 & 1347 & 1342 & 1297 \\
WFO & 340 & 386 & 348 & 349 \\
Indirect & 780 & 760 & 782 & 644 \\
Total Lab Personnel & $\underline{\mathbf{2 6 5 0}}$ & $\underline{\mathbf{2 5 9 5}}$ & $\underline{\mathbf{5 7 6}}$ & $\underline{\mathbf{2 4 3 0}}$ \\
\hline
\end{tabular}

\section{Figure 2: \\ Proposed Fiscal Year 1996 Funding}

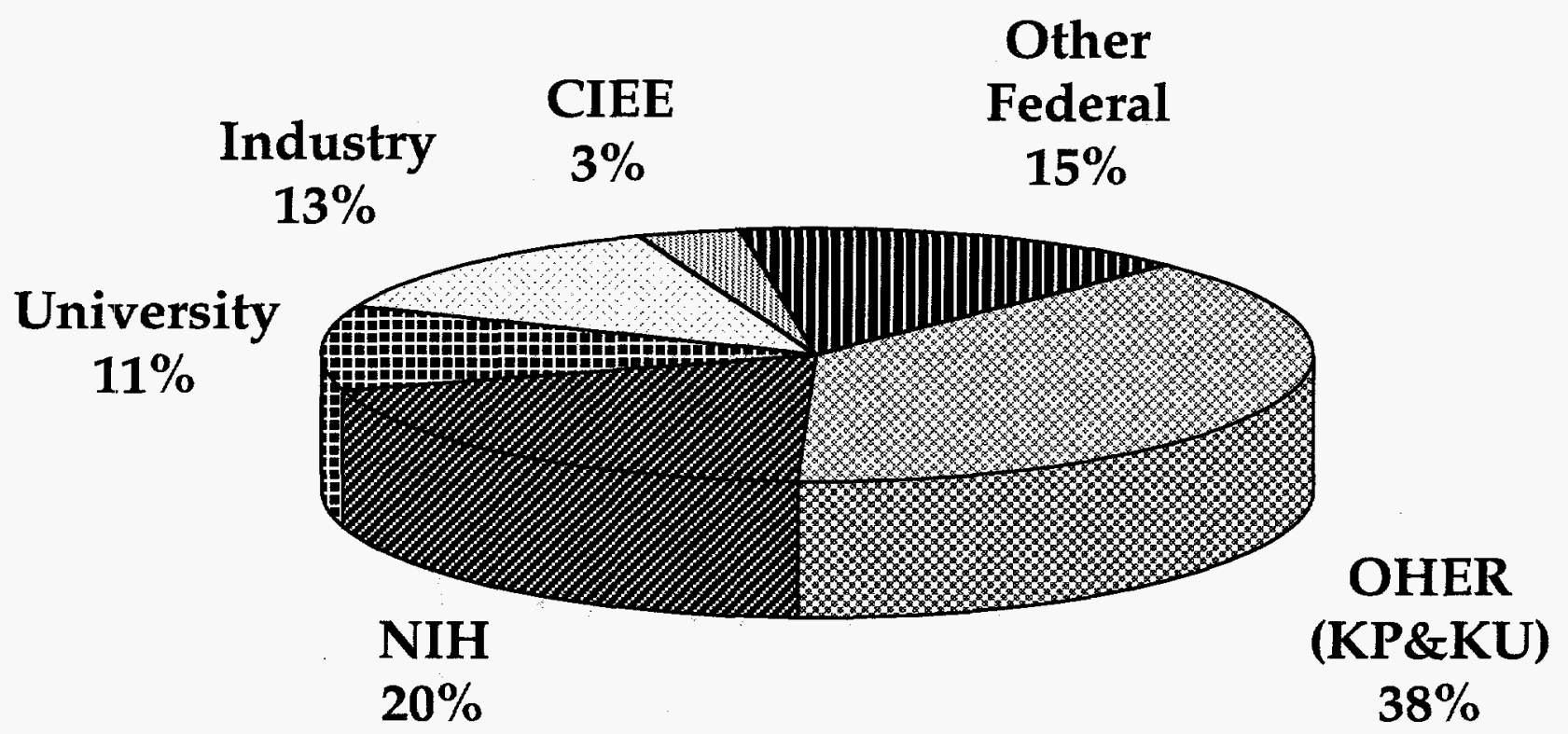

Sponsors of biosciences and environmental sciences research programs at Lawrence Berkeley National Laboratory. CIEE - California Institute for Energy Efficiency; NIH-National Institutes of Health 


\section{LBNL OHER-Funded Principal Investigators}

\begin{tabular}{|c|c|c|c|c|c|c|}
\hline KP01 & Analytical Technology & Principal Investig & Division & telephone & fax & mailstop \\
\hline KP0102 & RM-temp Semicond Field Applications & Luke, $P$ & ENG & 5104 & 5857 & $70 A-3363$ \\
\hline KP0102 & Silicon Array Spect. for Synchrontron & Ludewigt, B & ENG & 7733 & 5788 & $71-259$ \\
\hline KP0102 & Near-Infrared Detection Complex Mixt. & Lucas, D & EE & 7002 & 7303 & $29 \mathrm{C}-102$ \\
\hline KP02 & Environmental Research & & & & & \\
\hline KP0201 & UV-B and Atmospheric Composition & Novakov, $\mathrm{T}$ & $\mathrm{EE}$ & 5319 & 5172 & $73-101$ \\
\hline KP0203 & Field Heterogeneity & Majer, EL & ES & 6709 & 5686 & $90-1116$ \\
\hline КР0203 & $\begin{array}{l}\text { Experimental \& Theoretical } \\
\text { Investigation of Radon }\end{array}$ & Sextro, $R$ & $\mathrm{EE}$ & 6295 & 6658 & $90-3058$ \\
\hline KP0203 & $\begin{array}{l}\text { Migration \& Biodegredation of NAPLs } \\
\text { Within Fractured Rocks in Vadose Zone }\end{array}$ & $\begin{array}{l}\text { Cartsen/Pruess/ } \\
\text { Hunter-Cevera }\end{array}$ & ES & $\begin{array}{l}6732 \\
7359\end{array}$ & $\begin{array}{l}5686 \\
4553\end{array}$ & $\begin{array}{l}90-1116 \\
70 \mathrm{~A}-3307\end{array}$ \\
\hline КР03 & Health Effects & & & & & \\
\hline KP0302 & Air Pollutant Exposures in Buildings & Gadgil, A & EE & 4651 & 6658 & $90-3058$ \\
\hline KP0302 & Mechanism of Tumor Promotion & Bissell, MJ & LS & $4365 / 6890$ & 5586 & 83-101 \\
\hline KP0302 & Rapid Transformation Assay & Stampfer, MR & LS & 7273 & 5735 & $934-47 \mathrm{~A}$ \\
\hline KP0302 & Radiation Transcript & Campisi, J & LS & $4416 / 4417$ & 4475 & $70 \mathrm{~A}-1118$ \\
\hline КР0302 & $\begin{array}{l}\text { Interspecies Extrapolation \& Risk } \\
\text { Assessment }\end{array}$ & $\begin{array}{l}\text { Gold, LS } \\
\text { Ames, B }\end{array}$ & $\begin{array}{l}\text { LS } \\
\text { LS }\end{array}$ & $\begin{array}{l}7080 \\
2-5165\end{array}$ & $\begin{array}{l}6773 \\
3-7935\end{array}$ & $\begin{array}{l}\text { Barker } \\
\text { Barker }\end{array}$ \\
\hline KP0302 & Bone Marrow Stem Cells & Narla, M & LS & 7029 & 6746 & $74-157$ \\
\hline KP0302 & Molecular Cytogenetics Resource & Gray, JW & LS & $5810 / 5812$ & 5343 & 74-157 \\
\hline KР0302 & DNA Damage by Radon Alpha Part. & Cooper, $\mathrm{P}$ & LS & 7346 & 5735 & $934-47 \mathrm{~A}$ \\
\hline KP0302 & Genetic Susceptibility \& Radiation & Pallavicini, $\mathrm{M}$ & LS & 6124 & 6746 & $74-157$ \\
\hline КР0302 & Elucidation of Chromosome Structure & Morgan, $W$ & MS & $2-8484$ & & Evans \\
\hline $\mathrm{KPO} 0303$ & Radiological Physics & Chatterjee, A & LS & 5415 & 6949 & $29-100$ \\
\hline КP04 & General Life Sciences & & & & & \\
\hline КР0401 & Molecular Struct Membrane Transpt Sys. & Jap, BK & LS & $7104 / 7990$ & 6488 & Donner \\
\hline КР0401 & Biophysical Chemistry & Klein, MP & SB & 4331 & 6059 & Calvin \\
\hline KP0401 & Structural Biophysics & Kim, SH & SB & 4333 & 5272 & Calvin \\
\hline
\end{tabular}




\begin{tabular}{|c|c|c|c|c|c|c|}
\hline KP0401 & Biomolecular Structure Analy by NMR & Wemmer, DE & $\mathrm{SB}$ & 4318 & 6059 & Calvin \\
\hline KP0401 & Synthesis \& Struct of Catalytic Antiboc. & Schultz, PG & SB & $642-9277$ & $643-6890$ & Latimer \\
\hline KP0401 & ALS Microscopy & Glaeser, RM & LS & $642-2905$ & 6488 & Donner \\
\hline KP0401 & ALS Spectroscopy & Cramer, SP & $\mathrm{EE}$ & 4720 & 4550 & $2-300$ \\
\hline KP0401 & ALS Crystallography & Kim, SH & SB & 4333 & 5272 & Calvin \\
\hline KP0401 & Semi-Conduct. X-Ray Detectors Synchr. & Jaklevic, JM & ENG & 5647 & 5857 & $70 A-3363$ \\
\hline КР0401 & Structure \& Function of Catalytic RNA & Holbrook, S & SB & 4304 & 6059 & Calvin \\
\hline KP0402 & Genetic Study on Yeast & Game, J & LS & 5651 & 5342 & Donner \\
\hline КР0402 & Center for Biomolecular Engineering & $\begin{array}{l}\text { Schultz, PG } \\
\text { Kim, SH }\end{array}$ & $\begin{array}{l}\text { SB } \\
\text { SB }\end{array}$ & $\begin{array}{l}642-9277 \\
4333\end{array}$ & $\begin{array}{l}643-6890 \\
5272\end{array}$ & $\begin{array}{l}\text { Latimer } \\
\text { Calvin }\end{array}$ \\
\hline KP0402 & Genetic Eng. of Mice for Health Effects & Rubin, E & LS & 5072 & 6746 & $74-157$ \\
\hline КP0402 & Hyperthermophilic Protein & Kim, SH & SB & 4333 & 5272 & Calvin \\
\hline KP0403 & Molecular Carcinogenesis & Bissell, MJ & LS & $4365 / 6890$ & 5586 & $83-101$ \\
\hline KP0404 & Human Genome Center & Palazzolo, M & LS & 6932 & 6798 & $74-157$ \\
\hline KP0404 & HGP Operations & Spengler, SJ & LS & 4879 & 5717 & Donner \\
\hline KP0404 & Molecular Cytogenetic Tech & Gray, JW & LS & 5812 & 6746 & $74-157$ \\
\hline KP0404 & Advanced Detectors for Mass Spect. & Jaklevic, JM & ENG & 5647 & 5857 & $70 \mathrm{~A}-3363$ \\
\hline KP0404 & Automated Users Interface Generation & Zorn, MD & ICS & 5041 & 4004 & $50 \mathrm{~B}-3238$ \\
\hline КР0404 & Lab. Info. Mgmt. Sys. Megabase Sequec. & Markowitz, VM & ICS & 6835 & 4004 & 50B-3238 \\
\hline KP0404 & Community College Proposal & Spengler, SJ & CSEE & 7249 & 5717 & Donner \\
\hline KP05 & Carbon Dioxide Research & & & & & \\
\hline КР0508 & Discounting in an Integrated Assessment & Howarth, R & $\mathrm{EE}$ & 4207 & 6996 & $90-4000$ \\
\hline KP0508 & Structural Models of Long Term Energy & Greening, L & EE & 5147 & 6996 & $90-4000$ \\
\hline КP06 & Medical Applications & & & & & \\
\hline KP0601 & Experi. Medicine Develop Radionuclide & Van Brocklin, $\mathrm{H}$ & LS & 4083 & 4768 & $55-121$ \\
\hline КР0601 & Positron 3D Imaging Instrument & Derenzo, SE & LS & 4097 & 4768 & $55-121$ \\
\hline KP0601 & Experimental Med. Clinic. Diagn \& Isto & Budinger, TF & LS & 5435 & 4768 & 55121 \\
\hline KP0601 & Imaging of Apolip. E-Binding Receptors & Krauss, RM & LS & 4277 & 5342 & Donner \\
\hline
\end{tabular}

All telephone and facsimile numbers are for the 510 area 486-prefix unless otherwise stated. E-mail address are in most cases the investigator's first two initials, last name (no spaces) @lbl.gov (e.g., mjbissell@lbl.gov). For other important phoné numbers LBL's WWW Home Page can be accessed at http://www.lbl.gov/ 


\subsection{Laboratory Facilities \& Resources}

\section{AdVANCEd Light SOURCE}

The Advanced LightSource(ALS), America's first thirdgeneration synchrotron, offers dramatic new scientific opportunities for the life sciences, especially in the fields of $x$-ray crystallography, $x$-ray spectroscopy, and $x$-ray microscopy. The brightness of the facility's $x$-rays and the advanced design of its insertion devices and beamlines are unmatched resources that are already opening up new horizons in biological research.

Life sciences research at the ALS will ultimately use several insertion device and bend-magnet beamlines, each the source of radiation for a different "resource center." In x-ray microscopy, our current vision includes two complementary $x$-ray microscopes, each offering its own advantages. The first one, called XM-1, became operational in August 1994 and is illuminated by a bend magnet source for full field imaging. The XM1 operates in transmission, providing information about material within a sample, not just on its surface. Researchers can analyze samples with thicknesses on the order of 1 to 10 microns with this $x$-ray microscope, making it an ideal complement to optical and electron microscopes. The microscope was designed as an easy to use instrument and is attracting a wide range of interest from the biological community. The light source for the second microscope will be an undulator producing ultrabright soft $x$-rays for scanning imaging.

A second resource center at the Advanced Light Source, the Macromolecular Crystallography Facility will be devoted to macromolecular crystallography, the primary technique of structural biology; it is under construction for commissioning and operation beginning in the fall of 1996. This resource is expected to match or 
exceed the performance of any synchrotron facility currently in operation. The heart of the crystallography facility will be a beamline delivering $x$-rays from a 38pole wiggler source to up to three automated endstations for high-quality data collection with rapid sample turnaround. The protein crystallography facility project was started in FY 94 with funding through OHER and the University of California, and is gathering further participants from academic and industrial groups to construct further beamlines and experimental stations and to operate the facility.

A third resource center, devoted to $x$-ray spectroscopy, will be based on an elliptically polarizing undulator of advanced design producing elliptically polarized radiation. Use of this wiggler will be shared with materials science users; accordingly, funds to begin its fabrication have been provided by both the Office of Health and Environmental Research (OHER) and the Office of Basic Energy Sciences. The resource center will consist of a variable included angle plane grating monochromator beamline. This project is now well underway with operation planned for mid-1997.

To provide the facilities and services the biological community will require to make full use of the ALS, construction is underway on the ALS Structural Biology Support Facility which will offer a full range of highly automated instrumentation and support laboratories, including high-performance computer workstations networked to beamline computers for on-site data reduction. The $\$ 7.9 \mathrm{M}$ facility is funded by the Department of Energy and scheduled to open in October 1996.

The Structural Biology Support Facility, which contains over 1000 sq. meters of laboratory and office space, is adjacent to the ALS experiment floor, making it easily accessible. Crystallographers will be able to check their crystals' quality and pre-align the crystals before their scheduled beamtime, and numerous microscopy and spectroscopy resources will be available for parallel investigations-laboratory space for cell and tissue culture, and facilities for EPR and Fourier transform IR spectrometry. Finally, high-performance computers will offer full graphics capabilities for visualizing experimental results.

\section{IMAGING FACILITIES}

The Donner 600-Crystal Positron Tomograph was designed and built at LBNL to provide better than twice the spatial resolution of any previous tomograph. The very high resolution is achieved by six hundred 3-mmwide bismuth germanate crystals, coupled individually to 14-mm phototubes. A commercial single-photon emission tomograph has been provided by the manufacturer. Magnetic resonance imaging facilities are also available for medical use; in particular, facilities for safety research into extending the use of NMR for noninvasive human studies are centered at LBNL. The Laboratory is also home to a unique array of electron microscope facilities, whose purchase and operation are funded from several sources. These facilities include the Atomic-Resolution Microscope and the High-Voltage Electron Microscope at the National Center for Electron Microscopy, as well as an Intermediate-Voltage Electron Microscope, funded by NIH, for high-resolution electron crystallography. In collaboration with the Lawrence Livermore National Laboratory, LBNL has also developed the capability of imaging biological macromolecules by scanning tunneling microscopy. Several STMs are operational at LBNL.

\section{National Tritium Labeling Facility}

This national facility, supported by the NIH, carries out research into the labeling of compounds to high specific activity with tritium and provides a tritium-labeling service for investigators throughout the country. A primary direction for this facility is now the development of tritiated reagents and techniques for NMR studies of biological macromolecules.

\section{BIOMEDICAL ISOTOPE FACILITY}

Nuclear and organic chemical synthesis instrumentation and laboratory facilities at LBNL include the 88Inch Cyclotron and radiation-containment devices for rapid synthesis of radiotracers.

On July 5th, 1995 the cyclotron was installed in the new Biomedical Isotope Facility, Building 56 on the LBNL campus. With this event, LBNL established the capability to expand its efforts in developing new labeling strategies for the incorporation of short-lived isotopes into medicinally useful compounds. On August 17th the first beam on target was achieved and the first batch of radioisotope was produced in early September. The first patient dose of fluorodeoxyglucose (FDG) was pro- 
duced in early January 1996 with [F-18]fluoro-metatyrosine and [N-13] ammonia produced in mid February (See Highlights" section, p. 116).

\section{Resource for Molecular Cytogenetics}

The mission of the Resource is to stimulate progress in molecular cytogenetics through (1) development of improved hybridization technology; (2) design and development of digital imaging microscopy; (3) production of probes optimized for molecular cytogenetic studies; (4) support of the molecular cytogenetic community through collaboration, distribution of probes and analysis technology and education; and (5) by transfer of useful reagents, processes and instruments to the private sector for commercialization. This is accomplished in cooperation with LBNL's Human Genome Center and Engineering Division, the chromosome microdissection and cancer genetics expertise from the National Institutes of Health, and clinical and genetic investigators at the University of California, San Francisco (UCSF), the Lawrence Berkeley National Laboratory, University of California, Berkeley, and elsewhere throughout the scientific community. These activities serve the research and clinical communities indirectly through general advances in technology, and directly through the production and distribution of probe reagents of clinical and biological utility, development of instrumentation, initiation of training programs, and technology transfer. The Resource receives funding from DOE's Office of Health and Environmental Research and Vysis, a subsidiary of AMOCO. For more information, the Resources' HomePage can be accessed through the World Wide Web at http:/ /rmc-www.LBNL.gov/.

\section{LBNL TRANSGENIC ResOuRCE}

Lawrence Berkeley National Laboratory has a well established infrastructure in place for the development of transgenic mice. This includes two microinjection setups, three trained staff members skilled in microinjection and embryo transfer techniques, and two trained animal technicians to assist with screening and breeding regimens. In addition, there are plans to add a third microinjection setup in the near future to further expand our injection capabilities. Currently, each investigator is asked to provide DNA which has been prepared according to our instructions. FVB mice are used primarily because they provide an excellent substrate for developing transgenics in an inbred background. Investigators are given tails from potential transgenics at weaning age along with detailed instructions in the preparation of tail DNA and screening techniques. The inclusion of the investigator in the preparative and screening phases has been found to keep them more involved in the process.

LBNL's transgenic expertise extends beyond the mere production of transgenic animals to providing detailed advice in construct design and preparation as well as advice regarding screening and maintenance of transgenic lines. LBNL has extensive expertise in all areas of transgenic production and provides assistance in designing experiments which utilize a minimum number of DNA constructs and a minimal number of transgenic animals. Discussions with the investigators provide an essential component in planning a welldesigned experiment that will efficiently and economically enable the less experienced investigator (with regard to transgenic experiments) design good experiments.

\section{Life SCIENCES Microscope Resource}

The LBNL Life Sciences Microscope Resource (LSMR) is currently in operation. A wide range of users have been trained and are currently obtaining and archiving video images, multicolor digital images, color prints and $35 \mathrm{~mm}$ color slides. The LSMR provides access to a variety of inverted and upright microscopes with a range of experimental capabilities including micromanipulation, real-time intensified video microscopy, multicolor quantitative $\mathrm{CCD}$ digital imaging, and multicolor 3D confocal microscope imaging. The LSMR also provides computer accounts and computer workstations for automated data acquisition, image analysis, data archiving, video digitization, and preparation of color hard copy (paper, transparencies, and $35 \mathrm{~mm}$ slides or prints). The resource provides access to four fluorescence microscopes with a variety of imaging capabilities: a Zeiss Axiovert 135 inverted microscope, a Bio-Rad MRC-1024 laser scanning confocal system built around a Nikon Diaphot 200 inverted microscope, an upright Zeiss Axioskop, and an upright Zeiss Standard microscope.

\section{Yeast Genetic Stock Center}

The Yeast Genetic Stock Center (YGSC) maintains a collection of approximately 1000 genetically defined strains of the yeast Saccharomyces cerevisiae. These strains are stored at $4^{\circ} \mathrm{C}$ in "milk-paper replicas" for ease of dissemination and at $-75^{\circ} \mathrm{C}$ in $20 \%$ glycerol as a back-up supply. The Center is located in Donner Laboratory in the Department of Molecular and Cell Biology at the University of California, Berkeley. The YGSC collects, 
Complex biological phenomena require sensitive and specific analytical techniques for analysis. OHER programs at LBNL have pioneered the use of such techniques as $x$-ray and electron crystallography, NMR spectroscopy, flow cytometry, and chemical probe analysis to study biological problems. Instrumental techniques such as analytical electron and x-ray microscopy, gas chromatography/mass spectrophotometry, confocal microscopy, fluorescent-detected circular dichroism, and differential polarization microscopy are also utilized for analytical purposes in the life sciences program. X-ray photoelectron and laser Raman spectroscopies are used to study atmospheric processes, and equipment and techniques have been developed to provide near realtime measurements of environmental concentrations of absorbing aerosols and of radon and its decay products.

Standard laboratory facilities and instrumentation include laminar flow biosafety cabinets, incubators, warm rooms, fermenters, cold rooms and ultracold storage units, fluorescence microscopes, all types of gel electrophoresis apparatus, cryostats, scanning densitometers, ultracentrifuges (analytical as well as preparative), highpressure liquid chromatographs, darkrooms, automated DNA and peptide synthesizers and sequencers, and a polymerase chain reaction (PCR) apparatus. We also maintain an AALAC-accredited animal colony, which has facilities for housing rodents (including transgenic mice), dogs, cats, rabbits, guinea pigs, goats, and monkeys.

Engineering facilities include: (i) a fully equipped semiconductor materials/detector fabrication facility with extensive diagnostics capabilities; (ii) a Van de Graaff accelerator (2-MeV protons) equipped for backscatter and $x$-ray fluorescence studies; (iii) extensive electronic design and development facilities, with particular emphasis on very low-noise measurements required for high-resolution spectroscopy; (iv) an ultralow-background radiation-counting facility equipped with highresolution gamma-ray spectrometers; and (v) a cleanroom facility devoted to the fabrication of microsystems such as detectors and electronic devices with micrometer-size structures. In addition, LBNL's Information and Computing Sciences Division maintains state-of-the-art information and computing resources. These resources include SEJEDIS, the LBNL Socioeconomic Environmental Demographic Information System, which contains the country's most complete computerized archive of U.S. health, demographic, and socioeconomic data. This archive is now being integrated with the OHER Comprehensive Epidemiologic Data Resource (CEDR) for use in OHER epidemiologic research activities.
Laboratory facilities of the Indoor Environment Program include the Indoor Air Quality Research House, which contains a three-room test space instrumented for studies of radon decay product behavior and for investigations of other specific pollutants, such as environmental tobacco smoke. A controlled $20 \mathrm{~m}^{3}$ chamber is also available for detailed studies of pollutant emissions and behavior. A new facility, consisting of two intensively instrumented, basement-like concrete structures in the Santa Cruz mountains, has been built for a detailed examination of radon transport and entry processes, and experimental validation of theoretical predictions based on complex numerical codes. Modeling is conducted on a Sun 4-280 and a Hewlett Packard series 7000 computer operated by the Indoor Environment Program and on Energy Research-sponsored CRAY supercomputers.

Additional facilities for environmental research include our fully functional cloud/aerosol observatory on El Yunque Peak, Puerto Rico. Measurements of cloud microphysical and optical properties, as well as aerosol physical and chemical properties will be complemented by NASA's Goddard Research Center satellite observations and a cloud chamber for studying cloud chemistry and physics. 


\subsection{Advisory Committees and Program Reviews}

The quality and direction of research in biosciences and environmental sciences at LBNL are evaluated within each of the four divisions that have a major role in OHER research. In particular, "Director's Reviews" are mandated for each Division. This is an opportunity for eminent scientists from around the country to review the Division's programs and report their findings directly to the Laboratory Director. The current committee membership for Life Sciences, Structural Biology, and Energy and Environment Divisions follows:

\section{LiFE SCIENCES Division Director's REVIEW} OCTOBER 27-28, 1995

Franklin H. Bunn

Research Director, Hematology/Oncology

Brigham and Women's Hospital

Harvard Medical School

Charles Daniel,

Professor, Department of Biology

University of California at Santa Cruz

Harold F. Dvorak

Professor and Chief, Department of Pathology

Beth Israel Hospital/Harvard Medical School

Uta Francke

Howard Hughes Medical Institute

Stanford University School of Medicine

Carmen A. Mannella

Associate Chairperson of Biomedical Sciences

Wadsworth Center for Labs and Research

Philip Hanawalt

Department of Biological Sciences

Stanford University 


\section{Human Genome Advisory Committee}

David Botstein

Professor and Chair, Department of Genetics

Stanford University School of Medicine

David R. Cox (Chair)

Professor, Department of Genetics

Stanford University School of Medicine

Raymond Gesteland

Human Genetics Department

University of Utah

Steven J. Gordon

Intelligent Automation Systems

Cambridge, MA

Joe Gray

Division of Molecular Cytology

University of California at San Francisco

Thomas Marr

Cold Spring Harbor Laboratory

Maynard Olson

Molecular Biotechnology \& Medicine Department

University of Washington

Edward Rubin

Life Sciences Division

Lawrence Berkeley National Laboratory

\section{ENERGY AND ENVIRONMENT DIVISION}

William Fulkerson (chair)

Associate Director for Advanced Energy Systems

Oak Ridge National Laboratory (retired)

Arnold P. Fickett

Vice President, Department of Customer Systems

Electric Power Research Institute (retired)

Adel Sarofim

Massachusetts Institute of Technology

Harrison S. Fracker, Jr.

College of Environmental Design

University of California, Berkeley

Morton Lippman

Institute of Environmental Medicine

New York University

Allan S. Miller

Center for Global Change

College Park, Maryland

\section{Structural Biology Division}

Chemical and Structural Biology Program

James Wells, Chairman

Department of Protein Engineering

Genentech, Inc.

Charles Craik

Pharmaceutical Chemistry

University of California, San Francisco

Harry F. Noller, Jr.

University of California, Santa Cruz

Energy Sciences Program

James Norris

Chemistry Division

Argonne National Laboratory

Peter R. Ogilby

Department of Chemistry

University of New Mexico, Albuquerque

\section{President's Council}

The University of California President's Council on the National Laboratories advises the President on matters related to the management and operation of the three DOE Laboratories: LBNL, Lawrence Livermore, and Los Alamos. The Council also serves as a source of advice and counsel to the Laboratory Directors, who have the opportunity to call upon the scientific and managerial expertise of the Council and its members.

The Council has three major functions. One is to review the strategic plans of the Laboratories as they change their research agendas. The Council is especially attentive to opportunities for the Laboratories to apply their capabilities to issues of increasing national importance. A second function of the Council is to review the scientific and technical quality of work undertaken at the three DOE Laboratories. The contracts between the University and the DOE require the University to carry out an annual performance evaluation of the management and major programs at the Laboratories. The Council assists the University in these evaluations. The Council provides the President an annual written report of its findings and recommendations, and prepares other written and oral reports at the request of the President or as the Council deems appropriate. The third function of the Council is to monitor the effectiveness of the Labo- 
ratories in fostering an atmosphere conducive to scientific inquiry and the development of new knowledge.

\section{President's Council on the National Laboratories-Current Membership}

Sidney D. Drell, Chairman

Deputy Director

Stanford Linear Accelerator Center

William R. Frazer, Vice Chairman

Department of Physics

University of California, Berkeley

John F. Ahearne

Executive Director, Sigma Xi

Research Triangle Park, North Carolina

Lew Allen, Director (retired)

Jet Propulsion Laboratory

Patricia Buffler

Dean, School of Public Health

University of California, Berkeley

Robert C. Dynes

Professor, Physics Department

University of California, San Diego

Edward Frieman

Vice Chancellor, U.C. San Diego

Director, Scripps Institution of Oceanography

Andrew J. Goodpaster

General, U.S. Army (retired)

William Happer

Department of Physics, Princeton University

Leroy Hood

Department of Molecular Biotechnology,

University of Washington, Seattle

Judson C. King

Provost, Professional Schools and Colleges

University of California, Berkeley

John W. Landis

Senior Vice President and Director

Stone \& Webster Engineering Corporation

Kaye Lathrop

Retired Associate Director,

Stanford Linear Accelerator Center

Venky Narayanamurti

Dean, College of Engineering

University of California, Santa Barbara

Thomas A. Page

Chairman and Chief Executive Officer
San Diego Gas \& Electric Company

Lucille Shapiro

Professor and Chairman

Department of Developmental Biology

Stanford Medical Center

Daniel Simmons

Associate Provost, Educational Relations

University of California

Neil S. Smelser

Director, Center for Advanced Study in

Behavioral Science

Larry N. Vanderhoef

Chancellor, University of California, Davis

Rochus E. Vogt

Professor of Physics, California Institute of

Technology

Herbert F. York

Director Emeritus,

Institute on Global Conflict and Cooperation

University of California, San Diego

Ex Officio

Siegfried S. Hecker

Director, Los Alamos National Laboratory

James E. Holst

General Counsel of the Regents of the

University of California

Wayne Kennedy

Senior Vice President, Business and Finance

University of California

C. Judson King

Provost and Senior Vice President Academic

Affairs, University of California

Arnold Leiman

Professor, Depart,ment of Psychology,

University of California, Berkeley

Duncan A. Mellickamp

Chemical and Nuclear Engineering,

University of California, Santa Barbara

Carl Poppe

Associate Vice Provost for Resaerch and Laboratory Programs, University of California

Charles V. Shank

Director, Lawrence Berkeley National Laboratory

C. Bruce Tarter

Director, Lawrence Livermore National

Laboratory 
Robert Van Ness

Interim Special Assistant, University of California

To advise the Division Directors on a more frequent basis, both with regard to scientific priorities and operational matters, a standing advisory committee comprising senior scientists from within the division meets periodically and discusses divisional issues. In several divisions, these committees (or councils) serve as the review panels for new Field Task Proposals and for proposals for Laboratory-Directed Research and Development funds. Group leaders' or project leaders' meetings also serve as forums for discussion, though in some cases the group leaders may constitute the advisory committee.

The Directors and Department Heads of Life Sciences and Structural Biology Divisions also meet regularly as the Biosciences Advisory Committee. Out of the three Divisions (including Energy and Environment) receiving the bulk of OHER funding, one Director is designated as the coordinator for communication among the three divisions and between the Laboratory and OHER, as well as coordinator of other multidivisional administrative functions. The coordinator is a member of the Laboratory Director's Action Committee which meets weekly.

Finally, mention should be made of the several specialized committees in each division, which support but do not influence directly, the conduct of scientific research. These include a professional staff committee, a salary committee, safety and space committees, and others.

\subsection{Laboratory-Directed Research and Development Program (LDRD)}

LDRD funding provides initial support for innovative research projects and encourages pursuit of promising new institutional directions in ongoing research. The goal of support for new initiatives is to produce preliminary results that will provide a credible basis for seeking long-term funding from DOE or another agency. In the case of ongoing projects, the objective is to test the feasibility of a new research direction quickly and, if truly promising, to provide documentation for future proposals to support those new aspects of the program.

LDRD proposals originating in a given division are reviewed each year by the Division Director, who prepares a prioritized list, typically based on the recommendations of a divisional advisory committee. This list is submitted to a Laboratory-wide review panel, which makes a final recommendation to the Laboratory Director.

\section{TABLE 5: Summary of Major FY 1996 OHER-Related Discretionary Funding Investments}

\section{EARTH SCIENCES}

Conrad, "Characterization and Monitoring of Subsurface Biologic Activity Using Stable Isotope Analyses" $-\$ 50,000$

Keasling, "Kinetics and Modeling of Anaerobic TCE Degradation for In-situ and Ex-situ Applications" $-\$ 60,000$

Russo, et al., "Metal-specific Chemical Sensors Using Polymer Films for Non-proliferation and Environmental Applications"- $\$ 80,000$

Wan, "Microbial Transport and Microbial and Nutrient Delivery..." $-\$ 80,000$

\section{ENERGY AND ENVIRONMENT}

Anderson, "Sediment Toxicity and Site Restoration at the Mare Island Naval Shipyard" $-\$ 60,000$

\section{LIFE SCIENCES}

Chatterjee, et al., "Computational Investigation of Chromatin Structure"

Gray, "Center for Discovery of Disease Related Genes" $\$ 400,000 \& \$ 60,000$ for equipment.

Rokhsar, et al., "Theoretical Models for DNA Structure and Function" $-\$ 50,000$

Schild, "Role of Recombinational Repair in Mammals: Analysis in Yeast of the Human DNA Repair Gene XRCC3" - $\$ 100,000$

Walian, "Crystallization and Structure Determination of Integrin $\alpha_{\mathrm{Ib}} \beta_{3}$, a Platelet Membrane Protein Receptor" $\$ \$ 90,000$

\section{MATERIAL SCIENCES}

Charych, et al., "Synthesis of Oriented Nanoparticulate and Dense Crystalline Ceramic Films Using Biomimetic Membranes" $-\$ 70,000$

Meyer-Ilse, et al., "Biological X-ray Microscopy"$\$ 100,000$ 


\section{STRUCTURAL Biology}

Pace, "Use of Automated rRNA Gene Sequence Analysis to Assess and Monitor Environmental Microorganisms"- $\$ 150,000 \& \$ 115,000$ equipment

\section{Multi-Divisional}

Benson, et al.,"SELECT: Development of a Site Remediation Analysis and Decision Support Software" $-\$ 320,000$

Bergman, et al., "New Chemistry for Pollution Prevention" $-\$ 300,000$

Chu, et al., "Physics and Biology of BNCT" $-\$ 100,000$

Hunter-Cevera, et al., "Bioavailability and Degradation of Neutral/Base Aliphatic and Aromatic Hydrocarbons from Soil" $\$ 100,000 \& \$ 100,000$ for equipment

Schlueter, et al., "Developing High Resolution Synchrotron $X$-ray Techniques to Study Porous Media" $-\$ 120,000$

TOTALS: $\$ 2,210,000 \&$ $\$ 275,000$ equipment $=\$ 2,485,000$

\subsection{Animal Welfare and Human Use}

The LBNL Animal Welfare and Research Committee (AWRC) oversees procedures that ensure compliance with policies of the U.S. Department of Agriculture and the NIH's Office for Protection from Research Risks (OPRR). The AWRC has the responsibility and the authority to deny animal use privileges to investigators found in noncompliance. Once approved, each research protocol is reviewed annually and prior to implementation of any changes in the protocol. The annual review verifies past and continued compliance with LBNL and OPRR policies and evaluates research progress derived from animal use. Members of the AWRC are selected in strict compliance with NIH principles.

In October 1975, following the recommendations of the Director, a Memorandum of Understanding between the Chancellor of the University of California at Berkeley and the Director of LBNL was issued regarding the use of human subjects in clinical research. The campus Committee for theProtection of Human Subjects (CPHS) assumed official responsibility for reviewing and approving all LBNL activities involving human subjects, pursuant to Office of Science and Technology Policy (OSTP), UC Systemwide, and campus directives. An
LBNL advisory committee assists the CPHS in their review of LBNL projects, and LBNL research scientists serve as committee members. LBNL protocols are submitted to the LBNL Human Use Committee (HUC), which reviews all submissions and approves them before submission to the CPHS for review. The LBNL HUC keeps LBNL Administration advised of all actions taken with respect to human use approvals, maintains a permanent file of all documents pertaining to human subjects, and serves as an advisory group for investigators on matters concerning human use.

\section{Waste Minimization and Pollution Prevention}

LBNL has made a strong commitment to waste minimization-to substantially reduce waste generation and to increase recycling. Our goal is to achieve an overall reduction in the generation of hazardous, radioactive, and mixed waste streams through reduced generation at the source, process chances, employee awareness, administrative controls, and increased recycling.

Through the Waste Minimization and Pollution Prevention Awareness Program we systematically eliminate or reduce the generation of waste from site operations to prevent or minimize the release of pollution in any environmental medium. The program seeks to make source reduction and environmentally sound recycling integral parts of the philosophy at LBNL.

The Waste Minimization and Pollution Prevention Awareness Program meets the requirements of DOE Order 5400.1 and other federal, state, and local waste minimization and pollution prevention requirements.

\section{Safety Committees}

Each LBNL division has a safety committee that includes staff members from all levels within the division. Committee members receive specialized training in federal, state, and local safety, environmental, and operational laws and regulations. The committees are appointed by the Division Directors and charged with the responsibility of conducting annual inspections of all divisional laboratories, offices and shops to uncover any safety violations or lack of compliance with environmental requirements. The primary activity of the safety committees is to carry out the self-assessment of divisional compliance with safety and environmental regulations on a pro-active, continuous basis, including maintaining documentation of reports from walk-through 
and follow-up inspections and alerting Division Directors to problem areas.

In addition, LBNL is using the safety committee network as a resource to assist in the installation of recommended operational procedures required of management by specific DOE orders and federal and state laws. The Environment, Health and Safety Division and the Office of Assessment and Assurance are prime resources in the implementation of DOE, state and other federal regulations. For example, conduct of operations requirements include detailed documentation of compliance with specific procedures related to record-keeping of visitors to controlled areas where radiation hazards exist. DOE orders also require detailed records of laboratory procedures and employee safety training. The safety committee network has been used to assist supervisors in complying with these responsibilities. Federal and state laws also require documentation of appropriate disposal of medical and biohazardous waste.

Federal and state laws are in effect that require individual laboratories to retain documentation of annual reporting of hazardous chemical inventories and of compliance with measures to ensure that the atmosphere and the water supply are not fouled by effluents from laboratories and shops. In some cases, permits are required to assure adequate monitoring of waste streams. LBNL administration has chosen a "notebook" and a "documentation matrix" approach to consolidate documentation required by regulations related to environment, health, safety, and operations. Facility (6) and Function (1) Notebooks have been formatted to assist LBNL staff. The safety committee network will provide assistance to responsible supervisors in nneeting the requirements.

The Life Sciences Division Environmental Safety and Health program structure consists of the Division Director, the Division Deputy Director, the ES\&H Team, the ES\&H Committee, Building Managers, Division Facility Supervisors and embraces the Departments Heads, Group Leaders, Supervisors and Staff of the Division. The ES\&H team consists of lead individuals in specialty areas as identified, outlined and detailed below:

The Division ES\&H Team routinely meets twice a month (first and third Wednesday), and more frequently when necessary, to discuss urgent action items and ongoing ES\&H activities, e.g., planning the ES\&H
Committee agenda; developing action plans for the introduction and implementation of new programs, policies, procedures and regulations. In addition, telephone, FAX and face-to-face communication on EH\&S issues and concerns is an on-going, daily process for the members of the Life Sciences Division EH\&S Team.

During the course of the previous year, the Life Sciences Division's safety program has been peer-reviewed through an LBNL Safety Review Committee (SRC) Management of Environmernt, Safety and Health (MESH) review. The division safety program was accorded a rating of "to be highly commended." 


\title{
4.0 Research in Progress \& Major Accomplishments
}

\section{Research in Progress}

\section{ANALYTICAL TECHNOLOGY (KP01)}

\author{
NEW INSTRUMENTS AND DETECTION METHODS
}

\author{
DONALD LuCAS-NEAR-INFRARED DETECTION \\ METHODS FOR COMPLEX MiXTURES
}
BernHARd LudeWigt- - High Rate, Low NoISE SiLICON ARRAY SPECTROMETER FOR SYNCHROTRON X-RAy Fluorescence Applications

\section{Paul Luke/Jack Walton-Development of ROOM-TEMPERATURE SEMICONDUCTORS FOR FIELD APPLICATIONS}

Donald Lucas has initiated a research program to develop a multi-fiber optical probe using near-infrared (NIR) light to quantify water, polyatomic ions, organics, and metals in the liquid portions of waste. These in situ methods have the sensitivity, selectivity, speed, and robustness required for this application; what is needed is research into the spectroscopy for such complicated mixtures to allow for optimization and quantification of the techniques. Different spectroscopic techniques, methods for sample introduction into the probe volume, and ways to introduce and extract the light using fiber optics in the tank environment will be examined. A number of NIR sensors can be mounted together, incorporating different design elements for optimized detection of particular species. The best methods for qualitative and quantitative analysis will be identified and advanced to the point where field measurements are possible. 
The objective of Bernhard Ludewigt's project is the development of a high rate, low noise $x$-ray spectrometer for synchrotron $x$-ray fluorescence applications which is based on silicon detector arrays connected to application-specific integrated circuits for signal processing. Experiments which are designed to fully exploit the capabilities of modern synchrotron sources require detectors that offer both good energy resolution and high count rate capability. Highly-segmented silicon detectors fabricated using photolithographic techniques offer the advantages of a high total count rate by distributing the flux over many detector elements and low noise due to the small capacitance of each element. Application-specific integrated circuits for charge integration, amplification, and digitization facilitate an economic solution to the signal processing requirements of many parallel channels. Such a detector system has applications in a wide variety of synchrotron x-ray fluorescence experiments and can also provide linear position information for one-dimensional diffraction experiments.

Advanced instruments are needed for the characterization of various contaminants at remote locations. Of these, radiological contaminants can be detected through their gamma-ray and $x$-ray emissions. This method of detection can be carried out directly on contaminated samples in-situ or with minimal sample preparation, thus avoiding the need for time consuming and costly chemical analysis. To identify specific radioisotopes, detectors with good energy resolution are required. In the past, high resolution detectors based on cryogenic $\mathrm{Ge}$ and $\mathrm{Si}(\mathrm{Li})$ devices, which are expensive and not well suited for field deployment, have been used. Recent advances in detector technology at LBNL have made it possible to realize high resolution detectors that can be operated at room temperature. The goal of Paul Luke and Jack Walton's project is to develop a portable spectrometer system based on these detectors for use in site remediation activities. Two types of detectors will be pursued-CdZnTe coplanar-grid detectors for gamma ray detection and Si drift detectors for $\mathrm{x}$-ray detection.

\section{HEALTH EFFECTS (KPO3)}

\section{TUMOR BIOLOGY}

\section{Mina Bissell-Interaction of MicroenVIRON- MENT AND GENOME IN THE GENESIS OF BREAST CANCER}

Mina Bissell-Regulation of Tissue-specific Genes in Normal and Malignant Breast Cells (KP0403)

\section{Judith CAMPISI-Functional IDENTIFICATION OF Cell Cycle Activator and Suppressor Genes}

\author{
Martha Stampfer/Paul Yaswen-IN Vitro \\ Transformation of Human Mammary \\ EptThelial Cells
}

\section{Joe Gray/Dan Pinkel- Resource for Molecular Cytogenetics}

Tumorigenesis is a multistep process, the result of specific genetic lesions. Among the lesions essential for tumorigenesis is a heritable loss of cellular growth control. Three types of genes are critical for regulated cell proliferation in higher eukaryotes: protooncogenes, tumor suppressor genes and cell division control (cdc)related genes. There are many questions about how these genes act and interact, particularly in the context of cell type and tissue environment.

Over the last fifteen years Mina Bissell has established that the microenvironment surrounding cells plays a crucial role in maintenance of functional differentiation, tissue-specific gene expression, branching morphogenesis and growth. For these studies she has developed a unique model system to study the regulation of normal function in the rodent breast in a culture dish. She is also using transgenic mice that overexpress stromelysin-1 which degrades extracellular matrix. Such mice are more susceptible to chromosomal abnormalities and mammary tumors. The overall aim of this work is to understand the molecular mechanisms involved in regulating tissue-specific gene expression in normal breast and how these are altered as cells become cancerous.

Dr. Bissell's work in rodents has demonstrated the feasibility of this approach to understanding breast cancer induction and progression in humans. The availability of a unique human breast cell line provides an exciting opportunity to extend this model to human cells. When grown on basement membrane, these cells gradually change from morphologically normal to premalignant to malignant cells, and the biochemical changes associated with these morphological changes can be followed. The program has demonstrated that critical biochemical changes can be related not only to 
the loss of response to ECM, but also to the loss of microenvironmental control. Furthermore, it is now becoming clear that correct tissue structure fundamentally regulates homostasis. These four OHER-supported projects form the core of LSD's commitment to elucidate the mechanisms whereby normal cells become malignant. The ultimate goal is to understand how a cell knows when to grow, differentiate, or apoptose, and how these mechanisms are altered during malignancy.

Judith Campisi's project is focused on understanding how protooncogenes, tumor suppressor genes and cdc genes regulate cell growth, with the ultimate goal of identifying new growth regulators and establishing their function. Dr. Campisi has discovered that a gene called Id-1 may be a protooncogene. The Id- 1 gene product is an inhibitor of myogenic basic helix-loophelix (bHLH) transcription factors, which are known to induce muscle-specific gene expression and inhibit cell proliferation. Because neither fibroblasts nor mammary epithelial cells express myogenic bHLH factors, she predicts that these cell types express analogous factors to regulate differentiation and inhibit cell proliferation, and she is attempting to identify and clone such factors.

Martha Stampfer and Paul Yaswen are attempting to identify genes in human mammary epithelial cells which normally prevent immortalization from occurring. The functions of such genes can be compromised by mutations, and Dr. Stampfer is using virally-inserted gene fragments to disrupt these genes, thereby allowing these cells to become immortal. The feasibility of this approach has already been demonstrated in preliminary work, where chemically-induced extended life span cultures have been infected with retroviruses carrying cDNAs from normal cells, and several promising immortalized cell lines have been obtained and are now being characterized. If this project is successful, this technique will provide a rapid transformation assay for genes important in preventing immortalization.

The Resource for Molecular Cytogenetics, led by Joe Gray and Dan Pinkel, not only complements the above work but also provides a link between the Health

- Effects and Human Genome Programs at LBNL. This resource develops molecular cytogenetic techniques, instruments and reagents that assist in identification and functional characterization of genes involved in cancer susceptibility, genesis and progression, and is closely coordinated with the work of the Human Genome Center. Of particular interest are regions on chromosomes $8,13,16,17$ and 20 which are involved in a variety of cancers, including breast and prostate cancers. Dr. Gray has developed collaborations with three other LBNL investigators supported by OHER, Drs. Campisi, Morgan and Pallavicini.

RADIATION DAMAGE AND GENETIC TOXICOLOGY

\begin{abstract}
Aloke Chatterjee- - Theoretical Modeling of MOLECULAR AND CELLULAR MECHANISMS IN RADIOBIOLOGY
\end{abstract}

\section{Priscilla COOPER-DNA DAMAge BY RADON ALPHA PARTICLES AND MOLECULAR MECHANISMS OF ITS REPAIR IN HUMAN CELLS}

\section{LOIS GOLD-INTERSPECIES EXTRAPOLATION AND RISK ASSESSMENT IN CARCINOGENESIS}

\section{WILliam MORGAN-ELUCIDATION OF CYTOGENETIC DAMAGE}

\section{Maria Pallavicini-Genetic susceptibility and RADIATION EFFECTS}

It has long been known that DNA damage is a strong risk factor for genetic instability, even though all cells contain robust systems to repair such damage. The molecular mechanisms used in base and nucleotide repair systems are fairly well understood in microorganisms, but less well understood in human cells. Even less understood are mechanisms employed in repair of double-strand breaks.

Priscilla Cooper's project uses radon $\alpha$-particles to damage DNA in human and rodent cells in culture and is testing the idea that clustered damage leads to poor repair. Using techniques which can distinguish between correct and incorrect rejoining of DNA fragments produced by double-strand breaks, she is comparing the ability of rodent and human cells to accurately repair DNA damaged by $\alpha$-particles. The results will provide information about how well data on rodents can be used to understand human susceptibility tocancer. In complementary studies, William Morgan is generating double strand breaks with either ionizing radiation or restriction endonucleases (overlapping ends). He is interested in what enzymes and other proteins are involved in double-strand break repair in human cells, and what are 
the genetic consequences of incorrect rejoining of disrupted chromosomes.

Maria Pallavicini is using mice with varying genetic susceptibility to radiation damage to study frequency of chromosome translocations in cells in peripheral blood. Translocations are detected by fluorescence in situ hybridization (FISH). Her particular interest is to determine whether translocation frequencies 1) are chromosome-specific, 2) correlate with genetic susceptibility, and 3) correlate with risk of developing radiation-induced myeloid leukemia. These results will be useful in assessment of risk to the public from a variety of environmental exposures.

Lois Goldl is developing an index called HERP (human exposure/rodent potency). This index ranks pesticides, food additives, synthetic chemicals found in the environment, and natural chemicals for their carcinogenic potential. Results indicate that there are many naturally occurring chemicals in the diet which are carcinogenic. The major goal of this work is to improve the methodology for interspecies extrapolation in carcinogenesis.

Theoretical modeling of radiation damage to chromosomal DNA can be used to make predictions about chromosomal structure. Aloke Chatterjee has calculated that a major fragmentation product should be about $80 \mathrm{bp}$, and this was subsequently confirmed experimentally. The results also indicated that a solenoidal chromosome structure is less likely than a zig-zag ribbon arrangement of nucleosomes and linker DNA. Continuing modeling efforts concern predictions about the impact of DNA damage clusters on the efficiency and fidelity of repair.

\section{STEM CELL BIOLOGY}

\section{MOHAN NARLA-BONE MARROW STEM CELLS}

Bone marrow transfusions are useful in the treatment of individuals exposed to lethal doses of radiation, patients with multiple genetic disorders, and patients with various malignancies. The effectiveness of such treatment depends on the transfer of primitive pluripotential long-term repopulating cells (LTRC) of the hematopoietic system. Mohan Narla's objective is to determine the properties of LTRC and how genetically different hosts respond to repopulation. Another goal is to develop new enriched sources of these cells such as embryonal cells derived from blastocysts and embryonic stem (ES) cell lines. A major goal of this project is to explore the use of these cells in transfused recipients in vivo, and study the role of stromal cells and cell-cell interactions in modulating the hematopoietic potential of ES cells.

\section{GENERAL LIFE SCIENCES (KPO4)}

\author{
STRUCTURAL BIOLOGY-PROTEINS
}

BING JAP-MOLECULAR STRUCTURE OF MEMBRANE TRANSPORT SYSTEMS

ROSALIND KIM-HYPERTHERMOPHILIC PROTEIN
STRUCTURES

Sung-Hou KIM-STRUCTURAL BIOPHYSICS

Peter Schultz-Catalytic antibodies

Peter Schultz-Center for Biomedical ENGINEERING

\section{DAVID WEMMER-BIOMOLECULAR STRUCTURAL ANALYSIS BY NMR}

Cell cycle control is exerted largely through a series of protein phosphorylations and dephosphorylations. These phosphorylations are effected by proteins known as cyclin-dependent kinases or CDKs. Sung-Hou Kim is determining the 3-dimensional structure of several of these proteins, especially in complexes with other proteins, using $x$-ray crystallographic methods. The structure of CDK2 complexed with a chemical inhibitor has already been determined, and Dr. Kim has plans to continue this work using 5 classes of proteins: cyclins, CDK inhibitor proteins, the CDK7-cyclin $\mathrm{H}$ complex, CDK-CDK inhibitor proteins, and CDK2 chemical inhibitor complexes. This work will provide insights into rationale drug design targeted against cancer.

Peter Schultz is employing protein engineering to facili- tate studies on biomolecular recognition and catalysis. One example is the introduction of amino acid analogs into specific positions in the ras $\mathrm{p} 21$ protein to study the role of these amino acids in the function of the protein. A second area of focus for Dr. Schultz is the development and structural determination of catalytic antibodies. 
NMR is an extremely powerful tool for determining the structure of organic compounds, and it is being increasingly used to solve protein structures. David Wemmer is using this tool to study proteins involved in genetic regulation, particularly transcription factors. Proteins under study include: NTRC (regulation of nitrogen regulation in bacteria), Pho4 (regulation of phosphate metabolism in yeast), and the heat shock transcription factor. NMR analysis will provide information about resonances, distances and angle restraints necessary for structure calculations, and the dynamics of various regions of the proteins, and this information can be used to understand how proteins carry out their biological functions.

Organisms living in extreme environments such as high or cold temperatures are faced with special problems, and enzymes from such organisms are unusually stable under these extreme conditions. Rosalind Kim is studying some of these enzymes to understand the structural basis for their unusual stability and activity. Such enzymes will have utility for industrial purposes and environmental remediation, and may catalyze unusual chemical transformations.

The primary objective of Bing Jap's program is to determine the structure of membrane proteins at atomic resolution through the use of electron and x-ray crystallography. The major effort is placed on the study of membrane transport systems such as the E. coli potassium channel, a water channel and cytochrome reductase. A substantial effort has also been given to the structural studies of a calmodulin-like protein, which has been implicated to play a role in breast cancer. The goal of his research activities is to obtain structural information about these medically important proteins. The structural information gained will help provide an understanding about the general principles that govern the functional mechanism of the proteins. This may, in turn, provide an understanding of the molecular basis for diseases such as diabetes, cardiac arrhythmias, sudden death syndrome, Kearns-Sayre syndrome and breast cancer.

Peter Schultz is developing new technologies for generating and screening large libraries of both biomolecules and synthetic molecules for new properties and function. These biotechnologies are being applied to key problems in the general areas of biocatalysis and biomolecular recognition with potential applications to human health and the environment. For example, structure-based libraries are being developed for discovering new inhibitors and antagonists for key signal transduction proteins involved in cancer. Libraries of
RNA's are being screened for new catalytic functions and ligand-regulated binding activity. New in vivo cellbased screens for assaying biological activity and function are being developed, as well as new rapid in vitro screening methods. Libraries of large biological and synthetic molecules are being synthesized and screened in an effort to generate tailor-made enzymes, antibodylike receptors and NMR imaging agents. Active molecules and systems that come out of this work will be studied in detail by NMR and x-ray crystallography in order to make further improvements in their function.

\section{STRUCTURAL BIOLOGY-NUCLEIC ACIDS}

\section{STEPHEN HOLBROOK-STRUCTURE AND MECHANISM OF CATALYTIC RNA}

\section{IGNACIO TINOCO-STRUCTURE AND STABILITY OF NUCLEIC ACIDS}

The discovery of catalytic activities of RNA for cleavage, ligation, and other reactions on RNA has opened up a new field of research to understand and utilize these activities in novel ways. Understanding the mechanism of RNA self-cleavage could lead to the design of new catalytic RNA molecules that could cleave RNA molecules at a desired position to inactivate RNA viruses or any undesired RNA function either in vivo or in vitro. Stephen Holbrook is studying the structural basis of the RNA self-cleavage reaction using a combination of biochemical, $x$-ray crystallographic and NMR methods to understand the mechanism of the reaction and discover the rules for designing new RNA molecules of biolgoical interest for treating disease and responding to environmental insults.

Because of the vital role of nucleic acids in cellular function, Ignacio Tinoco is using two- and three- dimensional NMR to determine atomic resolution structures of nucleic acids and their complexes. $\mathrm{He}$ is also studying the thermodynamic stabilities of these structures, and their rates of formation to learn what the structures are, how difficult it is to disrupt them, and how fast they can form, with the ultimate goal of understanding the biological functions of these molecules.

STRUCTURAL BIOLOGY-USE OF THE ALS 
ThOMAs EARNeST-MulTi-USER

CRYSTALLOGRAPHIC FACILTTY

STEPHEN CRAMER - Circular POLARIZATION X-RAY RESOURCE

\section{Robert GLAeSer/Mario MoronNe-ALS x-RAY MICROSCOPY}

\section{Joe JakLeVIC/CAROLYn Rossington- SEMICONDUCTOR $X$-RAY DETECTORS FOR SYNCHROTRON APPLICATTONS}

\section{Melvin KleIN-Biophysical CHEMISTRY}

The Advanced Light Source (ALS) at the Lawrence Berkeley National Laboratory is the first third-generation synchrotron radiation facility optimized for insertion devices, and thus offers structural biologists a unique opportunity to study the structure of biological macromolecules using this new LBNL facility. Thomas Earnest has been instrumental in the development of the Macromolecular Crystallography Facility at the ALS which is coming on-line in FY 1996 as a national user facility for biological crystallography. A biological Xray Spectroscopy Resource is also being developed at the ALS by Stephen Cramer. This facility will provide a unique circular polarization capability and will be shared with materials scientists and industrial collaborators.

The ALS is being used by Robert Glaeser and Mario Moronne at LBNL to develop X-ray microscope techniques to obtain unique information about biological structures at the subcellular level. $\mathrm{He}$ is using dosefractionated microtomography and fluorescent labeling methods to take advantage of the very high flux rates now available from this new resource. Dr. Glaeser is focusing on the development of radiation-resistant luminescent probes based on lanthanide probes, and on computer simulation to explore the feasibility of soft $X$ ray microtomography. Melvin Klein is using the ALS to understand the bioenergetics and redox state of the cell and its important constituents, with emphasis on sulfur-containing components such as glutathione.

The development of new light sources requires the concomitant development of new detectors. Joe Jaklevic and Carolyn Rossington are developing new semiconductor detectors specifically designed for synchrotron applications, in particular for low noise $x$-ray fluorescence spectroscopy and diffraction experiments such as are encountered in the field of structural biology. A primary goal is the realization of specialized spectrometers which are capable of exploiting the unique properties of synchrotron radiation sources. His approach combines existing expertise in semiconductor device fabrication, x-ray analytical measurements and synchrotron radiation experimentation. Current work focuses on the development of semiconductor detectors and detector systems optimized for high count rates and very good energy resolution. The development of multi-element silicon array detectors is now well under way. These silicon detectors will initially be targeted for high-count-rate fluorescence spectroscopy experiments, such as XAS (x-ray absorption spectroscopy) and EXAFS (extended $x$-ray absorption fine structure spectroscopy). Much of the work for this program is undertaken in a collaborative mode with synchrotron radiation experimenters in the life sciences and materials sciences who utilize synchrotron facilities, and who will be able to effectively exploit the new technologies for specific applications.

\section{MODELING HUMAN PATHOLOGY IN TRANSGENIC} MICE

\section{EDWARD RUBIN-TRANSGENIC/KNOCKOUT MICE TECHNOLOGY DEVELOPMENT AND PRODUCTION}

Use of transgenic and gene-targeted mice is expanding in all areas of biological research and will clearly play a fundamental role as part of the Human Genome Program in the discovery of important genes and their functions. The Lawrence Berkeley National Laboratory's transgenic and gene knockout program is a high-throughput production facility for creating such genetically engineered animals. In addition, new technologies are being pursued to accelerate the creation of transgenic and knockout mice to more efficiently exploit information generated by the human genome program and by other biological and disease-related programs. This includes ways of facilitating the construction of in vivo libraries of human DNA in YAC transgenic mice, developing new strategies for engineering targeting vectors, and the means for creating large targeted deletions in mice of regions syntenic to that of the human genome being sequenced at the Berkeley Lab. 
Edward Rubin is capitalizing on this opportunity by generating transgenic mouse libraries for both the Down Syndrome region of chromosome 21 and a region of chromosome 5 thought to contain many genes for cytokines and cytokine receptors. He is also pioneering the development of more efficient methods for creating transgenic mice and for creating large deletions in targeted regions of the mouse genome.

\section{HUMAN GENOME CENTER (HGC)}

\section{Mohandas Narla-Human Genome Center}

\section{Michael Palazzolo/Chris Martin-Sequenc- ING AND GENOME TECHNOLOGIES GROUP}

\section{Frank Eeckman-The Human Genome Center INFORMATICS GROUP}

\author{
ANTHONY HANSEN-CONVEYOR AUTOMATION \\ SYSTEM FOR LARGE SCALE GENOMICS
}

\section{WILLIAM KOLBE-DNA SEQUENCER DEVELOPMENT}

\section{Martin Pollard-DNA PREPARation Machine}

\section{LINDA SINDELAR-High THROUGHPUT DNA SYNTHESIS IN A MULTICHANNEL FORMAT}

Henry BenNer/Joseph JAKLEVIC-AdVANCED DETECTORS FOR MASS SPECTROMETRY

\section{SYLVIA SPENGLER- \\ HUMAN GENOME FIELD OPERATIONS COMPUTATIONAL BIOLOGY INTTIATIVE COMMUNTTY COLLEGE INTTIATTVE}

\author{
VICTOR MARKOWITZ-DATA MANAGEMENT TOOLS \\ FOR GENOMIC DATABASES
}

\section{MANFRED ZORN-METADATA-DRIVEN DATA SUBMISSION TOOLS}

The Human Genome Center at LBNL has been under the direction of Mohandas Narla since January, 1994. The primary focus of the LBNL HGC is to develop and implement automated technology for the mass production of finished genomic sequence through the interdisciplinary efforts of the human biology, automation and instrumentation, informatics, and sequencing groups. Two distinct functional units concentrate on 1) production sequencing and 2) research and development.

The Automation effort led by Joe Jaklevic, Anthony Hansen, William Kolbe, Martin Pollard and Linda Sindelar is scaling up the LBNL custom instrumentation to achieve a higher throughput by use of conveyor systems coupled to robotic workstations and electrophoretic separations in capillary tubes. Other projects include designing a machine to extract plasmid DNA from bacteria and development of a multichannel DNA synthesizer.

The Informatics effort is led by Frank Eeckman and provides all of the hardware and software for the UNIX workstations; this effort also maintains and updates all databases for use within the Center and by other LBNL and UC campus collaborators.

The Sequencing Group is led by Michael Palazzolo and Chris Martin and aims to produce large amounts of high quality human genomic DNA sequence, with the ultimate goal being 100 megabases of DNA per year. Current sequencing efforts are focused on chromosomes 5 and 20 because of collaborations with LBNL investigators Edward Rubin and Joe Gray who are developing physical maps of regions of these two chromosomes. Henry Benner and Joseph Jaklevic are studying the possibility of using mass spectrometry for DNA sizing and sequencing.

Sylvia Spengler serves as coordinator of many DOEfunded genome research activities. In this capacity she assists OHER in overall coordination of genome activities, management and sharing of data and samples, participation in national and international efforts, and establishment of ad hoc task groups to analyze specific questions such as ethical, legal and social issues. She also coordinates a computational biology initiative which includes computational genetics, computational genomics, bioinformatics for genome, and tools and standards for biological databases. Dr. Spengler also manages the Community College Initiative to prepare college students for careers in biotechnology.

Molecular biology data are currently maintained in numerous databases including the Genome Data Base at Johns Hopkins University, the Genome Sequence Data Base at the National Center for Genome Resources, and 
the Protein Data Bank at Brookhaven National Laboratory. Victor Markowitz and his group are building and refining an Object-Protocol Model to provide facilities for efficiently constructing, maintaining and exploring molecular: biology databases using application-specific constructs on top of commercial database management systems. Manfred Zorn directs a project to develop mechanisms and software to facilitate public distribution and annotation of genome information.

\section{DNA REPAIR}

\section{JoHN GAME—GENETIC STUDY ON YEAST}

John Game's project is to understand how DNA doublestrand breaks (DSB) are processed in cells, with specific focus on the recombinational mechanisms that are thought to be important in DSB repair. The project grew out of earlier work by Dr. Game and others using the yeast Saccharomyces, although the current focus is on repair mechanisms in mammalian cells. In yeast, a group of about ten genes is known to be essential for the major pathway of DSB repair, which involves recombination. Many of these genes are now known to have human homologs, and a major part of this project involves identifying and characterizing analogous repair systems in mammalian cells. Earlier work had suggested that recombinational mechanisms were not involved in repair of DSB in mammals, but it is becoming increasingly clear that recombination plays an important and possibly essential role in DSB repair.

\section{MEDICAL APPLICATIONS (KP06)}

\section{Henry V AN BrockLin-Experimental Medicine DEVELOPMENT OF RADIONUCLIDES}

\section{Stephen Derenzo-Positron 3D Imaging INSTRUMENT}

ThOMAS Budinger-Advanced Nuclear MEDICINE AND NMR TECHNOLOGIES FOR INVESTIgating Mechanisms of Aging, Atherosclerosis, Mental Disorders and CANCER

\section{Scott Taylor/Mary Helen Barcellos-HofF- LABELING OF DNA APTAMERS FOR PET AND}

\section{SPECT}

\section{Ronald Krauss/Diane Tribble-Imaging of APOLIPOPROTEIN E-BINDING RECEPTORS IN VIVO}

LBNL has a RDS-111 medical cyclotron for producing short-lived isotopes. Henry Van Brocklin is developing new methods for production and incorporation of these radionuclides into biochemical substrates useful for imaging studies. These compounds are being used for monitoring blood flow, oncology imaging, glucose metabolism, and dopaminergic function. They are also used to synthesize radiopharmaceuticals for the study of physiological processes in normal and diseased states.

This complements the studies of Stephen Derenzo who is focusing on the development of advanced detector concepts for imaging of radio-labeled tracers by improving the spatial and temporal resolution. These improved techniques will be made available to other research institutions and industries for the benefit of medical research throughout the world.

The program of Thomas Budinger focuses on improving the design and data analysis of advanced positron emission tomography (PET) and NMR systems for commercial implementation to study atherosclerosis, cardiovascular disease, aging, mental disorders and cancer. The joint approach of new isotope technologies and experimental physiology is being applied to medical science problems using a team of physicists and research physicians devoted to development of quantitative methods of experimental medical science. Autoradiography, in vitro tracer studies, mathematical modeling and statistical analyses are being used in addition to PET and NMR.

A new approach to imaging is the use of radiolabelled DNA oligomers (aptamers) to target biologically active peptides that have a significant role in cancer and other human diseases. Aptamers are chosen which will localize in a primary tumor and can then be visualized by PET or SPECT. Scott Taylor and Mary Helen BarcellosHoff are developing this technique to image breast cancer using radiofluorinate and radioiodinateaptamers.

Imaging can also be used to identify critical oxidative events involved in the development of atherosclerosis. Ronald Krauss and Diane Tribble are using cells and perfused arteries to evaluate by imaging how varying the amount of antioxidant enzymes induced influences either intracellular oxidant-induced stress or macrophage-mediated LDL oxidation in the extracellular compartment. These studies will permit more precise delineation of the molecular basis for the involvement of specific lipoproteins in atherogenesis, and aid in identification of approaches for targeting tissue interventions and diagnostic imaging. 


\section{Table 6: Significant Science and Technology Achievements}

\section{Analytical Technology}

KP-01-02

Development of RoOm-Temperature Semiconductors for Field ApPLications (LUKE, WaLton)

- Studied material defects in CdZnTe crystals, which can degrade detector performance. Methods to identify these defects and to screen crystals for detector fabrications have been developed.

- Achieved energy resolution 3 times better than conventional scintillation detectors $(2.4 \%$ FWHM at 662 $\mathrm{keV})$. This is the best resolution obtained for a $1 \mathrm{~cm}^{3}$ CaZnTe detector.

- Using a-Si/c-Si contacts on $\mathrm{Si}(\mathrm{Li}) \mathrm{x}$-ray detectors, a reduction of about $50 \%$ in the photo-peak induced background counts had been demonstrated.

\section{KP-01-02}

High Rate, Low Noise Silicon ArRay Spectrometer for SYNCHROTRON X-RAY FLUORESCENCE APPLICATIONS (LUDEWIGT)

- Silicon detector arrays wire-bonded to preamplifiers realized as custom designed integrated circuits have achieved the desired energy resolution of $200 \mathrm{eV}$ FWHM for $6 \mathrm{keV}$ photons.

- An application specific integrated circuit, which features 48 channels of low noise charge-sensitive preamplifiers and shapers, has been designed for the parallel processing of signals from $x$-ray detector arrays. 


\section{Environmental Research}

KP-02-01

Aerosol \& Cloud Chemistry (Novakov)

- Demonstrated that the organic aerosol component is a major contributor to cloud condensation nuclei. Analyses of field measurement data at two marine locations (Puerto Rico and California) show that the contribution of sulfate to $\mathrm{CCN}$ concentrations is between $20-65 \%$, vs. the contribution of organic particles of $4-80 \%$. Our laboratory experiments show that biomass smoke particles free of inorganic impurities are efficient $\mathrm{CCN}$, demonstrating that some classes of organic aerosols are intrinsically CCN active. Measurements made under typical Atlantic trade wind conditions show that organic aerosol mass concentrations exceed sulfate concentrations. These particles are CCN active and most likely of natural oceanic origin.

KP-02-03

Field Heterogeneity (MaJer)

- Imaged both geological and hydrological properties at a unprecedent resolution in both field and lab scales. Seismic tomography is being used to image fine scale ( $10^{\prime} \mathrm{s}$ of centimeter resolution) variation in geologic properties at DOE field sites. These results are being coupled with radar measurements to provide information on flow and transport properties. Multiple surveys are being used to obtain 3-D images of the subsurface at small scales such that microbial properties can be correlated with the geologic and hydrologic properties.

- Conductedlaboratory measurements of seismic, electrical, and flow properties on core and blocks of sediment in cooperation with scientists at PNNL from the field sites to link and calibrate the field studies to actual physical properties such as sediment type, flow properties, and microbial heterogeneity.

Advanced Methods to Identify STres With Potential for LARGE EXPOSURES TO RADON (GADGIL)

- Developed a predictive statistical approach for identifying regions of the country that contain high radon homes that determines the county Geometric Means
(GM) where data are relatively sparse.

- Produced predictive maps, at country-level identifying regions of the country that contain high radon homes, that substantially exceed in quality anything that has been published on this topic by EPA or other environmental authorities.

- Expanded the method to include geologic units and apply it to large (multi-state) regions to cover the entire US.

- Developed statistical methods that can use the distribution short term state survey (SRRS) data to predict local distribution of long term concentrations, and demonstrate it for a region of the country.

\section{Health Effects}

KP-03-02

The Resource for Molecular Cytogenetics (Gray)

Fluorescence In situ hybridization (FISH). Progress has been made in four areas; 1 . Comparative genomic hybridization (CGH), 2. Thick section FISH, 3. DNA fiber mapping and 4. Quantitative FISH analysis of mRNA levels.

1. Comparative genomic hybridization (CGH) detects and maps changes in relative DNA sequence copy number onto normal chromosomes, which represent a physical map of the genome. It has been applied successfully for analysis of numerous human and murine tissues with a particular focus on discovering new genetic abnormalities involved in cancer development. More than 10 have been discovered by collaborating investigators in breast cancer alone. However, CGH is limited in genomic resolution to $\sim 10 \mathrm{Mb}$ by the locally non-linear organization of DNA in chromosomes, and the analysis of metaphase chromosome is slow. To overcome these difficulties, we are developing CGHa in which copy number changes are mapped onto arrays of cloned probes. This year, we have shown that comparative hybridization of genomic DNA to target elements consisting of P1 clones allows detection of amplified sequences in tumors and that differences in relative copy number can be assessed accurately over a range of 1000. Rights for commercial development of CGH have been licensed to Vysis, Inc. They will be introducing reagent products and quantitative image analysis equip- 
ment for CGH in April 1996.

2. FISH to frozen and paraffin-embedded tissue sections up to $\sim 20 \mu \mathrm{m}$ thick using directly labeled repeat and gene-specific probes has been developed to enable analysis of the genetic status of individual cells in relation to the tissuestructure. This opens the way for detailed analysis of the relation of genetic abnormalities and instability on the behavior of cells within tumors.

3. DNA Fiber mapping has been developed to allow cloned probes to be mapped along individual DNA fibers with resolution of $\sim 5 \mathrm{~kb}$. DNA fibers may be "pulled" from individual cells or chromosomes or prepared from cloned probes (e.g. YACs, P1, BACs, etc.). Fibers prepared from cloned probes are made linear and uniformly stretched using molecular combing (a procedure where the molecules are hydrodynamically stretched by the action of a receding meniscus). These procedures allow rapid assembly of physical maps, accurate analysis of probe overlap, assessment of gaps between probes, and increased the efficiency of directed genomic DNA sequence analysis.

4. In collaboration with other projects, FISH procedures developed for quantitative analysis of mRNA levels in C. Elegans have been adapted fot the analysis of gene transcription in mammalian cells. This will allow assessment of transcription levels using as probes, gene fragments recovered using exon trapping, cDNA selection or genomic sequencing. This procedure will facilitate annotation of genomic sequence and will provide critical information about gene function.

Probe development and physical map assembly. The Resource has generated a set of probes for use in FISH mapping and has collaborated on assembly of physical maps in regions thought to contain genes that are important in tumorigenesis or tumor progression.

1. FISH probe development. 1123 probes covering 695 genes or genetically mapped loci and 119 anonymous sites have been developed or acquired by the Resource for use as FISH probes. These include 568 P1 clones, 326 YAC clones, 161 cosmid clones and a few BAC and PAC clones. This list includes probes developed by the Resource and those acquired from Yale University (D. Ward), LLNL (A. Carrano), and Albert Einstein College of Medicine (K. Montgomery). In addition, the Resource collaborated with the
Whitehead Institute and Genome Systems to select P1 clones for locations at both ends of each mouse chromosome. Each probe was selected by PCR using primers that identify a distal or proximal genetically mapped polymorphism. FISH with these probes facilitates identification of mouse chromosomes . Information about these probes and their availability is available through the Resource Web Page (http: / /rmc-www.lbl.gov). This year, probes developed by the Resource have been distributed to 60 different laboratories. These probes have now been transferred to Vysis, Inc. and Genome Systems for commercial distribution.

2. Physical map assembly. The Resource, in collaboration with the UCSF Breast Cancer SPORE, has developed a sequence-ready physical map spanning an $\sim 1.5 \mathrm{Mb}$ region at chromosome $20 \mathrm{q} 13.2$ that is frequently amplified in solid tumors. Gene fragments from this region have been recovered using exon trapping, direct cDNA selection and analysis of genomic sequence. The Resource is collaborating with the LBNL Human genome Center to sequence $\sim 500$ $\mathrm{kb}$ from the core region. Ten genes have been discovered in this region, two of which are strong candidate oncogenes. The Resource also has collaborated on development of physical maps at 20q13.1 (site of a second amplicon in breast cancer) and 20p12 (Alagille syndrome) and identified a candidate gene for benign neonatal and frontal lobe epilepsy.

\section{Digital imaging microscopy}

Microscopic, image processing and analysis methods have been developed for CGH, 3D FISH, rare event detection, multi-color image acquisition, aberration scoring for biodosimetry, and analysis of FISH to DNA fibers. Specifically:

1. Instrumentation evaluation and control modules were developed for: a) Accurate measurement of chromatic shift, chromatic cross-talk, and chromatic illumination uniformity, b) Control of the digital cameras, motorized stages, filter wheels, and shutters on automated microscopes, $c$ ) Precise positioning $( \pm 1 \mu \mathrm{m})$ of a microscope's stage so that the same field of view can be revisited after slide removal and remounting and d) Removal of the autofluorescence component from an image of a sample stained using FISH.

2. Chromosome analysis procedures were developed to: a) Track linearized DNA molecules and accurately measure hybridization signal intensities along 
their lengths, $b$ ) Enhance banding patterns in DAPIstained chromosomes, c) Improve chromosome segmentation, medial axis determination, end extension, and profile extraction.

3. 3D image display and analysis modules were developed to: a) Project through a stack of images so the user can see FISH signals at all depths in the specimen in a single 2D display, b) Enable an analyst to identify FISH signals in a 3D image, c) Allow an analyst to interactively segment nuclei in 3D image and d) Automatically segment nuclei in 3D images. Further development of this system is being pursued in collaboration with Zeiss.

4. Remote controlled interactive microscopy was developed to allow users to interact with a remotely located microscope in pseudo-real-time. This capability will allow remote collaborations, teaching, and remote pathologic analysis of clinical and biological samples.

The proven success of our analysis methods generated considerable interest in the cytogenetic research community. Clones of our system have been installed in 13 different locations in the US, Japan and Europe. In addition, our industrial partner, Vysis, has licensed our system for commercial distribution. A prototype version was demonstrated at the 45th annual meeting of the American Society of Human Genetics in Minneapolis, Oct 24-28, 1995. First customer shipments were in April, 1996.

\section{Informatics}

1. A laboratory notebook has been developed to support Resource probe mapping and map assembly. The notebook includes information about locus definition, primer pair design, library screening, and mapping. Each section builds on the preceding section and adds information specific to it's particular stage. Entries are time-stamped and moved along the protocol steps automatically within a section. Releasing entries to the next stage requires explicit approval from the responsible scientist.

2. A public web interface (http://rmc-www.lbl.gov) was developed that provides information about probes developed by the Resource and others. Each probe name is a hypertext link to detailed information about the probe, the target, primer pairs used, etc. and to relevant public databases such as GDB. Probes may be requested through the interface. The web server also features sample images for users of
Resource imaging software, pages about policies, and procedures employed in the Resource.

3. SubmitData,a generic application to translate data from a tabular record format into complex structures, was developed to format data for submission of Resource data to GDB. The program has been successfully used in the Resource and is currently being evaluated by the LLNL-WashU-Merck cDNA project.

Mechanssms of Tumor Promotion; Regulation of TissueSpectfic Genes in Normal and Malignant Breast Cells (BISSELL)

- Using a basement me mbrane assay and antisense technologies, we have established that ECM-degrading enzymes are necessary for invasion of mouse (and human) mammary epithelial cells. "Normal" cells downregulate the endogenous levels of this enzyme when in contact with ECM; malignant cells are upregulated pointing once more to the importance of using non-malignant, "normal" cells when studying mechanism of malignant conversion.

- We have shown that transgenic animals that have a disrupted ECM in the breast develop mammary tumors showing that ECM is crucial in maintaining the normal phenotype, but also astonishingly, that perturbations in the microenvironment can lead to genomic instability and cancer.

- Using degenerate probes and RT-PCR, we have isolated a number of homeobox genes from the mammary gland and shown them to be regulated by $E C M$, the stages of pregnancy cycle and whether the cells are "normal" or "maglinant".

- The cellular and "tissue structure" is dominant in determining the phenotype of breast cells. This was established in collaboration with colleagues in Denmark using human breast epithelial cells in a progression from "normal" to malignant. Using this system, we have shown that despite major changes in the genome of the cells as they progress towards malignancy, they behave normally in a 3-D assay until they lose structural integrity. It is only after this point that the cells become malignant. 
- Identified a transcription factor (ITF2) in mouse mammary epithelial cells that may be an important negative regulator of invasiveness - a property of adult mammary epithelial cells that is commonly "switched on" during malignant transformation.

- Showed that breast cancer cell lines derived from invasive human tumors express high levels of Id-1, a factor that appears to bind and inactivate ITF2 or an ITF2-interacting factor.

- Constructed a retrovirus capable of introducing high levels of expression of Id-1 into normal human cells or non-invasive human tumor cells to test the idea that inactivation of ITF 2 by Id- 1 turns on the invasive phenotype.

IN Vitro Transformation of Human Mammary Eptthelial Cells (Stampfer, Yaswen)

- Used a protein, lactoferrin, whose production appears to be important to the well-being of the organism rather than to that of an individual cell, and which is often lost in breast tumor cells, to explore the influence of a cell's local environment on gene expression. We have learned that mechanochemical signals that regulate cell shape may influence expression of particular traits, independently of other factors. In an intact organism, such mechanochemical signals are likely to be derived from interactions with extracellular matrix. Thus, the extracellular context in which a cell finds itself is likely to influence its propensity to exhibit cancerous traits.

- Begun to use our extensive collection of normal and abnormal human mammary epithelial cells to explore the molecular mechanisms responsible for immortalization of cultured cells.

- Accumulated evidence indicates a strong correlation between such immortalization and carcinogenesis, and we hypothesize that mutations in genes which normally prevent cellular immortalization contribute a critical step in malignant progression of human cancers.

- Established a World Wide Web site (http:// www.lbl.gov $/ \sim$ mrgs) to facilitate comunication among researchers using normal and transformed human mammary epithelial cells.
- Chronic cell division at the maximum tolerated dose (MTD) is plausible as the major reason that more than half the chemicals tested, whether natural or synthetic, are classified as carcinogens in our Carcinogenic Potency Database of standard cancer tests. A low positivity rate of $9 \%$ in a 1969 series of experiments on pesticides has been frequently cited as evidence that the proportion of carcinogens among all untested chemicals is low, since only $9 \%$ were judged positive. We have pointed out that these tests were deficient in power compared to modern tests, and we havenow investigated whether any of the Innes-negative chemicals have been retested using current protocols. We found that 34 have been retested and 16 were carcinogenic, again about half.

- For trichloroethylene (TCE) we have estimated PBPK-based Maximum Concentration Levels (MCLs) for human exposures from contaminated drinking water, based on animal no-observedadverse-effect levels and a peak-blood-concentration dose metric, assuming a purely cytotoxic mechanism of hepatocarcinogenic action. Using this approach together with a 1000-fold safety factor, for TCE in 2 liters of drinking water/day the estimated MCL is $210 \mathrm{ppb}$. This compares to the EPA MCL of $5 \mathrm{ppb}$ in drinking water, which is based on a linearized multi-stage model. In contrast, for TCE in workplace air, the U.S. OSHA permitted exposure level (PEL) would not be expected to be protective because it is about equal to our estimated no-effect level without any safety factors.

- We have reviewed the literature on cancer causation with an emphasis on mechanism of carcinogenesis. Epidemiological evidence indicates that avoidance of smoking, increased consumption of fruits and vegetables, and control of infections will have a major effect on reducing rates of cancer. Other factors include avoidance of intense sun exposure, increases in physical activity, and reduction of alcohol consumption and possibly red meat. A substantial reduction in breast cancer is likely to require modification of sex hormone levels, and development of practical methods for doing so is a high research priority. Resolution of the potential protective roles of specific antioxidants and other constituents of fruits and vegetables deserves major attention. Mechanistic studies of carcinogenesis indicate an important role of endogenous oxidative 
damage to DNA that is balanced by elaborate defense and repair processes. Also key is the rate of cell division (which is influenced by hormones, growth, cytotoxicity, and inflammation), as this determines the probability of converting DNA lesions to mutations. These mechanisms may underlie many epidemiologic observations.

- We have shown that an estimate of the standard regulatory Virtually Safe Dose (VSD) can be obtained using solely the Maximum Tolerated Dose (MTD) of a chemical, i.e. without using cancer test results. The estimate obtained by MTD $/ 740,000$ is within a factor of 10 of the regulatory VSD for $96 \%$ of chemicals that are positive in rodent bioassays. We also found that the VSD estimate based on MTD/740,000, is about as precise as the estimate obtained from near-replicate experiments on the same chemical. These results can be exploited to provide a preliminary estimate of the standard, hypothetical upper bound cancer risk for exposure to a chemical without conducting a 2-year animal bioassay. The expected level of human exposure relative to the MTD can be used to determine the priority for further research on a chemical, such as mechanistic studies.

Bone Marrow Stem Cells (Narla)

- Achieved a long standing goal of sickle cell disease research, the creation of a transgenic/knock-outstrain of mice that no longer produces mouse hemoglobin but produces exclusively human sickle hemoglobin. This authentic mouse model of sickle cell disease provides an important new substrate for the development of improved treaments for sickle cell disease in humans.

DNA Damage by Radon Alpha Particles (Cooper)

- DSB Misrejoining: Developed novel approach for quantitation of DSBs in selected regions of the genome by hybridization detection of unique large (e.g. NotI) restriction fragments separated by PFGE.

- Provides potential to address intra-genomic heterogeneity in either induction or repair of damage.

- Measures rejoining of correct DNA ends by reconstitution of hybridizing restriction fragment.

- Together with measures of total rejoining, therefore gives misrejoining frequency.

- Found $\sim 30 \%$ misrejoining for DSBs induced by $X$ ray in normal human cells in G0 .

- Damage Clusters: Demonstrated that non-randomness of DSB induction by high LET radiation in human cells explains apparent decline in yield with inceasing LET when measured on megabasepair scale.

- Increased clustering with increasing LET in size interval of $100 \mathrm{bp}$ to $2 \mathrm{kbp}$ due to organization of chromatin as $30 \mathrm{~nm}$ fiber.

- Increased clustering on larger scale, between 2 and 200 $\mathrm{kb}$, possibly reflecting higher order organization of mammalian chromatin into loops.

- When clustered breaks are taken into account, DSB yield for $\mathrm{N}$ ions (LET $97 \mathrm{keV} / \mathrm{mm}$, similar to radon a-particles) compared to $X$-ray becomes somewhat greater than 1.0 (RBE).

Question: still not nearly as high as the RBE for biological endpoints (3-10x); does difficulty in correctly rejoining breaks in damage clusters contribute to the high biological effectiveness of high LET radiation?

- Rejoining of Heavy Ion-Induced Double-Strand Breaks Compared to X-ray Induced DSBs:

- The measured proportion of breaks which are not rejoined in normal human cells increases with LET; the proportion that are misrejoined does not change significantly.

- The rate of both correct and overall rejoining appears to decrease with increasing LET.

- Caveat: both of these conclusions are complicated by presence of clustered breaks that are measured as single breaks by the assays employed.

Question: is there a high misrejoining frequency within damage clusters? Does this result in a high deletion frequency at sites of clusters?

- Induction and Repair of Oxidatively Damaged Bases by High LET Radiation:

- Used sensitive immunological assay to quantitate the oxidatively damaged base thymine glycol after exposure of human cells to X-rays, protons, and a 
variety of high LET particles including low energy aparticles.

- Thymine glycols are induced linearly with dose and independent of LET.

- Thymine glycols are removed more slowly after high LET radiation.

Question: is this slow removal a consequence of clustering of the damage?

- Demonstrated that thymine glycols (and presumably other oxidatively damaged bases) are removed preferentially from transcribed strands of active genes.

- Transcription-coupled repair occurs for both low and high LET damage.

- Human cells with defects in transcription-coupled repair of oxidative base damage are hypersensitive to killing by both low and high LET radiation.

Genetic Susceptibility and Radiation (Pallavicini)

- Demonstrated preferential chromosome susceptibility to radiation-damage. Chromosomal regions that are recurrently abnormal in leukemias appear to be preferentially damaged by radiation.

- Demonstrated that the translocation frequency of circulating lymphocytes is approximately 5-10 fold lower than the frequency of aberrant lymphocytes in marrow and spleen. These data are significant because they suggest that the frequency of aberrant circulating lymphocytes may not reflect the number of damaged cells in tissues at risk of leukemic transformation

- Developed experimental strategies to test proof-ofprinciple concepts to facilitate evaluation of compounds in mixed waste with potential to increase risk of developing leukemias.

Radiological Physics (ChatterJee)

- Just as important as the sequence of human genome, is a knowledge of the structure of the genome. It is well known that structure and function are correlated and significant effort is underway to determine the way DNA is compacted. When DNA is folded in the chromatin form, a solenoidal structure is created which is known as the condensed form of DNA. However, a few years ago as a result of three dimensional electron tomography studies a new structure in the form of a ZIG-ZAG ribbon model was suggested by a structural biology group at UCSF. Recently, in the proces of analyzing radiation-induced damage to the genome, we accidentally ran into the same structure as proposed initially by the UCSF group. Our method involved computational analysis as well as experiments suggested by the computational technique. We are in the process of submitting this work to the journal NATURE.

\section{General Life Sciences}

KP-04-01

Molecular Structure of Membrane Transport System (JaP)

- Successfully cloned and expressed the E. coli potassium channel.

- Developed general two-dimensional crystallization techniques which yield crystals diffracting to high resolution.

- Developed a protocol for two-dimensional crystals of AQP1 water channel, yielding crystals that diffract to $3.0 \AA \AA$ resolution. A high resolution projection map of this channel protein has been obtained, showing the organization of the putative transmembrane helices forming the channel.

- Developed protocols for three-dimensional crystallization of cytochrome reductase, yielding two crystal forms that diffract to about $3.2 \AA$ resolution. A potential heavy atom derivative has also been obtained.

- Establishing a unique capability for structural determination of membrane proteins by the use of both electron and X-ray crystallographic methods. These involve the expression of membrane proteins using various novel and established techniques for the expression of clinically important proteins that are naturally expressed at a very low level such as the cystic fibrosis transmembrane conductance regulator (CFTR) and potassium channel proteins. 
Biophysical CHEMSTRY (KLEIN AND YACHANDRA)

- By employing X-ray Absorption Spectroscopy (XAS) using synchrotron radiation we are ascertaining the oxidation state(s) of cellular sulfur, especially that of glutathione in the living cell. Preliminary results demonstrate that the precise energy and shapes of the Sulfur X-ray absorption edge can distinguish among all of the oxidation states of sulfur and, in particular, among the three oxidation states of glutathione. This result has important consequences for understanding the cellular responses to oxidative insult and damage.

Structure and Mechanism of Catalytic RNA (HOLBROOK/KIM/TiNOCO/WEMMER)

- Retroviruses are RNA viruses that cause AIDS and leukemia in humans, and similar diseases in animals. We have determined the three-dimensional structure of a part of the retroviral RNA from mouse mammary tumor virus necessary for its reproduction. This can lead to the design of drugs that specifically target the structure, and thus prevent reproduction of the virus.

- Three RNA dodecamer double helices incorporating internal loops of sequence UUCG:UUCG, UUUG:UUUG and GAAA:GAAA have been determined and the coordinates are available both here and through the Protein Data Band, PDB (link) and the Nucleic Acid Database, NDB (link). Structural determination is in progress on an active hammerhead type catalytic RNA with high resolution diffraction data in hand. Synthesis and crystallization studies have been initiated for a hyperthermophilic $5 S$ ribosomal RNA.

- Based on existing structural and sequence databases, stereochemically reasonable models of RNAs of unknown structure are constructed which retain the architecture of homologous known structures; small molecule ligands which bind RNA are proposed; and structural features of novel RNA sequences can be preclicted by computational methods.

- Currently, the bottlenecks in crystallography are crystallization and phase determination. Sparse matrix screening has been successful in protein crystallization. We have developed and are continuing to explore novel techniques for RNA crystallization. Molecular replacement and isomorphous replace- ment with heavy atoms is very time consuming and not routinely successful. We have begun studies to determine a correct set of phases for small sets of crystallographic data with the goal of identifying the molecular envelope and ultimately its three-dimensional structure.

SOFT X-RAY MicrosCoPy (GLAESER, MORONNE)

- Demonstrated that lanthanide conjugated probe molecules including DNA, avidin, secondary antibodies, and biotinylated polychelates produce useful luminescence under x-ray excitation. A consistent observation regardless of the specific lanthanide compound studied is that useful luminescence is obtained at doses well above 1010 rads. Calculations based on this data show that our reagents are sufficiently bright to visualize microtubules at $50 \mathrm{~nm}$ resolution. This latter figure compares very favorably with confocal microscopy, but at 4 to 5 times better resolution.

- Obtained images of lanthanide labeled specimens of actin stress fibers in mouse 3T3 cells and isolated microtubule assemblies that confirm the ability of these probes to be used for high resolution x-ray excited luminescence microscopy in actual biological samples.

- Using extensive numerical simulations, we have shown that it is possible to compute in advance the dose required for a 3-D reconstruction, and that it is feasible to use tomography with soft $x$-ray microscopy to obtain $50 \mathrm{~nm}$ resolution of frozen hydrated specimens without causing extensive structural alterations.

Semiconductor X-Ray Detectors For Synchrotron ApplicaTIONS (JAKLEVIC, ROSSINGTON)

- A 200-element silicon detector, covering an area 0.5 $\mathrm{cm} 2$, achieves $200 \mathrm{eV}$ FWHM energy resolution (at $5.9 \mathrm{keV}, 2$ microseconds amplifier peaking time, $25 \infty \mathrm{C})$ when used in conjunction with low noise integrated circuit pulse-processing electronics.

- High purity GaAs epilayers have been grown on GaAs substrates, 100 microns thick with a residual donor concentration of $5 \times 1013 \mathrm{~cm}-3$, for the application of room temperature diode arrays. 
- 16-channel CAMAC-based ADC (Analog to Digital Converter) developed.

Biomolectlar Structure ANalysts by NMR (Wemmer)

- Studies to determine the structures of DNA oligomers modified by psoralen, a natural plant product and also a drug, were completed and published. Local distortions induced in the structure were characterized in detail and suggestions were made regarding how these damaged DNAs might be recognized by repair proteins.

- A high resolution structure of the complex of a dye with DNA was completed. This compound is very useful in genome mapping and sequencing technologies, and this structure will aid in new designs for analogous molecules with different useful properties.

- The structure of a part of a bacterial regulatory protein, NTRC, was calculated and reported. Features of the structure suggest a mechanism for how it is able to change conformation to regulate a specific gene. A system for preparing it in its active, phosphorlated form has been developed, and some mutated versions which are always partially 'on' have been prepared.

- Structures for the DNA binding domain of the heat shock transcription factor from yeast were calculated and reported. This protein is critical to the cell's ability to respond to environmental stress. Surprisingly it was found that an attached activation domain of this protein is completely flexiblein solution, but is active in controlling other proteins in the cell. Structural characteristics of other parts of this important protein were also determined.

- A human regulatory protein, HMG-I, involved in response to viral infections among other things, was characterized. Unlike most proteins, it does not take on a defined conformation in solution. It has unusual interactions with other proteins, which seem to be critical for its activity; samples of the protein and complexes are being made to examine these.

- The protein Sxl (sex-lethal) acts as a genetic switch. It is on in females, but off in males, and acts as the master switch in sexual development. Unlike most genetic switches it acts at the level of RNA rather than DNA. We have determined the structure of part of the protein, and have begun disecting which portions are most important for activity. Studies of the complex with RNA, defining the 'on' state, are well underway.

- We have studied a DNA sequence that acts as an 'adaptor' binding to the amino acid arginine, one example of a whole class of such adaptor molecules that can be selected for binding to almost any target. We have found that it changes its structure in the process of binding. Better understanding of such processes will help in future designs.

- All of these studies are at a fundamental level, helping understand the processes which underlie all of biology. Improved understanding of the molecules involved allows better interpretation of biological function, and facilitates our ability to modify and control it.

STRUCTURAL BIOPHYSICS (KIM)

- During the current fiscal year we have determined the crystal structure of the complex between a chemical inhibitor and cyclin-dependent protein kinase 2 (CDK2). For the coming several years, we plan to focus on five classes of proteins, cyclins: CDKinhibitor proteins (CKIs), the CDK7/cyclin $\mathrm{H}$ complex, CDK/CKI complexes, and CDK2/inhibitor drug complexes.

\section{Catalytic Antibodies (Schultz))}

- Introducing novel amino acids into loops 1, 2 and 4 of ras p 21 protein in order to study the (i) mechanism of GTP hydrolysis, (ii) ras-raf interactions and (iii) $\pi$ cation interactions in ligand binding.

- Crystalling the amino terminal SH2 domain of GAP.

- Studying the catalytic mechanisms of two novel biochemical reactions, the self-splicing reaction of DNA vent polymerase from Thermococcus litoralis and the hydrolytic mechanism of the novel dicobalt protease, methionine aminopeptidase.

- Developing antibodies that (i) catalyze epoxide hydrolysis (a glutathione-S-transferase like activity), and (ii) catalyze chemiluminescence. At the same time efforts have begun to clone, crystallize and solve the three dimensional structure of an antibody 
with ferrochelatase activity in order to better understand the molecular basis for antibody catalysis.

SEMICONDUCTOR X-RAY DeteCtors (JAKLEVIC, Rossington)

- A 200-element silicon detector, covering an area 0.5 $\mathrm{cm} 2$, achieves $200 \mathrm{eV}$ FWHM energy resolution (at $5.9 \mathrm{keV}, 2$ microseconds amplifier peaking time, $25^{\circ} \mathrm{C}$ ) when used in conjunction with low noise integrated circuit pulse-processing electronics.

- High purity GaAs epilayers have been grown on GaAs substrates, 100 microns thick with a residual donor concentration of $5 \times 10^{13} \mathrm{~cm}-3$, for the application of room temperature diode arrays.

- Developed a 16-channel CAMAC-based ADC (Ana$\log$ to Digital Converter).

KP0404

Human Genome Center

(Narla, Palazzolo, Martin, Rubin, JaKlevic, Eeckman)

\section{Sequencing Production}

- The Human Genome Center has surpassed the 5 million base pair (bp) milestone. The rate of sequence generation is currently at $500,000 \mathrm{bp}$ a month and increasing steadily. This figure is up from 80,000 bp a month last year. Cost per base pair is currently at 38 cents direct, 56 cents total.

- In the past year, we have produced over 728,550 base pairs of human genomic DNA sequence. A new approach to developing a minimal set of $3 \mathrm{~kb}$ subclones that span a physical mapping clone to be sequenced has been developed and put into routine production use. A novel and very low cost 96-well DNA preparation procedure for plasmid templates suitable for sequencing has been developed and put into routine production use. Significant disposables cost reductions have been achieved in the production process.

- We have completed over 1.2 million base pairs of human genomic DNA sequence. This sequence is publicly available through our ftp site and through the public sequence database GSDB.

\section{Genome Informatics}

- Move-Track-Trim (MTT) is in production.This module checks the tracking of gels, does automated vector and quality trimming and moves the raw datafiles to the appropriate storage space. An ACeDB-derived browser was added recently. MTT was successfully transplanted to the Stanford Genome Center.

- Directed Assembly is in production using the FAK II kernel, developed by Eugene Myers.

- Editing, Finishing: SPACE (Sequencing Platform using $A C E$ ) was recently introduced in the lab. Further development is needed over the next several months. Incorporation of end-sequencing and automated basecalling is under way.

- Reconstruction of P1 clones from DOGs, can now be done using FAK, SPACE and a modified version of DRAW.

- Annotation: the annotation scripts are nearing completion, the annotation browser, using Tk/perl, is operational and interfaced with $\mathrm{ACeDB}$, the package has been tested and sample annotated P1 sequences are available from our web site. Gregg Helt at the Drosophila GenomeCenter Informatics group, and researchers in the biology groups (E. Rubin, P.I.) have used the browser and provided feedback. We need to discuss with the Sequencing groups, and the GSDB staff, what types of annotation to include with our submissions. The annotation browser is also used at UCSC in the computational biology group. Within 3-6 months we expect to interface with ACeDB and the WWW.

- Submission: a semi-automated system using various scripts and a SmallTalk program, SubmitData/DB, is in place.

- End-Sequencing Support: The end-sequencing software is in production. Sam Pitluck is still refining the software for this effort and this will go on until the strategy is stable and the protocols are set. Hugh Salamon is working with Terry Speed (UCB Statistics) to optimize the end-sequencing strategy.

- Automated $Q$ control: This is now part of the submission protocol. A master script was developed and tested and integrated with SubmitData/DB.

- Basecalling ( $a b$ initio): We have tested the Bass package, developed at MIT and Stanford and are ready to 
integrate these efforts with the in-house sequencer developed by the Automation group.

- Post-processing of $\mathrm{ABI}$ basecalls: We have access to various post-processing algorithms, including one developed in-house by Martin Reese, that make editing/finishing more automatic. These algorithms need to be tested, and integrated into SPACE. This effort is scheduled to begin in February 1996. We do some collaborative work with Terry Speed on both post-processing and ab initio basecalling.

\section{Human Biology}

- A library of mice containing large segments of human chromosome 21 was generated to understand the genes involved in Down's Syndrome.

- Using these mice, a candidate gene involved in human learning disabilities associated with Down's Syndrome was identified.

Data Management ToOls for Genomic Databases (MARKOWITZ)

- Object-ProtocolModel(OPM) data management tools have been extended in order to address specific requirements of developing MBDs such as GDB 6.0 and the new version of PDB. In the past year, the OPM data management tools were extended several times; the current version of the tools, 4.1, was released on July 1, 1996, for Sun/OS, Sun/Solaris, DEC/Alpha and SGI.

- The following OPM tools are available on the Web at http://gizmo.lbl.gov/opm.html:

(1) an editor for specifying OPM schemas;

(2) a translator of OPM schemas into relational database specifications and procedures (Sybase 4-11; Oracle 7);

(3) utilities for publishing OPM schemas in text (Latex), diagram (Postscript), and Html formats;

(4) a translator of OPM queries into SQL queries;

(5) a retrofitting tool for constructing OPM schemas (views) for existing relational genomic databases;

(6) a tool for constructing Web-based form interfaces to MBDs that have an OPM schema; this tool was developed by Stan Letovsky at Johns Hopkins School of Medicine, as part of a collaboration.

- The OPM data management tools have been extended in order to address specific requirements of developing MBDs such as GDB, GSDB, and PDB.

- The OPM tools have been highly successful in developing new MBDs, especially GDB 6.0 (released in January 1996; http: / gdbgeneral.gdb.org/gdb/) and PDB (http://terminator.pdb.bnl.gov:4148).

- The OPM tools have been applied for constructing $O P M$ views and interfaces for existing MBDs such as GSDB 2.0.

- The OPM tools are currently used by over ten groups in USA and Europe.

Human Genome Coordinating Committee And Operations (SPENGLER)

- Five DOE Genome Contractors and Grantees Workshops have been held in Santa Fe, NM. Both plenary and poster facilities now have direct $\mathrm{T} 1$ access to the network for on-line display of software, databases, etc. Directors of NIH Genome Centers, representatives from industry, other funding agencies, and the press attend.

- ELSI working group meetings are supported by this office. Other ELSI activities include a pilot program for community college students trained in biotechnology to gain laboratory experience at LBNL, now successfully funded as a separate FTP.

- Meetings associated with the genome informatics efforts have been organized and supported by this office. For example, in January 1995, the Genome Section of the Hawaii International Conference on System Science was part of the administrative activities. The subsection was split off into a separate meeting in 1996, which has also been supported by this office.

- The DOE Biotechnology Forum meets throughout the year on a previously determined schedule. In addition, the joint DOE-NIH Advisory Committee meets annually in Washington D.C. 
- Using support from the TRAC program at the Center for Science and Engineering Education at LBNL, we have developed world-wide-web pages (http:// www.lbl.gov/Education/ELSI/ELSI.html) on ELSIderived questions regarding resource allocation, genetic testing, air pollution, and intellectual property that are aimed at the 6th grade level and above. Classroom activities are associated with each module. The module on testing was presented at the Notre Dame Conference on Ethical, Legal and Social Issues in October, 1995.

LABORATORY INFORMATION MANAGEMENT SYSTEMS (ZORN)

- Developed a data submission tool, SubmitData, that will strike a balance between ease of use, assistance in specifying the information for the authors and consistency, accuracy of the sequence submissions for the database. The published submission protocol of the database, the metadata, is interpreted by a parser and directly defines internal objects of the submission tool. Based on these objects, a form display is created to fill in data interactively. Templates can be created, edited, and merged with tabular datafiles to submit large volumes of similar data. By relying on metadata, the submission tool adapts to changing protocols and can be easily extended to work with different submission formats.

- To facilitate the free data exchange between Resource for Molecular Cytogenetics researchers at UCSF and LBL we developed a World Wide Web interface to access and modify information. The data are located on a central database. The browser client allows to formulate retrieval and edit operations that are sent to the database. Results are filtered through a Perl script which generates HTML documents with Hypertext links that are sent back to the browser. Data from the Resource are made available using a similar mechanism that is open to outside access (URL: http://rmc-www.lbl.gov).

- In order to handle large amounts of images we are developing an image annotation data-base. The images themselves are automatically transferred to the LBL Mass Storage System. The annotation will be reformatted and loaded into a relational database to allow efficient query processing.

- Using the acedb framework, we are currently building a database to integrate and visualize information for gene identification on chromosome 20.
- Released version 2.0 SubmitData \GSDB for data submission to GSDB.

- Developed User manual for SubmitData

- Upgraded to use VisualWorks 2.0

- Integrated SubmitData \GSDB with an assembly program, GRM by C. Lawrence, Baylor College of Medicine.

Mass Spectrometry Detectors (BenNer, Jaklevic)

- Development of charge detection mass spectrometry, an analytical procedure that provides a capability for sizing large molecules. This device supplies a technique that substitutes for time-consuming gel electrophoresis separations of large DNA molecules.

- Development of an electrostatic ion trap for large electrospray ions. When ionized by electrospray, large ions acquire many charges which confounds mass determination via mass spectrometry. This device simplifies such measurements and has applicability for mapping purposes in the Human Genome Project.

- Demonstration of a bolometric type of detector for ions generated with matrix-assisted-laser-desorption time-of-flight mass spectrometry. This detector extends the mass range of this type of mass spectrometer which was previously limited by the low response of microchannel plate ion detectors to large ions.

\section{Medical Applications}

KP0601

Experimental Medical Development of Radionuclides (VAN BROCKLIN)

- On July 5th, 1995 we installed the cyclotron in the Biomedical Isotope Facility, building 56 on the LBL campus. On August 17t the first beam on target was achieved. The first batch of radioisotope was produced in early September. Construction was nearly complete on the building by the end of November. An Accelerator Readiness Review was initiated. The 
first patient dose of FDG ([F-18] fluorodeoxyglucose) was produced in early January 1996 with [F-18]fluorometa-tyrosine and [N-13] ammonia produced in mid February.

- Throughout the last year we provided fluorodeoxyglucose, fluoro-meta-tyrosine(FMT) and iodonitroquipazine (INQUIP) for several projects. We have improved the yields and developed means for more efficient production using a semi-remote synthesis apparatus for FMT. Metabolic studies on INQUIP were performed in preparation for human studies.

- In our mitochondrial agent project, iodorotenone and iodorotenol were labeled with I-125. Initial evaluation studies were carried out in rats. Iodorotenone demonstrated good heart uptake. Iodorotenol showed lower uptake in mitochondrial rich tissues. We synthesized the $5^{\prime}$ epimers of fluorodihydrorotenone (FDHR) and separated the $6^{\prime}$ epimers of FDHR. The biological activity of each of the individual 6' epimers is the same. The 5' FDHR epimers possess about half of the activity of the $6^{\prime}$ epimers. FDHR was tested in the isolated perfused rabbit heart and showed a peak instantaneous extraction of $90 \%$. These tracers continue to look promising for a variety of applications in the neurology, cardiology and oncology.

- We synthesized [I-123]-1-(iodopropen-2-yl)-4-(4cyanophenoxymethyl)piperidine ([I-123]TCPNE) (collaboration with Dr. Rikki Waterhouse, ANSTO) a high affinity, selective ligand for the sigma-1 receptor and evaluated the uptake of this tracer in nonhuman primates using SPECT. Brain distribution corroborates uptake studies in the rats and in vitro autoradiographic studies in primate brains.

- RS-15385-[F-18]FP (decahydro-3-methoxy-12-(3-[F18] fluoropropyls ulf onyl)-6H-isoquino[2,1g][1,6]naphthyridine) a potent alpha-2 adrenoceptor ligand was produced. Rat studies demonstrated receptor-mediated uptake in the brain with localization in the locus coeruleus as seen by F-18 phosphor imaging autoradiography. Iodoatipamezolelabeled with I-125 was synthesized from the tributyltin precursor and evaluated in rats. The tributyltinatipamezole precursor was reacted with high specific activity [F-18]fluorine gas (Finnish collaborators), produced electrolytically from fluoride ion, to yield fluoroatipamezole. Initial rat studies revealed good brain uptake. Two talks were presented at the Annual Society of Nuclear Medicine Meeting in Den- ver, Colorado.

- We have recently labeled a DNA aptamer with fluorine-18 using a photoaffinity label. Work continues to improve the radiochemical yield and determine the biological distribution of this molecule in model systems.

PostrRon EMISSION TOMOgRAPHy INSTRUMENTATION (DERENZO)

- A prototype advanced detector module for high rate, high resolution PET was built and tested. The module consisted of 64 LSO scintillators, an $8 \times 8$ array of silicon photodiodes, and custom integrated circuit readout. This achievement paves the way for the construction of a tomograph with an image resolution finer than $2 \mathrm{~mm}$ for tracer studies of the human brain and small animals.

- Using the 100 ps pulsed $x$-ray facility, precision measurements of the risetime and decay times of commonly used scintillators were made. For several scintillators, new decay components were found, which provides new information on scintillation mechanisms. In addition, the new, bright scintillator LSO (lutetium orthosilicate, activated with cerium), was found to have the shortest risetime $(0.15 \mathrm{~ns})$ of all the Ce-activated scintillators measured.

IMAGING OF APOLIPOPROTEIN E-BINDING RECEPTORS IN VIVO (KRAUSS/ TrRBBLE)

- Identified environmental oxidant stress conditions (irradiation and diet) that are capable of promoting atherosclerosis in susceptible mice, and have used these exposure conditions to investigate the protective effects of human transgenes coding for proteins with antioxidant activity.

- Observed that a single dose (8 Gy) of ionizing radiation, administered in conjunction with a high $(1.25 \%)$ cholesterol diet, accelerates atherosclerosis in susceptible (C57BL/6) mice, as indicated by a three-fold greater mean lesion area in the proximal aorta of irradiated versus sham-irradiated mice. Mechanisms underlying the disease-accelerating effects of radiation are not known, but are suggested to involve oxidative tissue damage.

- In collaborative studies with Dr.Jay Heinecke(Washington University, St. Louis), we have observed that 
levels of tyrosine metabolites indicative of hydroxyl radical-mediated protein modification (ortho-, meta, and di-tyrosine) are only modestly elevated (15$30 \%$ ) above background levels in aortic tissue obtained post-irradiation. This suggests that aortic cells are able to respond effectively to the oxidant stress imposed by ionizing radiation at the dose used in these studies, and thus that marked oxidative injury to the vasculature is not essential to the atherosclerosis-accelerating effects of radiation.

- Irradiation had no effect on plasma lipid or lipoprotein levels in C57BL/ 6 mice either on chow or the $1.25 \%$ cholesterol diet, providing further evidence that the atherosclerosis-promoting effects are due largely to vascular alterations. Disease acceleration was observed only in animals exposed to high cholesterol diets, however, suggesting that radiationinduced vascular alterations are not sufficient alone, but rather occur in conjunction with a conducive lipoprotein milieu.

- Among the reactive oxygen species generated in vivo, the superoxide anion $\left(\mathrm{O}_{2}^{-}\right)$has been implicated as a primary mediator of atherogenic oxidative modifications. In many cases, the atherogenic potential of $\mathrm{O}_{2}{ }^{-}$has been inferred from observations of an attenuating effect of $\mathrm{CuZn-SOD.} \mathrm{CuZn-SOD} \mathrm{has}$ been shown to inhibit macrophage- and vascular cell-mediated lipoprotein oxidation, and leukocyte adhesion to the vascular endothelium, and to promote endothelium-derived relaxing factor induced vasodilation. To evaluate the pathogenic involvement of $\mathrm{O}_{2}^{-}$and $\mathrm{CuZn-SOD}$ in diet-induced atherogenesis, we examined atherosclerosis susceptibility in fat-fed C57BL/ 6 mice expressing the intracellular form of human copper-zinc SOD (CuZn-SODh) in collaborative studies with Dr. Charles J. Epstein (University of California, San Francisco). SOD activity was found to be elevated 2- to 3-fold in aortic tissue and peritoneal macrophages from $\mathrm{CuZn}$-SODh-transgenics, yet there were no measurable differences in aortic lesion area relative to littermate controls after 18 weeks on an atherogenic diet.

- The lack of an antiatherogenic effect of CuZn-SOD does not rule out the involvement of $\mathrm{O}_{2}^{-}$in the development of atherosclerosis. Among the various alternative explanations for these results, we plan to evaluate whether protective effects are observed over a different range of SOD activities (e.g., such as may be attained by inhibition rather than amplification of activity) and whether localization of SOD in the extracellular compartment is critical to its protective effects. With regard to the latter, we have observed that despite the elevation in intracellular SOD activity, phorbol ester-stimulated $\mathrm{O}_{2}{ }^{-}$release is not decreased in peritoneal macrophages derived for $\mathrm{CuZn-SODh}$ transgenics. Thus, macrophage-mediated LDL oxidation and vascular damage are unlikely to be affected by amplification of intracellular SOD activity. 


\section{TABLE 7: Major Examples of Collaborative Research}

The Resource for Molecular Cytogenetics serves as a model of collaborative interaction. The resource staff collaborate with numerous groups throughout the the World. Active collaborations include:

\section{$\underline{\mathrm{UCSF} / \mathrm{LBNL}}$}

Dr. Judith Campisi, Life Sciences Division, LBNL, Berkeley, CA. Mapping of genes involved in cellular senescence.

Dr. William Morgan, Dept. of Radiation Biology, UCSF, San Francisco. Characterization of translocation breakpoints on human chromosomes following exposure to restriction enzymes.

Dr. David Young, Veterans Administration Medical Center, San Francisco. Vascularization of transplanted human skin.

Dr. Mike Skinner, University of California, San Francisco. Investigation of the distribution of bovine, murine and human tissues in multi-tissue ovarian tumor models developed in nude mice.

Dr. I. Craig Henderson, University of California, San Francisco. Investigation of the genetics of chemoresistance in human breast cancers.

Dr. Marco Zarbin, Eye Research Center, UCSF, San Francisco. Development of techniques to differentiate between graft and host cells in sex mismatched RPEcells transplantations.

Dr. Charles Vidair, Dept. of Radiation Oncology, UCSF, San Francisco, CA. Heat shock induced aneuploidy in Chinese hamster cells.

Dr. Thea Tlsty, University of North Carolina. Investigation of genetic instability in human malignancies

Dr. Douglas Hanahan, University of California, San Francisco. Investigation of genetic progression in transgenic murine tumors.

Dr. Harold Varmus, University of California, San Francisco (and the NIH). Investigation of genetic aberrations in transgenic mammary tumors.
Dr. Devron Char, University of California, San Francisco. Investigation of genetic progression in ocular melanoma.

Dr. Fredric Waldman, University of California, San Francisco. Investigation of genetic progression in breast and bladder cancer.

Dr. Burt Feuerstein, University of California, San Francisco. Investigation of genetic progression in human brain tumors.

Dr. Helene Smith. California Pacific Medical Center. Investigation of genetic progression in breast cancer.

Dr. Ronald Jensen, University of California, San Francisco. Investigation of genetic progression in human prostate cancer.

Dr. Maria Pallavicini, University of California, San Francisco. Investigation of genetic progression in human leukemias.

Dr. O. Clarke, Dept. of Endocrine Surgery, UCSF, San Francisco, CA. Cytogenetic aberrations in thyroid cancer.

\section{North America}

Dr. Teresa Yang-Feng, Yale University. Investigation of genetic progression in ovarian cancer.

Dr. Julie Korenberg, Cedars Sinai Medical Center, Los Angeles. Application of comparative genomic hybridization in prenatal diagnosis.

Dr. Norman Doggett, Los Alamos National Laboratory. Investigation of genetic aberrations on chromosome 16 associated with breast and prostate cancer.

Dr. Peter K Rogan, Division of Genetics, College of Medicine, Penn State University. Application of $\mathrm{P} 1$ probes for clinical diagnosis of deletion syndrome.

Dr. Lillian Y F Hsu, Prenatal Diagnosis Laboratory of New York City and Dept. of Pediatrics, New York University, Medical School. Application of $\mathrm{P} 1$ probes for clinical diagnosis of deletion syndrome. 
Dr. Peter Quesenberry, Cancer Center, University of Massachulsetts, Worchester, MA. Application of mouse $Y$ chromosome-specific probes to differentiate between graft and host cells in sex mismatched bone marrow transplantations in mice.

Dr. Santiago Munne, IVF-lab., Cornell University Medical Center, New York, NY. Cytogenetic studies in preimplantation embryos.

Prof. Andrei Dyban, Reproductive Genetics Institute, Chicago, Il. Cytogenetic analysis of germ cells in mice carrying balanced reciprocal translocations.

Dr. Marille Herrmann, Dept. of Surgery, Henry Ford Hospital, Chicago, Il. Cytogenetic aberrations in endocrine tumors.

Dr. Scott Cram, National Flow Resource, LANL, Los Alamos, NM. Generation of high complexity libraries for rat chromosomes by AP-PCR from flow sorted chromosomes.

Dr. Verne Chapman, Roswell Park Cancer Center, Buffalo, NY. Generation of high complexity DNA libraries for the mouse $\mathrm{X}$ chromosome.

Dr. Laurie Shepel, Cancer Center, University of Wisconsir, Madison, WI. Generation of high complexity libraries for rat chromosomes by AP-PCR from flow sorted chromosomes.

Dr. Andrew Wyrobek, Lawrence Livermore Natl. Laboratory, Livermore, CA. Determination of baseline frequencies of aneuploid sperm in normal human donors.

Dr. Ben Seon, Roswell Park Cancer Center, Buffalo, NY. Determination and control of cytogenetic markers during establishment of a mouse model for CLL.

Dr. Michael Andreeff, MD Anderson Cancer Center, Houston, TX. Detection of minimal residual disease in CLL by fluorescence activated cell sorting and fluorescence in situ hybridization.

Dr. James Allen, EPA, Research Triangle Park, NC. Specific probes for mouse and hamster chromosomes for detection of aneuploidy in various tissues after exposure to mutagenic or aneuploidogenic agents.

\section{International}

Prof. I.T. Young and Dr. Lucas van Vliet, Pattern Recognition Group, Delft University of Technology, The Netherlands. Characterization of CCD cameras.

Dr. Kohsuke Sasaki, Iwate Medical University, Morioka, Japan. Investigation of genetic progression in solid tumors.

Dr. Olli-Kallioniemi, Tampere University Hospital, Tampere, Finland. Investigation of genetic progression in human breast cancer.

Dr. James Piper, MRC Edinburgh, Scotland. Development of improved software for image cytometry.

Dr. Trond Stokke, Oslo Norway. Positional cloning of an amplified region of chromosome 20 in human breast cancer.

Dr. Masaru Sakamoto, Sasaki Institute of Medicine, Tokyo, Japan. Investigation of genetic progression in ovarian cancer.

Dr. Lars Bolund, Aarhus University, Aarhus, Denmark. Investigation of the utility of comparative genomic hybridization in clinical genetics.

Prof. Manfred Bauchinger, gsf-Forschungszentrum, Neuherberg, FRG. Stable chromosomal changes following low level ionizing irradiation in humans.

Dr. Beate Miller, Hoffmann-La Roche, Inc., Basel, Switzerland. FISH applications in the micronucleus assays for assessment of aneuploidogenic and clastogenic effects of various agents.

Drs. J.J. Cassiman and I. Wlodarska, Center for Human Genetics, University Leuven, Leuven, Belgium. Characterization of marker chromosomes in hematological tumors by WCP-FISH.

Dr. Sandor Szuecs, University Munich, Munich, FRG. Cytogenetic abnormalities in renal cell carcinomas.

Dr. K. Harry Scherthan, University Kaiserslautern, FRG. Direct visualization of homologous regions on metaphase chromosomes from different mammals by chromosome painting. 
TABLE 8: Patents, Licenses, $\mathcal{E}$ CRADAs in FY 1995 \& FY 1996

\section{Biotechnology \& HeALTh CRADAs}

Amgen/Schwartz, Rick

Tendon Repair Factor.

Develop a drug for improving tendon and ligament repair.

\section{Chiron/Kim, Sung-Hou}

Structure Determination of M-CSF and its Variants.

Determine 3-dimensional structure of M-CSF and several site-specific mutants. Understand the complex mechanism of immune regulation and development.

\section{Somatix Therapy/Jagust, William}

Neurochemical Imaging of Gene Therapy.

Apply two technologies, neurochemical imaging and gene therapy, which will permit the insertion of genes into cells to develop therapeutics for Parkinson's disease.

\section{Rhône-Poulenc Rorer/Rubin, Edward}

Cloning Genes for Diabetes, Obesity and

Atherosclerosis. Clone mouse genes responsible for atherosclerosis and respiratory ailments in the mouse and isolate therapeutic agents for the treatment of these diseases in humans.

\section{Vysis/Pinkel, Daniel (NIST)}

Development and Commercial Application of Genosensor-Based Comparative Genomic Hybridization (CGH). Develop and evaluate techniques and DNA reagents for performing CGH to arrays of DNA on solid supports.

\section{General Atomics/Chu, William}

Medical Accelerator Technology

Adapt and transfer LBNL-developed technologies relevant to the use of accelerated beams (e.g. heavy charged-particle radiotherapy) for the treatment of human cancer.

\section{Kaiser Foundation Hospital/Johnston, William} National Information Infrastructure (NII) Prototype for Distributed Health Care Imaging. Develop enabling technologies that will provide extremely high speed distributed computing and health care imaging data such as coronary angiograms.

\section{Amgen, Inc./Earnest, Thomas}

Structure of the Erythropoietin Receptor.

Determine the 3-dimensional structure of the erythropoietin receptor (EPO-R is the primary hormone involved in the production of red blood cells.) by the use of electron crystallographic techniques.

\section{Biotechnology Technology Maturations}

\section{Moronne, Mario/Glaeser, Robert}

Radiation Resistant Fleorescent Probes Suitable for XRay Microscopy.

\section{OTHER BIOTECHNOLOGY PARTNERSHIPS}

\section{Cotton Biotechnology Project}

AMTEX - Cotton Incorporated/John McCarthy TReC Textile Resource Conservation Project

Fish, Richard H. IMehlhorn, Rolf J.

Implement appropriate genome technology to increase cotton fiber performance and reduce the cost of the product for the U.S. textile industry.

\section{ENERGY \& ENVIRONMENT CRADAs}

\section{Enzymol International/Glazer, Alexander}

Enzymatic Remediation of Waste Streams.

Develop the enzyme soybean peroxidase as a commercial product for the degradation of toxic waste chemicals such as polychlorobiphenols (PCBs), nitroaromatics and chlorophenols.

\section{DuPont Company/Somorjai, Gabor}

Catalytic Conversion of Chloro-Fluorocarbons over Palladium-Carbon Catalysts.

Develop alternate refrigerant chemicals to replace chloro-fluorocarbons because of their adverse effects on the earth's protective ozone layers.

\section{ENGINEERING SMALL CRADAs}

eV Products Inc./Luke, Paul

Development of Room Temperature Semi- Conductor Radiation Detectors

DIGIRAD/Millaud; Nygren Instrumentation of Gallium Arsenide Pixel Detectors 


\section{Personnel Exchanges}

Fisons/Kevex/Rossington, Carolyn S.

Technology Transfer of Fabrication for New Si(Li) XRay Detector

\section{EngINEERING TechNOLOGy Maturation}

Applied Electron/Walton, Jack

X-Ray P-type Silicon Drift Detector (x p-SiDD)

\section{PATENTS ISSUED}

Ludewigt B., Berkovitz, J., Nyman, M., and Chu, W. Method for Selecting Minimum Width of Leaf in MultiLeaf Adjustable Collimator while Inhibiting Passage of Radiation Through Sawtooth Joints between Collimator Leaves $(8 / 1 / 95)$

Gray, J., and Pinkel, D. Methods for chromosome-specific staining. U.S. Patent \#5,447,841 (1995).

Covers the use of unlabeled DNA enriched in repeated DNA sequences to competitively inhibit hybridization of interspersed repeats during fluorescence in situ hybridization (FISH). This procedure allows specific hybridization using genomic probes containing interspersed repeats without removing the repeats. This technology has been licensed exclusively to Vysis and forms the basis for their corporate activities.

Gray, JW, Stokke, T, and Pinkel, D. Detection of Amplified or Deleted Chromosomal Regions. \#5,472,842 (1995).

Covers the use of FISH with collections of mapped probes for definition of regions of increased or decreased DNA sequence copy number.

Weier, H.-U. and Gray, J.W. Repeat sequence chromosome specific nucleic acid probes. U.S. Patent 5427932 [Jun. 27, 1995].

\section{PATENTS PENDING}

Gray, J.W., and Weier, H-U., Y-Chromosome specific nucleic acid probe and method for identifying the $y-$ chromosome in situ.

Gray, J.W., and Weier, H-U. PCR Method for diagnosis of fetal gender from maternal blood.
Waldman, F., Gray, J.W., and Pinkel, D. Simultaneous in situ hybridization and cell proliferation analysis.

Gray, J.W., Pinkel, D., Kallioniemi, O-P., Kallioniemi, A., and Sakamoto, M. Chromosome-specific staining to detect genetic rearrangements.

Pinkel, D., Gray, J.W., Kallioniemi, A., Kallioniemi, O$P$. and Waldman, F. Copy ratio reverse cytogenetics.

Nakamura, H., Gray, J.W., and Collins, C.. Methods for detecting cancer-associated chromosome deletions using in situ hybridization.

Christman, M.F., Gray, J.W., Levin, N., Brzoska, P., and Nakamura, $\mathrm{H}$. Genetic alterations that correlate with lung carcinomas.

Pinkel, D., Gray, J.W., and Albertson, D. High density array fabrication and readout method for a fiber optic biosensor.

Pinkel, D., Albertson, D., and Gray, J.W. Comparative fluorescence hybridization to nucleic acid arrays.

Pinkel, D., Kallioniemi, O-P., Kallioniemi, A., Waldman, F., Gray, J.W., and Sakamoto, M. Comparative genomic hybridization (CGH).

Gray, J.W., and Weier, H-U. Quantitative DNA fiber mapping.

Gray, J.W., Johnson, D., Tkachuk, D., and Pinkel, D. Preparing achromosome-specific probes by PCR adapter-linker amplification of flow-sorted chromosomal material.

Pinkel, D., Kallioniemi, O-P., Kallioniemi, A., Waldman, F., Gray, J.W., and Sakamoto, M. Genomic probing.

Gray, J.W., Pinkel, D., Kallioniemi, O-P., Kallioniemi, A., Waldman, F. Chromosome-specific staining methods and reagents to detect gene amplifications.

Gray, J.W., Pinkel, D. Collins, C., Kallioniemi, O.-P. and Tanner, $\mathrm{M}$. Amplification of chromosomal region $20 \mathrm{q} 13$ as prognostic indicator in breast cancer.

Gray, J.W., and Fejzo, M.S. Increased gene copy number and cancer. 


\section{Work for Others}

The success of DOE life and environmental sciences programs at LBNL has depended not only on DOE support but also on complementary work, sponsored by others, that is closely coupled to the DOE programs and benefits directly from LBNL facilities and expertise. Examples include the National Dairy Promotion and Research Board's support of atherosclerosis work, the National Heart, Lung and Blood Institute's support of nuclear imaging methodologies, and the National Institute of Health's support of programs at the National Center for Electron Microscopy and the National Tritium Labeling Facility. Some projects supported by outside agencies have not been strictly dependent on large facilities or unique instrumentation but have made contributions that could only have been made in a national-laboratory type environment. Examples-in fields ranging from cell and molecular biology to environmental research to structural biology-abound. Non-OHER support expands the base of investigative activity and makes possible a wide diversity of staff expertise, thus greatly enriching the accomplishments of OHER programs themselves.

\section{DOE Office of Basic Energy Sciences (BES)}

The DOE Office of Basic Energy Sciences (BES) sponsors a continuing effort directed toward using knowledge of green plant photosynthesis to design artificial systems for the utilization and storage of solar energy. In addition, we focus effort on chemical reactions that suggest new concepts for photo-associated synthesis of high-valued chemicals from abundant chemicals, photocatalysis, temporary chemical storage of near infrared photons, and conversion of photon energy into electricity.

Also under the sponsorship of BES, we are studying the synthesis of chlorophyll in a purple, photosynthetic bacterium, Rhodobacter capsulatus. We have recently 
completed the sequence of all of the genes required for pigment synthesis in $R$. capsulatus. As many as twenty gene products may be involved in bacteriochlorophyll (Bchl) production, and many of the enzymatic steps require the combined activity of two or more gene products. Erwinia herbicola, a non-photosynthetic bacterium, has a $12.7 \mathrm{~kb}$ gene cluster of its carotenoid biosynthesis genes. This region has been completely sequenced and functions of the six genes determined. The sequencing of these regions has facilitated the understanding of the interrelationships and regulation of some of these genes. Our efforts are now concentrated on understanding how these enzymes work and how their gene expression is regulated by environmental factors. We are also studying photosynthetic oxygen evolution in higher plants and cyanobacteria.

Another BES-funded project concerns the absorption of visible light photons, followed in less than a nanosecond by excitation transfer and trapping in reaction centers of photosynthetic membranes. We are investigating the detailed kinetics and energetics of this process using wavelength-resolved transient absorption change and fluorescence decay measurements applied to welldefined preparations of antenna pigment proteins or reaction center complexes. Recent $x$-ray crystallography studies in several laboratories have provided detailed structural information for several of these proteins. This has enabled us to carry out excitation transfer calculations using exciton theory and/or Forster inductive resonance transfer applied to pigment arrays of known geometry.

\section{DOE Office of Energy Efficiency and Renewable Energy (EERE)}

Approximately 13 Quads of energy are used annually to condition and move the outside air supplied to residential and commercial U.S. buildings. This energy is used to maintain acceptable indoor air quality and occupant health, cornfort, and productivity. A major goal of DOE, specified in the National Energy Strategy, is to increase the energy efficiency and ventilation efficiency of buildings, while maintaining or improving indoor air quality. The DOE Office of Conservation and Renewable Energy (CRE) supports an LBNL project that is developing and disseminating the information and technology needed to achieve this goal. Research covers the relationships among building energy usage, ventilation and infiltration, indoor air quality, and human factors.

We employ a combination of modeling, laboratory experiments, and field studies. In addition to developing methods for reducing energy use by heating, ventilating, and air conditioning systems, we are investigating indoor air pollutant concentrations and source strengths and their dependence on ventilation and building characteristics. Factors that cause the occupants of large buildings to have building-related health symptoms are also being investigated. Much of the research conducted for EERE depends upon the OHER-supported research to develop a sound scientific understanding of exposures and health risks from indoor air pollutants.

\section{National Institutes of Health (NIH)}

Activities sponsored by the National Institutes of Health (NIH) complement OHER-supported work in the following theme areas: hematopoiesis, carcinogenesis, atherosclerosis, aging, mental disorders, and physical health effects. In these areas NIH-supported work is strongly related to OHER missions through exploitation of unique instruments, methods and scientific personnel at LBNL.

An example of $\mathrm{NIH}^{\prime} \mathrm{s}$ interest in improved instrumentation is support for the development of positron emission tomography (PET) technology. Topics range from scintillation mechanisms for PET to algorithms and processing architectures for tomography. NIH alsosponsors several studies that use LBNL's unique PET instrumentation to characterize diseases of the brain.

A new emphasis in PET and nuclear magnetic resonance (NMR) is the practical interpretation of the human genome project. As the OHER program in medical applications seeks to modernize nuclear medicine activities and couple them with research in molecular genetics and gene expression, LBNL has emphasized those areas of clinical medical science that have potential for correlation to genome mapping activities.

Another area of NIH's interest is atherosclerosis research based on unique methodology for lipoprotein analysis developed at LBNL over the past 45 years. These tools are being applied in NIH-supported studies directed at understanding genetic, cellular, and metabolic mechanisms of heart disease. In addition, the NIHsupported research on PET and NMR enhances our understanding of the pathophysiology of atherosclerosis. Transgenic mouse studies and other atherosclerosis research programs supported by $\mathrm{NIH}$ call on unique LBNL facilities such as PET instrumentation, as well as the preliminary work for a very high field NMR spectrometer that will allow precise metabolic studies. 
Research support from NIH also encompasses all areas of current $L B N L$ research activities in cell and molecular biology. One program project provides support for determining the high-resolution structure of various membrane proteins, while another program project provides support for delineating the detailed molecular structure of the red blood-cell membrane. In addition, a large number of research grants to individual scientists support research in various aspects of cell and molecular biology. Topics include growth regulation in normal and transformed cells, the molecular mechanisms of cell senescence, molecular analysis of differentiation of human mammary cells, the physical structure of viruses, molecular mechanisms involved in DNA damage and repair, mechanisms of mutagenesis in human cells, and the molecular and cellular basis for sickle cell anemia. These projects enhance OHER-sponsored studies in cell differentiation, carcinogenesis, and DNA damage and repair.

The National Tritium Labeling Facility (NTLF), which receives funding from $\mathrm{NIH}$ as well as DOE, serves as one of the few facilities in the nation equipped to label compounds to very high specific activities of $3 \mathrm{H}$. It thus serves as a laboratory where researchers from across the U.S. can carry out labeling and radiopurification procedures that would be impossible at their home institutions. The mandated functions of the NTLF are to engage in research and development of advanced labeling techniques and to disseminate the results, to promote collaborative research using labeled molecules, to provide labeling services to the nation's scientists, and to train researchers in labeling methodologies. One of the NTLF's most important activities is to supply labeled biomolecules for tritium-NMR spectroscopy, a key technique in our OHER-funded structural biology research.

Research supported by NIH complements OHERsupported research to characterize air pollutant exposures in buildings and to assess the risks associated with human exposure by providing information on the gas-particle distributions and particle-size distributions of carcinogens in environmental tobacco smoke. This information is needed to understand the risks from exposures to this complex mixture.

The National Institute for Environmental Health Sciences supports research that directly benefits work we are doing for OHER by providing information on a source and mechanism of indoor exposures, i.e., soil-gases. This research will also be of value to DOE in its environmental restoration efforts since it will provide information to assess the potential for human exposures at contaminated DOE-sites.

\section{National Aeronautics and Space Administration (NASA)}

The National Aeronautics and Space Administration (NASA) utilizes the unique capabilities of accelerators, detectors, and scientists at LBNL to assess the health risks of space exploration. The nation's need for LBNL facilities for the Space Exploration Initiative is readily understood by the following example: The major radiation on extended manned missions to the moon and planets is galactic cosmic particles consisting of atomic nuclei from hydrogen to iron and even uranium. These particles penetrate the space craft and tissues at high velocity and cause biologic damage varying from cell death to cancer cell induction. Though the total conventional radiation dose is only a few rads to the whole body, the true situation is that each cell could be hit by one high-energy projectile on a two-year mission. Thus, to learn the consequences of this form of radiation, NASA needs the DOE facilities and personnel at LBNL to perform cell and animal studies. NASA sponsors a number of research projects aimed at assessing radiationinduced DNA damage and the mutagenic and tumorigenic potential of radiation.

In 1992 NASA awarded LBNL its Specialized Center for Research and Training (NSCORT) in Radiation Health. This is a five year grant. The major objective of the NSCORT is to conduct basic and applied radiobiological research with HZE (high atomic number and energy) particles that is directly applicable to the assessment of the radiation risk associated with extended manned space missions. Proper knowledge of these risks will allow NASA to determine themeasures needed toprotect human beings against the effects of ionizing radiations in space. The NSCORT also represents a Consortium with the Department of Radiological Health Sciences at Colorado State University and the Lawrence Berkeley National Laboratory. The Consortium has as a second major objective to further the nation's scholarship, skills, and exploitation of opportunities in space life sciences and related technology areas toward a goal of enhancing the pool of trained research scientists to meet the forthcoming challenges of the nation's commitment to prepare for future human space exploration missions. Several individual research projects are supported by the NSCORT.

OHER-sponsored detector studies in the Engineering Division are supplemented by more applied research supported by other offices in DOE and by NASA. These 
projects benefit from the basic knowledge gained in the OHER projects and at the same time provide an excellent background of knowledge of real-world problems, which helps focus our fundamental OHER work.

\section{Environmental Protection Agency (EPA)}

The EPA supports research on numerical modeling of radon entry into houses, as well as analysis of animal cancer tests and studies of chemically induced damage to human mammary epithelial cells.

\section{California Air Resources Board}

The California Air Resources Board is sponsoring research to measure emission factors of selected toxic volatile organic compounds (VOCs) and respirable particulate matter in environmental tobaccosmoke(ETS) using the LBNL room-size environmental chamber. Environmental tobacco smoke is suspected to be a major source of exposure for many of the toxic VOCs of concern to both the state of California and to EPA. Emission factors are being determined for selected $\mathrm{N}$-nitrosamines, nicotine, aldehydes and other VOCs, including 1,3butadiene, and for respirable suspended particles for a subset of cigarette brands which have the largest market shares. Emission factors for freshly generated sidestream smoke are also being measured and compared to those measured for ETS, which is more diluted and aged. This research will provide data needed to model indoor exposures to toxic VOCs for the California population.

\section{University of California Tobacco- Related Disease Research Program}

Environmental tobacco smoke is a major indoor air pollutant. LBNL has support from the UC TobaccoRelated Disease Research Program to investigate factors affecting the size distribution and concentration of environmental tobacco smoke particles to provide a more accurate estimate of the lung dose of particles and radon progeny attached to these particles. This research, thus, extends our OHER-supported research efforts to characterize indoor air pollutant exposures and assess their risks. It also complements and extends our OHER research to characterize indoor radon and radon decay products, their attachment to airborne particles, and their removal through deposition to indoor surfaces.
LBNL also has funding from the UC TobaccoRelated Disease Research Program to conduct a basic study aimed at establishing, at the molecular level in human epithelial cells, the mechanisms of the inter-related phenomena of procarcinogen activation, co-carcinogenesis, and oxidative DNA damage involved in tobacco-related cancer. A detailed understanding of these inter-related processes could lead to effective preventive treatment for individuals previously exposed to cigarette smoke. 


\section{Table 9: Summary of Work for Others}

The budgets shown on the following pages do not include Laboratory overhead costs. (Only those grants over $\$ 10,000$ are listed).

\section{Analytical Technology}

H. Brenner

E. Haller

E. Haller

A. Hodgson

J. Jaklevic

P. Luke

R. Sextro

J. Walton

J. Walton

J. Walton

J. Walton

J. Walton
DOE/Ion Diagnostics

Volcano Field Ionizer for Mass Spectrometers

$\$ 150,000$

NASA, Headquarters, Washington

$\$ 130,000$

Far Infrared Semiconductor Detectors and Materials

University of Arizona

$\$ 70,000$

Space Infrared Telescope Facility Phase A Study

Multiband Imaging Photometer

CARB

$\$ 93,666$

Common Indoor Sources of VOC Emissions:

Rates and Techniques for Reducing Consumer

Exposures

AMGEN, Inc.

Development of an Automated Environment

for Construction of cDNA Libraries

$\$ 1,200,000$

DOD, Office of Special Technology

Development of CdZnTe Detectors for GN-3

Portable Radiation Detection Instruments

U. S. EPA

Radon Entry into Florida Homes

$\$ 36,186$

NASA Ames

Various Special Silicon Detectors

$\$ 60,500$

The Aerospace Corporation

$\$ 25,000$

Fabrication of Detectors

Quantrad

Amorphous Silicon/Crystalline Silicon

Hetero Junctions

$\$ 56,940$

California Institute of Technology

$\$ 183,280$

Innovative Research

NASA Ames

$\$ 128,620$

CRIS Detectors II 


\section{Health Effects}

M.H. Barcellos-Hoff

M. Bissell

M. Bissell

M. Bissell

M. Bissell/M. Chen

E. Blakely

J. Campisi

J. Campisi

J. Campisi

J. Campisi

A. Chatterjee

J. Conboy

P. Cooper

J. Daisey
NIH grant

$\$ 100,652$

Stromal Influence on Expression of

Preneoplasia

NIH grant

$\$ 99,532$

Role of Metalloproteinases in Mammary

Gland Remodeling

NIH grant

$\$ 112,930$

Definition of Microenvironment in Human

Breast Cancer

Research Gift-Monsanto

$\$ 75,000$

DOD

$\$ 71,127$

Mechanisms of Abnormal Cell Extracellular

Matrix Interactions in Human Breast Cancer

NIH grant

$\$ 90,408$

Lens Epithelium and Proton Induced

Cataractogenesis

NIH grant

$\$ 193,759$

Cellular Senescence and Control

of Gene Expression

NIH grant

$\$ 156,049$

Growth Requlation in Normal and

Transformed Cells

NIH grant

$\$ 206,390$

Senescence- and Longevity-Modulating Genes

Sennes

Genetic Studies on Immortality

Complementation Groups

NASA Specialized Center of

$\$ 704,377$

Research and Training

NIH grant

$\$ 145,817$

Red Cell Band 4.1: Dev. Changes

in RNA Splicing

NIH grant

$\$ 117,551$

Mechanisms for Repair of Radiation

Damage in Human Cells

DOE (EERE)

Infiltration, Ventilation and Indoor Air Quality
$\$ 12,299$ 
J. Daisey

J. Daisey

A. Kronenberg

A. Kronenberg

A. Kronenberg

R. Liburdy

R. Liburdy

R. Liburdy

S. Lockett

J. Miller

M. Narla

M. Narla

M. Narla

M. Narla

R. Schwarz
NIH grant

$\$ 94,800$

Environmental Tobacco Smoke:

Physico-Chemical Properties

UCB / NIH grant

Soil Gas Transport:

A Mechanism of Indoor Exposures to VOC

NIH grant

$\$ 12,940$

Heavy-Ion Mutagenesis

$\$ 99,585$

NASA

Mutagenesis in Human Cells with

Accelerated $\mathrm{H}$ \& Fe Ions

NIH grant

$\$ 131,222$

Radiation Delayed Mutation and Instability

in Human Cells

NIH grant

High Field NMR Bioeffects:

Lymphocyte $\mathrm{CA}^{+} 2$ Metabolism

DOD

$\$ 39,375$

Human Breast Cancer Proliferation and

Modulation by Melantonin and Environmental

Magnetic Fields

Johns Hopkins

Effects of VDT Magnetic Fields on Breast

Cancer Cell Growth

Whitaker Foundation

Development of Automatic 3D Microscopic

Imaging of Fluorescent Stained Clinical Specimens

NASA

Experimental Study of Nuclear Interactions

Relevant to High Energy HI Transport

NIH grant

Red Cell Deformability In Vitro and

Survival In Vivo

NIH grant

Red Cell Membrane Studies

Univ. British Columbia Subcontract

Rheological and Adherence Properties

$\$ 131,246$

of Sickle Cells

UCSF/NIH grant

Cellular Consequence of Hemoglobin

$\$ 75,001$

Membrane Interaction

CRADA - Amgen

$\$ 65,369$

Tendon Repair Factors 
G. Shyamala

G. Shyamala

B. Singer

B. Singer

B. Singer

M. Stampfer

M. Stampfer

P. Yaswen
NIH grant

$\$ 63,246$

Normal and Neoplastic Growth:

Role of Estrogens and HSP90

NIH grant

$\$ 138,715$

Progesterone Receptors in Mammary

Development Neoplasia

NIH grant

Alkylation of Polynucleotides In Vitro and In Vivo

NIH grant

Biochemical Mechanisms of Vinyl

Chloride Carcinogenesis

NIH grant

$\$ 34,461$

Chemical Basis of Carcinogenic Risk

from Benzene

NIH grant

Characterization of Human Mammary

Epithelial Cells

DOD

Human Mammary Cell Resource

NIH grant

Calmodulin - Related Gene and

Epithelial Transformation

\section{General Life Sciences}

J. Bastacky

J. Bastacky

K. Downing

R. Glaeser

T. Head-Gordon
UC Tobacco-Related Disease Research

$\$ 47,843$ Program. Effects of Tobacco on Rat Lung Alveolar Lining Liquid

NIH grant

$\$ 99,897$

Surface Tension Gradient Along the

Airway in Lung

NIH grant

$\$ 111,497$

Tubulin Structures by Electron

Crystallography

NIH grant

High Resolution Electron Crystallography of Proteins

USAF grant

$\$ 49,277$

Neural Networks as a Predictive Tool for

Constrained Optimization Protein Folding 
B. Jap

B. Jap

M. Maestre

R. Mortimer

M. Palazzolo

M. Palazzolo

M. Palazzolo

E. Rubin

E. Rubin

E. Rubin

E. Rubin

E. Rubin

D. Wemmer
NIH grant

$\$ 42,651$

Electron Microscopy of a Member of the

ABC Superfamily

WFO-Pfizer

$\$ 134,363$

Crystallographic Studies of

Potassium Channels

NIH grant

$\$ 93,360$

Physical Structure of Viruses

$\$ 106,152$

NIH grant

Molecular Analysis of X-Ray Damage

and Repair in Yeast

UCB subcontract (NIH)

$\$ 1,210,641$

Drosophilia Genome Center

NIH grant

Drosophilia Genome, Phase III,

Sequencing Technology

WFO-AMGEN

$\$ 71,838$

Development of an automated environment

for construction of cDNA libraries

AHA grant

Analysis of HDL Atherosclerosis

in Transgenic Mice

Miles, Inc.

Cloning of APO-A1

Stanford University

LPA, Effect on Atherosclerosis in

Transgenic Mice

Rhone Poulenc Rorer, Inc.

$\$ 325,907$

Cloning Genes for Diabetes, Obesity and

Atherosclerosis Therapeutics

UCSF/NIH subcontract

$\$ 204,788$

Construction of a Transgenic Mouse

Model for Sicle Cell Anemia

NIH grant

$\$ 504,174$

National Tritium Labeling Facility

Medical Applications

J. Bielicki

AHA grant

$\$ 23,669$

Extracellular HDL Assembly with

Apolipoprotein AI Variants 
T. Budinger

T. Budinger

M. Callow

J. Castro

P. Coxson

S. Derenzo

J. Enas

T. Forte

B. Ishida

W. Jagust

W. Jagust

R. Krauss

R. Krauss
NIH grant

Cerebral Blood Flow Patterns

in Alzheimer's Disease

NIH training grant

$\$ 70,577$

Quantitative Cardiovascular Research

$\$ 17,484$

AHA grant

$\$ 200,561$

NIH grant

Treatment of Cancer with Heavy

Charged Particles

NIH Grant

$\$ 35,701$

Statistical and Modeling Uncertainties in Dynamic PET

NIH grant

$\$ 159,116$

Search for Ultrafast Heavy Atom

Scintillators

NIH grant

$\$ 68,359$

Radiolabeled Alpha-2 Adrenergic

Receptor Ligands

NIH training grant

$\$ 82,328$

Lipoprotein Methodology, Structure and Function

NIH grant

Pre-Beta Migrating High Density

Lipoproteins

NIH grant

$\$ 107,530$

Alcohol and Memory: A PET Study

NIH grant

$\$ 135,254$

Longitudinal SPECT and PET Studies in Dementia

NIH grant

Lipoprotein Subclasses: Structure, Origin, and Metabolism

Children's Hospital/National Diary

Promotion and Research Board Subcontract

Genetic Influences on Lipoprotein and

Atherogenic Responses to Dietary Fat 
R. Krauss

R. Levy

R. Marshall

W. Moses

A. Nichols

T. Nordahl

M. Roos

L. Stark

H. Van Brocklin

P. Williams

P. Williams

P. Williams
Sequoia Hospital Subcontract

$\$ 292,290$

Metabolic Atherosclerosis Management

Loma Linda

$\$ 146,686$

Proton Radiosurgery for Arteriovenous

Malfunctions

NIH grant

$\$ 243,441$

Fluorodeoxyglucose Kinetics in

Myocardium

NIH grant

High Resolution PET Dectors Using Solid

State Photonics

NIH grant

Apolipoprotein-Specific HDL and

Cholesterol Transport

NIH grant

$\$ 51,007$

Hippocampal Metabolism in

Schizophrenia

NIH subcontract

Development of NMR Assisted Cryosurgery

ARMY

$\$ 14,387$

Visual Perception Experimentation,

Modeling and Analysis

UC Davis

Mitochondrial Imaging Agents for

PET and SPECT

NIH grant

$\$ 20,145$

Effects of CHD Prevention on Lipoprotein

Subclasses

NIH RCDA

$\$ 40,357$

Effects of Exercise, Diet and Fat Lost on

Lipoproteins

NIH grant

$\$ 180,068$

Weight Set Point and HDL Concentration

in Runners

\section{Laboratory Directed Research and Development}

L. Gold

B. Jap

M. Pallavicini

E. Rubin
SELECT Program: An Interdisciplinary

Environmental Research Project

New Initiatives of Electron Crystallography of Selected Membrane Proteins

Genetically-Damaged Hemopoietic

Stem Cells

Creation of Transgenic Mice
$\$ 67,124$

$\$ 148,000$

$\$ 46,178$

$\$ 190,000$ 
G. Shyamala

D. Sudar

D. Tribble

P. Yaswen
Transgenic Model for Clinical Testing of Progestins

Integrated Molecular Cytogenetic Workstation

Variations in Susceptibility to

Environmental Oxidants as Studied

Using Transgenic Mice Models

Isolation of Genetic Suppressor Elements in Human Mammary Epithelial Cells

Technology Maturation and CRADAs

J. Bastacky

A Specimen Holder for Low Temperature

$\$ 69,593$

S. Derenzo

Scanning Electron Microscopy

Positron Tomograph Detector

Module with Improved Resolution and

Data Rates

W. Jagust

Neurochemical Imaging of Gene Therapy

$\$ 136,244$

M. Roos

Low Cost Magnetic Resonance Imager

$\$ 13,285$ for Breast Cancer Diagnosis

E. Rubin

Cloning Genes for Atherosclerosis and Respiratory Therapeutics

$\$ 360,000$ 


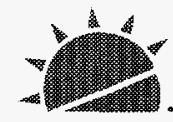

\subsection{Program Orientation and Future Directions for FY 1997-1999}

\section{Analytical Technology}

DEvelopment of RoOM-tEMPERATURE SEMiconductors For FIELD Applications (Paul N. Luke/John T. Walton)

\section{Gamma-ray Detectors}

Using the method developed to evaluate CdZnTe crystals, we will seek to improve detector performance through careful material selection. We will work closely with commercial suppliers to improve the quality of CdZnTe crystals and to develop criteria for material selection. In addition, alternate electrode designs will be developed to reduce edge effects and thus improve spectral resolution. Techniques for fabricating the grid electrodes on CdZnTe crystals using photolithography are being developed. This would give us more flexibility in electrode design compared with the shadow-mask technique that we have been using. Currently, lowpower electronics are being developed to process the signals from the coplanar grid detectors. A compact detector module that includes the detector, front-end electronics and detector biasing network will be fabricated.

\section{$X$-ray Detectors}

Our primary expected accomplishment here is to have, in FY96, a $2 \mathrm{~cm}$ diameter, $1 \mathrm{~mm}$ thick silicon drift detector that we can evaluate in terms of its performance in the detection of actinide $L$ x-rays. However, our immediate plans are to begin fabrication of $300 \mathrm{~mm}$ thick p-type $x$-ray detectors using the photomask set, noted above, before making the thicker detectors, with their 
attendant processing challenges discussed earlier, that are required for this project. The $300 \mathrm{~mm}$ detectors will allow us to evaluate our various designs against published results before committing to a fabrication plan on the thicker, more expensive, silicon we will use in the final detectors for our prototype field spectrometer. In addition we intend to draw on the experience we gain in developing amorphous silicon/crystalline heterojunctions under our STTR grant. These heterojunction structures offer, among other features, the potential of low temperature processing, which is vital in preserving the carrier lifetime in silicon.

\section{Prototype Field Spectrometer}

As detectors with the required level of performance become available in the latter part of this project, they will be integrated into a prototype portable spectrometer unit. The spectrometer will be evaluated for its effectiveness in the characterization of contaminants in actual soil samples and under field operation conditions. This will be carried out in collaboration with the geochemistry group at LBNL.

\section{Milestones:}

\section{September 1996}

Fabricate large volume prototype CdZnTe detectors and develop front-end electronics for signal readout. Fabricate prototype Si drift detectors with and without imbedded FET structure and evaluate $x$-ray detection performance.

\section{January 1997}

Develop interconnect and packaging techniques for CdZnTe detectors. Integrate readout FETs onto thick drift detector structures.

\section{June 1997}

Integrate $\mathrm{CdZnTe}$ detectors, Si drift detectors and signal processing electronics into a complete portable spectrometer unit. Evaluate in laboratory.

\section{September 1997}

Compare portable spectrometer system to existing instruments in detecting contaminants.

June 1998

Initiate field test of the spectrometer in environmental monitoring activities.

\section{Area of Concern:}

The requested funding for this program was originally in the range of $\$ 350 \mathrm{~K}$ per year, which was needed to carry out this project effectively. However, the actual funding appropriated is at the level of $\$ 130 \mathrm{~K}$ per year. This necessitated a substantial rescoping of the project to significantly reduce the impact that this project might have otherwise. In addition, the lack of adequate longterm funding commitment has made it very difficult for us to plan and carry out developments in basic detector technology upon which future advances in instrumentation will be based.

\section{Health Effects}

The Resource for Molectlar Cytogenetics (Joseph W. Gray/Daniel Pinkel)

The LBNL/UCSF Resource for Molecular Cytogenetics will continue to develop molecular cytogenetic techniques, reagents, informatics and instruments needed to facilitate large scale genomic DNA sequencing and to assist in the discovery and functional characterization of genes involved in disease susceptibility, tumorigenesis and cancer progression. These techniques will be applied in collaboration with the Human Genome Program, the LBNL Life Sciences Division and the UCSF Cancer Center. Future emphasis will be on increasing the robustness or ease of use of techniques developed so far and on development of techniques for analysis of gene function. The latter area is especially important since it will support interpretation of genomic sequence coming from the Human Genome Program. Development of in situ hybridization technology, digital microscopy, probe development and map assembly and informatics will continue to support work in four areas:

1. Gene localization. CGH is now being used to map regions of abnormal copy number in disease tissue. Our image analysis package for CGH will be improved by implementing automated chromosome identification and by increasing the accuracy of chromosome length determination. In addition, our electronic laboratory notebook will be expanded to include images, interpreted CGH profiles and clinical and biological information needed for analysis of CGH data. This will require that we convert to a relational database management system to provide better flexibility to handle various aspects of the data. 
CGHa will be developed to speed aberration mapping and to increase the precision to which aberrations can be defined. Improved procedures will be developed to attach target DNA to substrates, produce arrays of cloned probes (e.g. using photolithographic techniques), and for high efficiency hybridization of genomic DNA and total cellular mRNA to probe arrays. In addition, digital microscopy procedures will be developed for quantitative analysis of hybridization to probe arrays.

2. Physical map assembly and probe development. Rapid assembly of high quality, sequence-ready physical maps is essential to large scale genomic sequencing and to disease gene discovery. The Resource will continue to improve procedures for physical map assembly and will collaborate in their application in disease gene cloning. Capabilities for assembly of both mouse and human clones will be developed to facilitate comparative studies.

The Resource will collaborate with the LBNL Human Genome Center to further develop fiber FISH to simplify production of complete, sequence-ready physical maps. Fiber FISH procedures will be optimized to increase speed and reliability and microdissection will be developed to fill gaps between elements of a contig. In addition, we will develop fiber FISH to increase the efficiency of directed genomic sequencing. This will be accomplished by mapping sequencing templates along the $\mathrm{P} 1$ (or PAC or $\mathrm{BAC}$ ) clone from which they were derived, thereby allowing directed sequencing to proceed in parallel at several loci along a P1 without danger of redundant sequencing.

The Resource will maintain mouse and human P1, PAC and BAC libraries and screen these by PCR and/or filter hybridization. The Resource will collaborate with investigators in the LBNL Life Sciences Division and the UCSF Cancer Center to develop sequence-ready physical maps across regions thought to contain genes associated with tumorigenesis or solid tumor progression including: a region at 20q13.1 that is frequently coamplified with the region we have already defined at $20 \mathrm{q} 13.2$, a region of frequently reduced copy number at $17 q 21$, a region of frequently increased copy number at $3 q 26$ and a region associated with radiation-induced leukemia on chromosome $20 \mathrm{q}$ (mouse chromosome 2). These maps will be made available for large scale genomic sequencing as needed.

The Resource will continue to serve as a central clearinghouse for information about molecular cytogenetics probes, methods, protocols, images, and software. This will be accomplished through the Resource public web server which will be upgraded to include protocols, a better display of mapped probes, images, software and a literature database.

3. Gene identification and characterization. Physical maps assembled by the Resource will be screened for genes using exon trapping, cDNA selection and genomic sequencing. Computational tools will be applied in analysis of genomic sequence to find similar sequences in large databases (e.g., GenBank, GSDB, dbEST, $\mathrm{dbSTS}$, prediction of potential coding regions) and to identify genes and promoter regions (e.g. GRAIL, XGRAIL, SORFIND, GeneParser, GeneLang, and other tools that utilize secondary and tertiary structure information to identify potential proteins). This work will be carried out in collaboration with the LBNL Human Genome Center and will contribute to genomic sequence annotation and accuracy analysis. We also will explore the extent to which cDNA molecules can be mapped along fibers using FISH and scanned probe microscopy. Success in this may lead to a simple procedure to generate intron-exon maps over megabase-size intervals.

4. Analysis of gene function. Determination of the functions of genes identified by genomic sequencing or through physical selection will become increasingly important as the genome program progresses. The Resource will devote increasing effort to development of procedures for this purpose including analysis of the cell and tissue localization of gene products and correlation between genotype and phenotype. Increased emphasis will be given to development of procedures for in situ analysis of mRNA levels. We believe that information about intracellular and/or cell type specific mRNA level and distribution is essential to studies of gene function. FISH procedures from mRNA level analysis appear preferable to methods based on detection of radioactively-labeled probes since they promise increased speed of analysis, spatial resolution and quantitation. In addition, FISH analysis of mRNA may prove useful in coalescence of gene fragments predicted from genomic sequence into complete genes since preliminary studies in C. elegans suggest that the intra- and extracellular pattern of hybridization is often gene specific. Eventually, we will combine FISH analysis of gene copy number and mRNA levels with immunofluorescence detection specific proteins in order to allow robust study of the consequences of genetic aberrations. This will require substantial developments in FISH and immunochemistry and quantitative digital imaging microscopy (specifically, multi-color confocal microscopy, segmentation of fluorescent domains in two and 3 dimensions and quantitation of material in these domains). 
The leaders of The Resource have three major concerns:

1. The capital equipment funds available for non-genome research are chronically inadequate. As a result, programs decay in capability as equipment becomes outmoded. There MUST be a program to maintain strength in this area if DOE programs are to remain competitive. Work in applied genomics is particularly limited in this area since advances in technology are occurring monthly as a result of commercialization of technologies developed by the genome program. Failure to maintain funding in this area will certainly result in second-rate science.

2. The current funding shifts in DOE make long range planning difficult. Worse, they force DOE researchers to pursue "hot" research areas in order to be continuously competitive. This strongly discourages researchers from pursuing long term research that has good promise but requires substantial development. Funding such research has long been one of the strengths of DOE. Loss of such activity removes one of the main distinctions between DOE and the NIH in Biomedical research.

3. Technology transfer remains exceedingly difficult in DOE laboratories. Most companies that we work with are reluctant to pursue DOE CRADAs or they refuse completely because of the historical difficulty in arranging such agreements.

INTERSPECIES ExtRAPOLATION \& RISK ASSESSMENT (LOIS SWIRSKY GOLD)

The major goals of this project are to improve cancer risk assessment methodology and develop strategies for setting research and regulatory priorities. We examine the scientific assumptions and data that underlie U.S. regulatory and cleanup policies designed to reduce cancer risk in the U.S. Our analyses, based on our database of more than 5000 animal cancer tests, are central to the current rethinking of risk assessment in the scientific and regulatory communities.

In order to evaluate energy-related risks, it is important to put risks in perspective and know more about the background of natural chemicals. We continue to broaden the perspective on possible cancer hazards by ranking on an index, HERP (Human Exposure/Rodent Potency) that expresses each human exposure (lifetime dose in $\mathrm{mg} / \mathrm{kg} /$ day) as a percentage of the rodent potency (TD50 in mg/ $\mathrm{kg} /$ day). HERP values are ranked for pesticide residues, food additives, synthetic chemicals in indoor and ambient air, workplace air, water, drugs, and chemicals that occur naturally as food constituents or the products of cooking food. Results indicate that there is a large background of naturally occurring chemicals in the diet that rank high in possible carcinogenic hazard, and that about half the natural chemicals are positive in rodent tests, a proportion similar to that for synthetic chemicals. These results cast doubt on the likely importance of synthetic pollutants or pesticide residues in human cancer, thus challenging many assumptions of regulatory policy.

Extrapolation from the high doses of rodent tests to the low doses of most human exposures should be based on knowledge of cancer mechanisms. Increasing evidence supports our hypothesis (Lois Gold and Bruce Ames) that increased cell division at the high doses of rodent bioassays can be mutagenic (and consequently carcinogenic) because it increases the probability of converting endogenous DNA damage into mutations. Many of our analyses of rodent cancer tests are consistent with this hypothesis, including high positivity rates. We make the best possible use of available bioassay data to improve the methodology for interspecies extrapolation in carcinogenesis, and all analyses use the most updated version of the Carcinogenic Potency Database.

In all years of the project we will continue to rank and compare possible carcinogenic hazards (HERP). Our focus is on rodent carcinogens in the diet, in pharmaceuticals, in indoor air (including chemicals in environmental tobacco smoke), ambient air (for rodent carcinogens listed in the Clean Air Act), workplace air, and from exposures from waste sites. Human exposures to the natural background of chemicals is the control group against which current regulatory policies for synthetic chemicals must be compared.

We will continue, in collaboration with Bruce Ames, to address theoretical questions of mechanism and how information about mechanism can be incorporated into risk assessment methodology in order to improve the extrapolation from animal bioassays conducted at the MTD to human exposures at low doses.

Risk assessment methodology work will focus on evaluation of strength of evidence of carcinogenicity and estimation of uncertainties in extrapolating bioassay results to human risk. We intend to improve the use of rodent data by providing a profile on the strength of evidence of carcinogenicity for a chemical, e.g. lethality of tumors, number of target organs, proportion of experiments that are positive. 
These measures will be combined with a simulation analysis of uncertainty in potency estimation which uses negative as well as positive bioassays. The analysis will use chlorination by-products that are rodent carcinogens, and will compare hypothetical cancer risks from contaminated well water to substitution risks generated by moving people from contaminated well water near waste sites to chlorinated municipal water supplies.

Since only a small proportion of the many chemicals to which humans are exposed will ever be tested in carcinogenesisbioassays, and since the natural world is vastly underrepresented among chemicals tested for carcinogenicity, we are identifying natural chemicals that should be considered for testing because they might be a hazard to humans if they were to be identified as rodent carcinogens. Our index, HERT, uses available LD50 values rather than the TD50 values from animal cancer tests used in HERP. HERT values are calculated for a typical portion and for average U.S. consumption of common foods. The chemicals with the highest HERT values could then be investigated further as to mutagenicity, pharmacokinetics, and carcinogenicity.

Genetic Susceptibiltiy \& Radiation (Maria Pallavicini)

Our plans for the immediate future are to:

- Directly assess whether the frequency of genetically aberrant stem cells is propagated faithfully throughout the hemopoietic system

- Extend translocation studies to investigate effects of chemicals in mixed waste by testing proof-of-principle concepts in exposed mice (proposal submitted)

- Develop gene-specific biomonitoring assays for environmental exposures (joint LBNL-UCSF proposal submitted).

\section{General Life Sciences}

SEMICONDUCtor X-RAY Detectors For SYNCHRotron APplicaTIONS (JOSEPH JAKLEVIC, CAROLYNROSSINGTON)

We will continue to develop semiconductor detectors for synchrotron applications: spectral performance of existing silicon detectors will be improved; detectors with thin entrance windows for very low energy $x$-rays; GaAs diode arrays for high efficiency room temperature $x$-ray detection; two-dimensional silicon arrays for low noise applications requiring spatial resolution.

Equipment needs: Major equipment needs: Plasma etcher $(\sim 150 \mathrm{~K})$ and large area contact printer $(\sim 80 \mathrm{~K})$ for photolithographic processing of semiconductor detectors.

Molecular Structure of Membrane Transport Systems (BING JAP)

We are currently establishing a unique capability for structural determination of membrane proteins by the use of both electron and X-ray crystallographic methods. These involve the expression of membrane proteins using various novel and established techniques for the expression of clinically important proteins that are naturally expressed at a very low level such the cystic fibrosis transmembrane conductance regulator (CFTR) and potassium channel proteins. Our effort in establishing such a capability would be enhanced by the availability of basic equipment such as incubators for cell culture, additional centrifuges, and a state-of-the-art coldroom for membrane protein crystallization. The quality and productivity of our research program would greatly benefit from the availability of an $X$-ray detector and focusing mirrors for our $X$-ray generator and an additional high resolution electron microscope. These two major equipment items are crucial to our research projects; the current situation of our research equipment has greatly hindered our research progress and competitiveness.

Biomolecular Structure ANalysis by NMR (David Wemmer)

The continuing objective of our research is to determine the relationship between structure and activity of important regulatory proteins and other biomolecules selected for interesting chemical behavior. To do this we apply multidimensional, multinuclear NMR experiments to assign resonances and determine distance and angle restraints that are used for structure calculations. As needed we develop new spectroscopic methods. NMR relaxation measurements allow us to determine the dynamics in various regions of the molecules, mapping both the amplitudes and frequencies of motions which are present. Computed structures, and maps of flexibility, are analyzed to understand how the proteins and nucleic acids carry out their biological functions. 
One focus of our effort is proteins involved in genetic regulation. Most of the proteins we study act as transcription factors controlling the level of gene expression. Studies are continuing on NTRC, a bacterial protein which is involved in nitrogen regulation. The phosphorylated form, and mutants which show partial activation, are being studied to understand the conformational change which allows interaction with the neighboring ATPase domain. Analysis of the DNA binding domain of NTRC has also been initiated. The DNA binding domain of the yeast transcription factor Pho4, involved in regulating phosphate metabolism, has been shown to be a helix-loop-helix fold, and the structure will be completed fairly soon. The complex of this protein with its cognate DNA is also being studied. Efforts will continue to make complexes of the DNA binding domain of the yeast heat shock transcription factor, HSF, and its target DNA, the heat shock element. The flexibility of the combined trimerization and DNA binding domains of HSF are being probed using selective isotope labeling; this should help explain the cooperative binding which occurs. The human transcription factor HMG-I will also be explored in complexes with other proteins (particularly ATF-2) to develop a model for how the three copies of the DNA-contacting element function. Studies of the iron-responsive bacterial repressor will be continued to determine how the metal interacts with the protein to regulate uptake. Studies of the protein sex lethal, and the complex with its messenger RNA, will continue to help determine how this critical master switch acts to determine male vs. female development.

We have also been actively studying DNA sequences which have been selected for specific binding activity, in particular to the amino acid arginine. Binding target ligands with nucleic acids is relatively new, and there is little information about how specificity in binding is achieved. We are seeing interesting induced folding behavior with these DNAs. Catalytic antibodies have many applications, acting as enzymes for 'unnatural' reactions. To help understand the mechanism by which some of these act we are characterizing the structures of bound substrates for some antibody reactions.

Overall the focus of the program will continue to be on molecules involved in biological regulation, using NMR spectroscopy to understand the relationship between their structure and function. We anticipate completing the structural studies that are currently underway, but will initiate new work on similar systems, and extend studies of the present proteins to larger complexes with other nucleic acids and proteins.
The immediate equipment needs are for addition of pulsed field gradient capability to our high field spectrometer $(600 \mathrm{MHz})$; the required electronics and probe cost ca. $\$ 75,000$ and have been requested. We also very much need to upgrade the console on our $500 \mathrm{MHz}$ spectrometer, as the electronics are badly out of date and deteriorating. The cost of a replacement system is $\$ 370,000$, and a proposal for this has been submitted to NIH. In the slightly longer term, but still within a three year range, we need to improve the overall equipment at Berkeley up to the state of the art through addition of a new 750 or $800 \mathrm{MHz}$ spectrometer. This would be shared among people in the Structural Biology Division as well as others in the Material Sciences Division. Although the total cost is high (\$2 million), having up to date equipment is critical to maintaining our leading position instructural biology and material science fields.

Multi-User Crystallography Factlity (Thomas N. EaRnest)

The research of this group consista of 1) the use of crystallographic methods to study the structure and function of transmembrane proteins involved in signal transduction, and 2) the development of tools to enhance our ability to study protein structure and function, such that by combining state-of-the-art technology with modern molecular biological and biochemical techniques we can attack extremely difficult structural problems. We are presently working on the structure determination of the erythropoietin receptor (EPO-R) in collaboration with Amgen, and the nicotinic acetylcholine receptor (AChR). EPO-R is the receptor responsible for the production of red blood cells. For these studies EPO-R is expressed in eukaryotic cells in culture, and purified for crystallization into three-dimensional crystals for x-ray diffraction, or two-dimensional crystals for electron crystallography. AChR is a neurotransmitter receptor which is purified from the electric fish Torpedo, and crystallized for structure determination. Both of these proteins are representatives of larger families of receptors which mediate a range of biological functions.

Development of the Macromolecular Crystallography Facility (MCF) at the Advanced Light Source will lead to the operation of biological crystallography beamlines, the first of which will open in late 1996. This is a collaboration between LBNL scientists and engineers, and several academic and industrial user groups, to construct and operate beamlines as a national user facility for structural biology. We are also collaborating with others at LBNL and UC-San Diego to design and construct a massively-parallel, two-dimensional pixel detector for diffraction studies in structural biology and material 
sciences, which will offer vast improvement in dynamic range, noise, and time-resolution over presently available detector systems.

The opening of the MCF and the Structural Biology Support Facility (SBSF) will dramatically enhance our ability to study difficult problems, such as membrane protein structure and function. The MCF will open in December, 1996 and the SBSF opens in September, 1996. The combination of these resources will allow for the production, purification, crystallization, and structure determination of proteins which could previously not be done. Further development of our capabilities to modify and express proteins in large quantities will be needed, as well as the further expansion of staff scientists and lab space for these studies - $\$ 400 \mathrm{~K}$ per year is needed for this. Another $\$ 500 \mathrm{~K}$ is needed to ensure adequate staff support at the MCF.

Long-range planning would be significantly improved by the increase of stable operating funds. For the MCF and SBSF there is presently great uncertainty regarding adequate funding support for staff. Also membrane protein crystallography can only be done with steady funding over time due

HYPERTHERMOPHILIC PROTEIN StRUCtURES (ROSALIND Kim)

This project will target the discovery of structural bases for understanding stabilities of proteins from organisms living in extreme environments such as hyperthermal or cold-adapted microorganisms. The benefits of the studies would include: (1) Identification of thermostable enzymes capable of catalysis at extremely high temperatures, and cold-stable enzymes that function at nearfreezing temperature. (2) Discovery of structural bases for understanding unusual stability of protein, nucleic acids, and membranes at extreme conditions. (3) Understanding enzymatic catalysis of unusual chemical transformations. (4) Identification of an enormous collection of genes and enzymes of utility for industrial purposes and/or environmental remediation, and (5) A source of protein and nucleic acid crystals better matched to high-resolution structural studies than their mesophilic counterparts.

Molactlar and Genetic Analysis of DNA Double-Strand Break Repair (John C. Game)

This project continues research on DNA double-strand break (DSB) repair, and the genes that control this. In yeast, DSBs are repaired primarily by a process involving homologous recombination. New methods of studying recombinational DSB repair have been developed using a ring chromosome and pulsed-field gel electrophoresis. This work will be expanded to focus on the role of recombinational repair in mammalian cells. Human homologues are known for several major yeast recombinational repair genes, and these are probably essential in human recombination. However, their specific roles in DNA metabolism and repair are still unclear. Studying yeast and mammalian cells in parallel will best enable us to determine the significance of recombinational repair in humans. Additional human homologues of yeast recombinational repair genes will be sought, as well as yeast homologues of human repair genes. Cloned human repair genes in yeast will be employed, using the two hybrid system, to identify human genes whose products interact with each other or with specific yeast repair proteins.

Clarification of the mechanism of resolution of double strand DNA breaks in meiosis and in mitotic repair in the yeast Saccharomyces is underway. Specifically, the yeast mutant known as rad50s has been much used to study meiosis because it accumulates breaks in meiotic DNA. It is thought that these breaks are the natural precursors of recombination events in wild-type yeast cells, and that they accumulate in the rad50s strain specifically because this mutant is unable to process such breaks into recombinant molecules. However, the rad50s mutant has until now been thought to be little affected in mitotic DNA repair, and has been used to argue that there is a separation between the mitotic and meiotic functions controlled by the RAD50 gene. Recent data indicate that this is not in fact the case, since rad50s mutant cells are signifcantly sensitive to $X$-rays. Characterization of the mitotic repair defect in rad50s cells is in progress, as are studies of the nature of the meiotic defect in this mutant. This will help us resolve whether meiotic recombination in wild-type does indeed initiate via DSBs, and to determine whether mitotic DSBs induced by radiation are truly repaired by the same machinery that the cell uses to bring about recombination in meiosis.

In the near term, the study of the rad50s yeast mutant will be extended by determining whether it is defective in recombinational repair following radiation. By screening directly for the presence of recombinant DNA molecules, this objectivewill be accomplished. Subsequently, extension of the studies of recombinational repair in yeast using the ring chromosome system will be undertaken. In addition, work aimed at studying mammalian recombinational repair will be pursued. 
The original project description involves work on mammalian DNA repair as well as work with yeast. One issue concerns making the difficult transition from yeast experiments to those involving mammalian cell culture. The project was funded at a sharply reduced level from the original request, so that the project has been unable to employ a technician to help with experimental work. This has delayed implementing the start of mammalian cell culture experiments, and it has seemed more productive to use the limited available resources to complete ongoing experiments before starting new directions. However, in the near future, a collaboration will be explored with a group at LBNL that is already involved in mammalian cell culture. The existing budget should allow some financial input into such a collaboration, even though it is insufficient to hire an assistant directly.

\section{Human Genome Center (HGC)}

The long term aims of the HGC's Sequencing and Genome Technologies Group are to: (1) produce large amounts of high quality human genomic DNA sequence, (2) substantially increase the scale of sequencing operations in order to make a significant contribution to the goal of sequencing the first human genome, (3) engage in research and development activities aimed at improving the efficiency of genomic DNA sequencing, and (4) develop a highly automated environment for the production of genomic DNA sequence.

The Production Sequencing Group is utilizing a directed approach to DNA sequencing, developed over the past four years at LBNL. This approach involves the construction of a set of very high resolution physical maps which are used to guide template selection and sequence assembly. The advantages of this approach are that it reduces the number of expensive sequencing reactions that must be performed while also greatly easing the DNA sequence assembly process. To date, our group has, using this approach, produced 1,417,474 base pairs of completed human DNA sequence. This sequence is complete, entirely double stranded, and of high quality (less than 1 error per 2,500 base pairs).

We are sequencing two particular regions of the human genome. The first is a large multi-megabase region on chromosome 5 that contains an abundance of growth factor genes. The physical map for this region is being developed by the group of LBNL's Edward Rubin. The second region is located on chromosome 20 . This target is about $600 \mathrm{~kb}$ in size and spans a region that is amplified in a large percentage of primary breast and colon tumor cell lines. The physical map of this region is being developed in the laboratory of Joe Gray (LBNL/UCSF Resourcefor Molecular Cytogenetics). The physical maps in both regions are being generated utilizing large insert single copy vector systems, which include P1s, PACs and BACs.

The $R \& D$ group is dedicated to the continuous improvement of the directed sequencing process. On the research end of the spectrum, this group works to design and implement new processes that are likely to have an impact on the sequencing process. At the development end of the spectrum, this group works to make new processes (which can arrive from groups outside of the Berkeley Lab or be generated from our genomics research activities) ready for use in the highly demanding production environment. This group works very closely with the Automation group of Joe Jaklevic and the Informatics group of Frank Eeckman in order to pursue this goal. It is the combined $R \& D$ efforts of biologists, engineers, and computer professionals that will allow the development of a highly efficient and automated assembly line for the production of large amounts of genomic DNA sequence.

As the Sequencing and Genome Technologies Group scales up its operations toward multi-megabase monthly sequencing goals on the two to three year horizon, plans are being drafted to accommodate such expansion at the HGC. The following figures present the resources currently devoted to high through-put sequencing, and the projections for planned expansion.

Current Status of Production Sequencing Effort and Plans for Expansion

1 team is 7.33 FTE (Full Time Employees):
0.33

1.33

4.00

1.50

0.17

DOE

NIH

LDRD

TOTAL
Principal Research Associate Senior Research Associate Research Associates Research Technician Technician

$\begin{array}{ll}\text { human } & 2.00 \text { teams } \\ \text { Drosophila } & 2.00 \text { teams } \\ \text { human ch 20 } & 0.33 \text { teams }\end{array}$

4.33 teams 
Upcoming Expansion in Production Sequencing

NIH:

- established in awarded grant:

+1 team

August 1996

+1 team

March 1997

- based on review late in 1996:

+1 team

August 1997

+1 team

March 1998

DOE:

- provided \$1.4 million for equipment

- sufficient for 3 additional teams

- explicit funding of teams not yet received

Expansion of Sequencing: Prospects

- DOE most likely source of funding increases

- DOE intent to provide $\$ 40$ million/yr for production sequencing

- NIH is potential source for further expansion beyond 6 teams

Current People in Production Sequencing: 31 FTE

Current Productivity at LBNL HGC: $1.25 \mathrm{Mb} /$ team/yr

Assume $R \& D$ effort doubles this to $2.5 \mathrm{Mb} /$ team $/ \mathrm{yr}$

Establishment of a $100 \mathrm{Mb} / \mathrm{yr}$ facility requires:

$100 \mathrm{Mb} / \mathrm{yr} / 2.5 \mathrm{Mb} /$ team $/ \mathrm{yr}=40$ teams

40 teams $\times 7.13 \mathrm{FTE} /$ team $=285 \mathrm{FTE}$

Staffing and Management Expansion Requirements

Staffing:

- greater than nine-fold increase in staffing

- large number of talented individuals to identify and hire
Management:

- building layered structures within each group

- subgroup managers work directly with their team members

- group managers coordinating efforts of subgroups and dealing with difficult problems not solvable within a subgroup

- expect management structure to evolve as effort expands

Current Space Expansion Requirements:

HGC Space Available:

(excludes the other 3 groups in the HGC)

Building 74

5 teams

Building 64 (with 2nd floor)

5 teams

Building 84 (fall 1997)

7 teams

TOTAL

17 teams

Current Staffing:

Drosophila physical mapping

0.67 team

DOE sequencing

2.00 team

NIH sequencing

2.00 team

LDRD sequencing

0.33 team

$R \& D$

2.00 team

TOTAL

7.00 teams

Renovated Building $64-9,500 \mathrm{sf}$

- could hold $\sim 5$ teams

- thus, assume 2,000 sf/team

Space for a $100 \mathrm{Mb} / \mathrm{yr}$ Facility-40 teams @2,000 sf/ team

- requires 80,000 sf of space 
Expansion Requirements-Offsite Space

Features:

- overcomes long lead times required for space development

- avoids high costs of space development on-site

Envision 30,000 sf modules:

- initially one module, supporting 15 teams

- ability to add 2-3 more at same site

Design features for a module:

- single floor

- large open space in center

- offices, conference, lunch, etc. around perimeter

- modular, allowing flexibility between bench, equipment, computer, and desk

Offsite Space Site Selection-Current desired features:

- within $\mathbf{4 0}$ minutes of LBNL

- availability of suitable developed space

OR

- availability of open space for new construction

- safety of the area

- affordable per sf costs

Near future:

- investigation of potential sites

- determination of LBNL requirements and capabilities

- input from current members of the lab

Automated User INTERFACE GeNeration (MANFred ZoRN)

The data submission tools will be expanded to cover submissions to multiple databases at the same time without requiring the user to repeat information. We plan to interface SubmitData with sequence analysis tools to map sequence annotations directly from the analysis programs into the submission formats. Direct connectivity to the public databases will provide immediate response for large scale submitter.

In order to facilitate and improve data annotation we plan to integrate several genome analysis packages into the data submission software. While we have already embedded SubmitData into an assembly package, initial tests with distributed object technology, CORBA, promise a better mechanism for integration of different software modules. Instead of custom solutions for each new analysis module, the use of distributed object technology offers a generic interface to most if not all of them. CORBA represents a software bus on which clients and server programs are able to communicate with each other. An interface definition language, IDL, describes the necessary data interfaces. Our plan is to develop a uniform work environment so biologists can access public and private databases, execute analysis tools, and transfer results directly to the appropriate databases. The collaborations with both the Human Genome Center and the Center for Applied Genomics at LBNL can serve as test bed for such an integrated environment.

Parallel processing provides an easy mechanism to increase performance on time consuming tasks, like sequence similarity searches. In conjunction with the NERSC supercomputing center at LBNL we plan to develop object-oriented frameworks, e.g., BioPOET, which act as a mediator between computational biology applications and various parallel processing environments. Applications might include detailed sequence analysis using all available knowledge about a sequence, and protein structure and function predictions through comparisons with related sequences and structures.

\section{Areas of concern:}

New software developments should emphasize the integration of tools and databases into a common tool set. Too many individual programs perform well on a single task but cannot be integrated or interfaced with other programs, making it necessary to write nuisance routines to reformat data, etc. Separating the analysis tools from the database access modules and graphical user interfaces is a first step in this direction. This, however, entails that efforts to develop infrastructure tools like DB access modules and graphical user interfaces, etc., 
are recognized as valuable pieces of work and open to acquire competitive funding with reasonable chances.

\section{Medical Applications}

Localization of Oxidative Processes in Atherogenests (Ronald M. Krauss/ Diane L. Tribble)

This proposal (Imaging of Apolipoprotein E-binding Receptors In Vivo) has been refocussed in the past year. The overall objectives are to:

- identify critical oxidative processes and oxidizing species involved in the development of atherosclerosis

- determine the intracellular and extracellular localization of atherogenic oxidative processes

- evaluate how intracellular/extracellular localization influences the ability to target these processes for diagnostic evaluation and intervention.

Specific goals for FY 1997-98 are:

1. Evaluate the effects of $\mathrm{CuZn}$ superoxide dismutase (SOD) gene dosage on atherosclerosis development in susceptible (C57BL/6) mice. Specifically, compare susceptibility to atherosclerosis in heterozygous vs. homozygous transgenics, and wild types vs. heterozygous knock outs.

We hypothesize that amplification of $\mathrm{CuZn-SOD}$ activity increases susceptibility to atherosclerosis. The disease potentiating effects of $\mathrm{CuZn}$-SOD overexpression are associated with perturbations in the intracellular redox state, with increased levels of some reactive oxygen species, and reductions in the adaptive response to oxidative stress.

We hypothesize that reduction of CuZn-SOD activity increases susceptibility to atherosclerosis, and that this is associated with increased $\mathrm{O}_{2}^{-}$production.

2. Compare the disease-altering effects of manipulating intracellular versus extracellular forms of SOD.

We hypothesize that the extracellular form of SOD is more effective in protecting against atherosclerosis, because of greater access to environments in which LDL is oxidized and exerts cytotoxic effects, and the absence of an effect on induction of the adaptive response.
3. Examine the effects of SOD overexpression on TNF $\alpha$-induced LDL retention and oxidation in perfused arteries in situ.

We hypothesize that TNF $\alpha$-induced LDL retention is $\mathrm{O}_{2}^{-}$dependent and involves LDL oxidation in the extracellular environment. These processes are inhibited in overexpressors of extracellular, but not intracellular, SOD.

\section{Background/Approach}

Radical-mediated oxidative processes have been implicated in the development of atherosclerosis, as well as other chronic and degenerative diseases including cancer. Specifically, considerable evidence indicates that oxidation alters the physical-chemical and biological behavior of atherogenic lipoproteins, and thereby promotes their involvement in intracellular and extracellular processes responsible for the development of atherosclerosis.

Among the reactive oxygen species generated in vivo, the superoxide anion $\left(\mathrm{O}_{2}^{-}\right)$has been implicated as a primary mediator of atherogenic oxidative modifications. In many cases, the atherogenic potential of $\mathrm{O}_{2}^{-}$ has been inferred from in vitro observations of an attenuating effect of superoxide dismutase (SOD). SOD has been shown to inhibit macrophage- and vascular cell-mediated lipoprotein oxidation, and leukocyte adhesion to the vascular endothelium, and to promote endothelium-derived relaxing factor induced vasodilation.

In this project, we are addressing the involvement of SOD in intracellular and extracellular atherogenic events using mice strains in which expression of SOD has been systematically varied by gene targeting (knockout) and overexpression. Atherosclerosis susceptibility will be assessed in these strains by quantitative histologic measures. Tissues and cells from these strains will be used to investigate intracellular and extracellular metabolic events putatively involved in influencing atherosclerosis susceptibility. Initial emphasis will be on stress-mediated expression of adaptive genes, such as heme oxygenase, that may reduce susceptibility to oxidative injury. 


\section{Table 10: Facility Construction and Modifications}

\section{Building 64 Renovation}

A new laboratory devoted to high through-put DNA sequencing has been developed in Building 64. The construction cost of the Genome Sequencing renovation was $\$ 1.72$ million and represented approximately 14,500 gross square feet including 9,500 square feet of labs and offices. A complete new mechanical and electrical system was included for the first and second floors. The renovation included complete outfitting of 4,700 square feet of labs on the first floor and the project was completed in February 1996.

\section{LBNL Human Genome Laboratory}

* Funds totaling $\$ 24,700,000$ for the construction of the new Human Genome Laboratory at Lawrence Berkeley National Laboratory were approved by Congress in December 1993. This facility contains:

* 44,400 gross square feet, and

* 24,200 assignable square feet.
- A planned total of 92 staff would be accommodated, including senior scientists, postdoctoral associates, graduate students, technicians and support personnel in light laboratories, equipment rooms and office space in support of the DOE Biological and Environmental Research Program.

* Building to be completed and occupied by 1998.

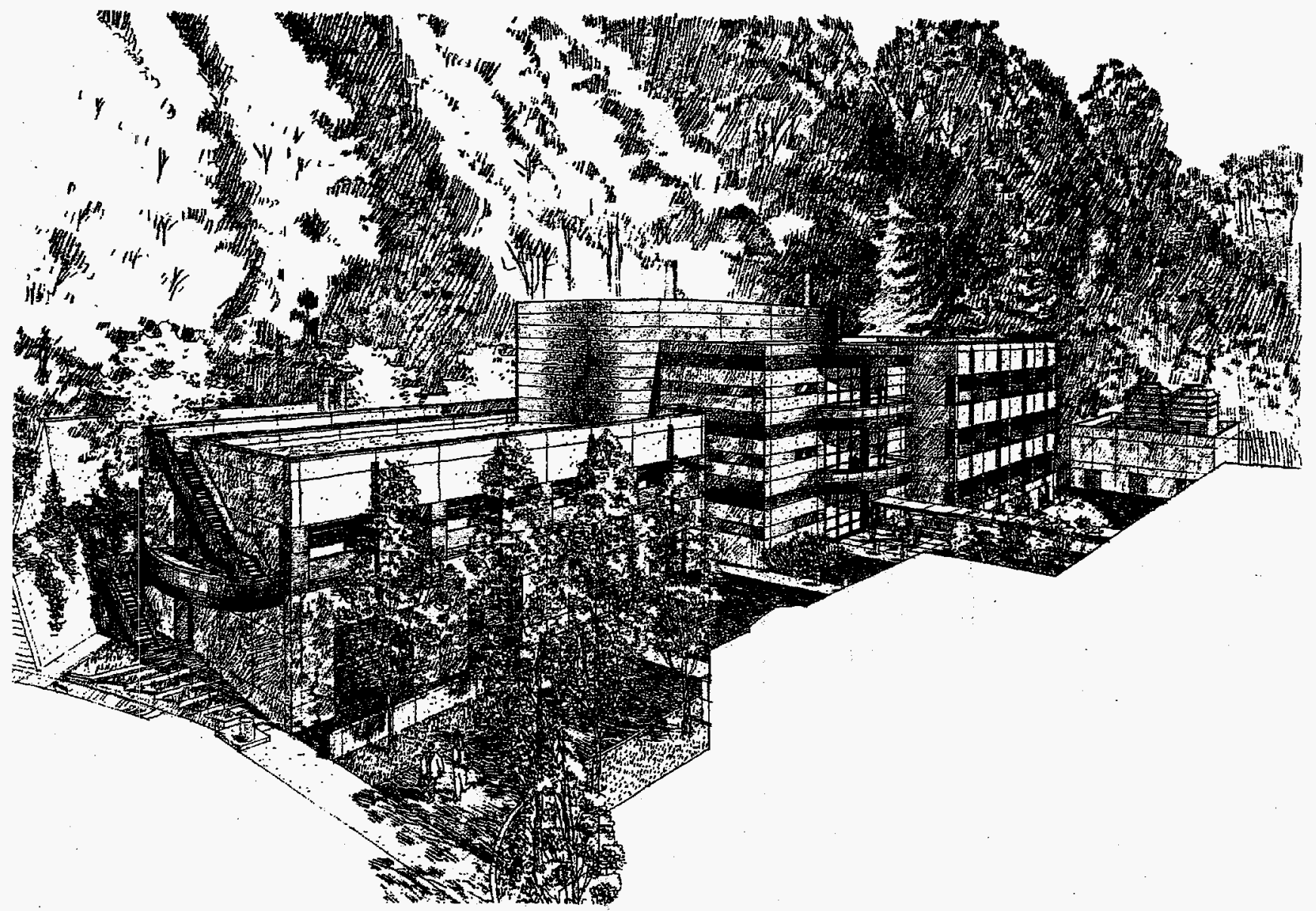

HUMAN GENOME LAB PERSPECTIVE VIEW 


\section{Table 11: Major Equipment Requirements for FY 1997-FY 1999}

PI Name

Equipment

(Equipment above \$5,000)

Temperature controlled rotary shaker

Thermostat controlled orbit environmental shaker

Microbalance

Laboratory glassware washer

Fume hood

Sonifier cell disrupter/lab blender

Lambda bio spectrophotometer

Multiple chamber peptide library synthesizer

Electroporation instrument

Two-dimension gel electrophoresis unit

Double cell culture incubator

Field inversion gel electrophoresis system

Gene Amp PCR system

Refrigerated benchtop microfuge

Refrigerated small volume centrifuge

Refrigerated small volume table top centrifuge

High resolution video camera with monitor

Phosphoimager

TKO 100 mini-flurometer

Imagemaster desktop scanner package

Silicon Graphics computer system

Blood gas analyzer

$\mathrm{CO}_{2}$ Incubator
$\$ 11,300$

Amount

7,700

9.800

5,200

8,700

5,500

8,500

6,000

5,550

13,500

7,700

12,800

8,900

7,300

44,000

9,800

23,500

80,000

2,200

82,200

45,000

20,000

14,000
Cooper/Rydberg 
Cooper/Rydberg

Derenzo

Derenzo

Derenzo

Derenzo

Derenzo

Derenzo

Glaeser

Glaeser

Glaeser

Gray

Gray

Gray

Gray

Gray/Pinkel

Gray/Pinkel

Gray/Pinkel

Gray/Pinkel

Jaklevic/Rossington

Jaklevic/Rossington

Palazzolo/HGC

Palazzolo/HGC

Palazzolo/HGC

Palazzolo/HGC

Palazzolo/HGC

Palazzolo/HGC

Palazzolo/HGC
Milli-Q UF plus water system

9,000

Pulsed x-ray facility

145,000

Vacuum tank with fluorescence analyzer

75,000

Four-channel, $500 \mathrm{MHz}$ digital oscilloscope

12,500

Mode-locked laser

135,000

Quadrupler crystal system

5,000

X-ray tube

22,750

Time resolved spectrofluorometer

75,000

Digital slide maker

20,000

High pressure liquid chromatography

30,000

Automated DNA sequencer

200,000

Fast scanning microscope system

210,000

Microdissection micromanipulators and microscope

90,000

Zeiss confocal microscope

290,000

Spectral imaging microscope

145,000

ABI Prism 310 Genetic analyzer \& software

66,500

Remote-controlled collaborative microscope

152,000

MJ research tetrad thermocycler

24,000

Plasma etcher

$\$ 150,000$

Large area contact printer

$\$ 80,000$

DNA sequencers (3)

350,000

DNA prep robot

250,000

ORCA robot and accesories

150,000

96-well UV spectometer

50,000

12-well UV spectometer

34,000

LBL colony picker

150,000

Sun Sparc stations (4) 
Palazzolo/HGC

Palazzolo/HGC

Palazzolo/HGC

Palazzolo/HGC

Spengler

Stampfer

VanBrocklin

VanBrocklin

VanBrocklin

Morgan
Custom LBL sequencers (4)

800,000

Gel analysis system for mapping

150,000

Gel imaging system

250,000

Liquid robot CRS pipetting system (2)

200,000

Power PC with expanded memory; printer; scanner;

Macintosh color notebook; portable color printer

12,500

Double door $\mathrm{CO}_{2}$ incubator

9,900

Gas chromatograph/mass spectrometer

60,000

Flow through HPLC detector

35,000

Data and chromatography control station

50,000

REVCO freezer; Coulter Counter
16,000 


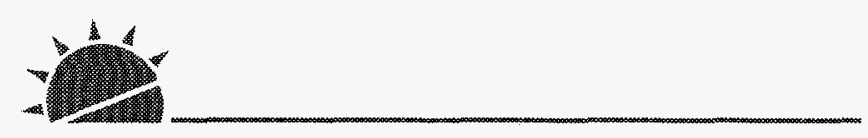

\subsection{Contemporary Issues}

The primary focus of this section will be on the following four points:

1) That the Health Effects Research Program indeed distinguishes the DOE biology effort from the efforts of the other funding agencies, and, as such, is vital to the future of OHER;

2) That the traditional epidemiological and animal studies are very limited in their ability to predict risk to environmental hazards at low doses, thus other approaches are necessary;

3) That the exposures of concern, both chemical and radiation, are primarily at low doses and low dose rates; and

4) That the budgets for Health Effects Research are being threatened and may be substantially reduced in the future. This necessitates a well-grounded rationale for the importance of this program within OHER.

The historical emphasis of OHER was on providing a scientific basis for risk assessment for a wide variety of radionuclides and chemicals. These studies provided definitive information concerning relatively high levels of radiation exposure, i.e., $>20 \mathrm{cGy}$. The program has accumulated a vast amount of animal data on a wide variety of radionuclides; in addition, considerable animal data exist for many of the chemicals found at DOE clean-up sites. However, most occupational and environmental exposures are several orders of magnitude lower than those for which experimental data exist. Thus, while useful data have been generated, these approaches do not have the sensitivity to evaluate the effects of low doses and low dose rates. 
The program should center on determining the effects of low dose exposures on cells, tissues, and organisms, examining the mechanisms of action, and developing improved technologies and assays to measure these effects, in order to better understand and predict risk from hazards that include radiation, chemicals, and other energy related agents. A central issue is moving from the prediction of risk from exposures at high doses and dose rates to the prediction at low doses and dose rates. Many factors, including individual genetic determinants, physiological factors, and defense mechanisms affect these risks. Understanding the role of these factors in determining cellular responses to low and high level exposures and understanding the mechanisms of these responses provides a basis for determining differences or similarities of responses at different exposure levels.

Indeed, it has been shown that cells and tissues do, in many cases, respond differently to high versus low levels of exposure due to toxicity, saturation of repair systems, etc. An understanding of the mechanisms of cellular responses to low levels of exposure is required to develop better models of low-level effects used to predict risk. This understanding can only be achieved by addressing these questions in the context of modern biological knowledge and by taking advantage of new technologies that are being developed.

Given the diminishing resources and the interest and demonstrated movement of industry into human genomics, OHER is beginning to consolidate some of its traditional programs that are no longer mainstream or could be better performed outside the DOE domain. This consolidation needs to continue.

\section{Recommendations}

The current focus on studies that emphasize low dose, low dose rate exposures to environmental hazards (including chemical agents) is appropriate. The studies should include analysis of the genetic determinants, microenvironmental regulators of genetic determinants, physiological factors, and defense mechanisms that affect individual susceptibility to these exposures. Studies that investigate the mechanisms of cellular responses to low dose, low dose rate exposures, with emphasis on the use of relevant animal models and functionally normal human cells are also of value.

Given the designated mission as outlined above, how can human genome and structural biology-derived technologies be brought to bear on individual susceptibilities and risk assessment at low exposures?
A focus on living tissues would seem to be not only reasonable but also essential. The approach needs to be vertical: the focus should encompass genes, gene products, gene function, gene structure, chromosome structure, and organization and cell/tissue architecture and function. This approach requires the multidisciplinary and interacting teams appropriate for DOE-supported research. Such focus is broad enough to allow shifts of direction as science changes. At the same time, it would allow us to stay close to the mission as defined: to assess low exposure and individual susceptibility. Thus, the evolving data should provide a rational basis for the selection and study of crucial susceptibility genes, which is an important aim of the mission.

Axiomatic to a risk assessment focus is the continuation and expansion of OHER's efforts in cellular and molecular biology, with emphasis on the mechanisms by which gene products regulate basic cellular functions and how these are altered by environmental insults. Another approach that directly couples the Human Genome Project and Structural Biology Program is the identification of genetic polymorphism in the susceptibility genes of environmentally relevant cancers and investigations of how minor structural variations in gene products alter the proficiency of their functions, e.g., reduced DNA repair capacity, alteration of cell cycle regulation, changes in the rate of apoptosis, etc.

We do not yet know enough about how the multitudes of important cellular functions are integrated in cells and tissues. In addition, there are genes that would not fit into the focus on replication and repair, yet are important models of mutation, e.g., fragile $X$ syndrome or Huntington's Disease. Thus, there is a need to combine gene isolation and identification with studies on their function and regulation. There is much work that needs to be done before the functions of the genes are understood within the tissue context. For example, p53 which was discovered in 1979, appears to be involved in 70 percent of all human cancers and is still subject to intense investigation today.

This indicates that while we are well on our way to isolating and sequencing genes, we need much more intense research to understand their function. Health Effects Research needs to be strengthened rather than reduced if we are to harvest the fruits of the genome and structural biology programs. In addition to generating primary data, we also need to begin to apply computational and theoretical biology to get at the broader "rules" of gene function. To get a handle on risk, one must sooner or later deal with the whole organism. Since 
we have agreed that epidemiology is too blunt a tool for low exposures, it is clear that one must study not only genes, cells, and tissues, but also animals. The cost, complexity, and political sensitivity of using larger animals are prohibitive. The choice is rodents, not the least for the availability of genetic strains and the magnificent modern biology technologies, such as transgenics and knockouts (especially conditional transgenics and knockouts-a technology OHER-funded scientists should be encouraged to develop further). As more oncogenes and tumor suppressor genes related to cancer or genes of interest to other radiation and chemically induced diseases are isolated and defined, these can be tested in the mouse using genetic engineering. Equally important, unexpected mechanisms and regulatory genes could be discovered by careful analysis of tissue-specific overexpression and knockouts of biologically important molecules.

In addition, the already existing mutations in mice need to be exploited. The national laboratory system maintains hundreds of different mutant strains, many of which could shed light on genes that may be involved in environmental insults. Utilizing the genome mapping and gene discovery programs at the national laboratories will greatly facilitate cloning of the genes associated with these mutations. Also, chemical mutagenesis or translocations in the mouse can generate new and unexpected phenotypes not necessarily achieved by targeted knockouts.

While animal studies are important, other approaches are also needed. Both humans and mice must be studied since animal models are not perfect models of human susceptibility. Indeed, if we only studied animals in an attempt to correlate our knowledge of the physical structure and map position of particular genes to specific functions in the individual, we may end up with partial answers. Since it is obvious that other than by epidemiology human populations cannot be studied, it is important to develop human cell culture models where the behavior of the cells mimics physiology in vivo. In addition, because of remarkable homology between chromosomes (synteny) of mice and men, the function of large pieces of human genetic material could be investigated using transgenic animals.

The problems of structure-function in the context of molecules, cells, and tissues are exceedingly complex and indeed are appropriate for national laboratories where multifaceted teams could be brought together to address them. Such problems will require massive knowledge about the genes, protein structure, subcellular structure, tissue structure, and gene expression, and will require the collaboration and cooperation between biologists, biophysicists, theoretical and computational biologists, engineers, chemists, computer scientists, etc.

A vertical approach is the key to OHER's future and indeed past success: there is a need for an integrated program that goes from the sequence of selected genes (as they are unraveled in the Genome effort), to their structure (through the Structural Biology effort), to their functions (in the basic Health Effects Program), and eventually to the organism (in conjunction with Medical Applications Program). In all areas of OHER activities related to health (Health Effects, Medical Applications, Cell \& Molecular Biology, and Genome), use of transgenics and knockout and natural mouse mutants, as well as functional human cell culture models to decipher the regulation of human genes, should be encouraged.

\section{Implementation}

OHER is well on its way toward an integrated approach to Health Effects Research, and has already begun to reorient and focus its efforts towards the unique capabilities of the DOE-supported research in the national laboratories. The strength of this program also lies in its ability to support long-term but innovative approaches to answer fundamental questions related to exposure and risk. The Office has had a remarkable history of success in a number of areas, made more impressive when one realizes the relatively small size of the budget and the broad areas of support it has had to cover.

In the last decade, the Office has moved to develop two enormously bold, important, and successful initiatives: the Human Genome and the Structural Biology Projects. These two areas have and will continue to generate the advanced technologies that must be applied to our understanding of health effects research.

OHER's current research emphasis is both appropriate and timely; however, the extreme cuts in the budget of the Health Effects Research Program is a subject of great concern. The initial budget, which has been too small to begin with, is becoming almost negligible. This is ironic because, as noted above, the program has been extremely cost-effective over all.

But most importantly, the Health Effects Research Program provides the rationale and the underpinning for the Genome and Structural Biology Efforts at DOE and OHER. It is crucial to recognize now that should the effort become any smaller than it has been in recent years, there will be a serious and irreversible erosion of 
effective research and application in low dose exposure and risk assessment. Not only OHER and DOE, but the basic scientific endeavor in health effects research in the country and the world will suffer.

Too often there is a perception that there are redundancies among the funding agencies as well as among the national laboratories. We know this not to be the case. Not only do NIH, OHER, NSF, and EPA, etc., have different and unique missions, they also "manage" their scientific programs very differently. In addition, diversity is as essential for a healthy scientific establishment as it is for the economy.

Whereas redundancy is wasteful and there may not be need to have biology in all national laboratories, there is real strength in a few laboratories attacking a complex problem from different angles. The fact that, for example, three laboratories are involved in human genome research is a good case in point. The size and complexity of the genome effort necessitates like involvement of more than one laboratory to allow multiple and diverse talents in different areas to be brought together to solve this huge problem. The current interactions on a "consortium" agreement between the genome centers and other OHER genome efforts is a good example of how the laboratories could work together in the future also in the area of health effects.

The mission of the Health Effects Research Program within OHER is unique and essential and should be supported and strengthened. Our recommendations above both support and extend the present focus of the Health Effects Research Program.

\section{Other Issues}

The ethical, legal, and social implications (ELSI) of predicting individual susceptibility to energy-related agents is an important issue that cannot be ignored. However, these concerns are not unique to the Health Effects Research Program. Rather, they are issues currently being encountered by a number of Federal agencies and being addressed by the Human Genome ELSI Program.

It is clear that computational and theoretical biology, as well as modeling, will play an increasingly important role in health effects research. An ultimate goal of modern biology is to achieve a full understanding of the relationships among macromolecular sequence, structure, and function. It will be important to develop a strong program that expands the capabilities of modeling to relate sequence to structure and function. The vast amount of data stemming from the genome program, together with rapidly increasing structural data, will offer a greatly expanded basis for such a concerted effort to develop improved modeling methodologies for proteins from all species. Such knowledge will have a major impact on our understanding of molecular mechanisms underlying the health effects of environmental expo sures as well as provide a huge number of new targets for dealing with such impacts. This integration of new approaches to health effects research, results from the Genome Program, and experimental and theoretical structural biology will create the foundation for vast improvements, even revolutions, in such diverse areas as health risk assessment, improved therapies, biofuels, and environmental cleanup and waste control.

The primary responsibility for implementation of the above recommendations rests with OHER. Along those lines we have several suggestions.

1) The proper balance needs to be maintained between the creativity of individual scientists and the value of team-oriented research at the national laboratories.

2) It is necessary to establish interlaboratory Working Groups in areas that represent core scientific or technology-based areas of interest to the Health Effects Research Program. These groups will serve as a focal point for developing collaborations that will both strengthen research programs and minimize unnecessary duplication of effort.

3) OHER should sponsor workshops on application of genome and structural biology-based areas for both individual programs and those that cut across program areas.

4) More efforts should be made to encourage research collaborations between the national laboratories and universities. OHER support for university-based research should involve collaborations with OHER laboratories.

5) Develop requests for applications in areas of:

- Computation-based modelling of gene expression; and

- Conditional knockouts and transgenics to study health effects. 


\subsection{Appendices}

\subsection{Information Transfer}

The following information is tabulated by division; a summary table is given at the end. The totals ( $T$ ) given in the tabulations of personnel data reflect DOE support of the entire division, except for the Engineering, Information and Computing Sciences, and Earth Sciences Divisions, and Structural Biology, where the totals reflect only effort directly related to OHER-sponsored, Biological and Environmental (BER) research. 


\section{Life Sciences}

Personnel (FTE)

FY 1994

FY 1995

FY 1996

BER

(T)

BER

(T)

BER

(T)

Professional (scientific) ${ }^{\mathbf{a}}$

32.1

91.1

33.8

91.0

$40.1 \quad 95.9$

Post-doctorates

$3.3 \quad 30.7$

5.2

31.0

12.0

31.0

Technicians

31.2

91.3

34.1

91.7

$46.2 \quad 110.4$

Animal care

Total direct personnel

$67.0 \quad 215.8$

$73.7 \quad 216.9$

$98.9 \quad 241.1$

Professional (adm.)

Clerical, adm. support

$6.0 \quad 17.0$

$6.0 \quad 17.5$

$7.2 \quad 17.6$

$6.7 \quad 19.1$

$6.7 \quad 19.8$

$8.1 \quad 19.7$

Maintenance

Total indirect personnel

12.7

36.1

12.7

37.3

15.3

37.3

Visiting scientists $\mathrm{b}$

Graduate students $b$

$14.0 \quad 40.0$

13.3

39.0

21.3

52.0

Undergraduates ${ }^{b}$

$7.0 \quad 21.0$

7.0

21.0

$9.0 \quad 23.0$

$22.0 \quad 65.0$

31.0

86.0

34.0

83.0

Information Transfer (OHER-Sponsored Research)

\begin{tabular}{r} 
FY 1993 \\
\hline 117 \\
22 \\
22 \\
30 \\
105 \\
8
\end{tabular}

FY 1994
144
26
24
15
161
12

FY 1995

Journal articles (peer-reviewed)

Chapters, reviews

Books, proceedings (edited)

Reports/documents

30

Presentations at technical meetings

Meetings organized

aNumber of OHER-sponsored scientific professionals by highest degree:

12 M.D.

63 Ph.D.

$52 \mathrm{MS} / \mathrm{BS}$

1 D.V.M.

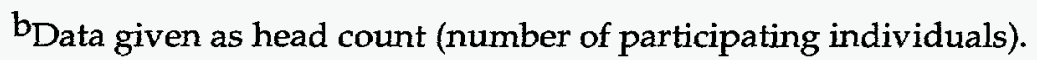




\section{Structural Biology}

Personnel (FTE)

FY 1994

FY 1995

FY 1996

$\begin{array}{llllll}B E R & (\mathrm{~T}) & \mathrm{BER} & (\mathrm{T}) & \mathrm{BER} & (\mathrm{T})\end{array}$

\begin{tabular}{|c|c|c|c|c|c|}
\hline Professional (scientific) ${ }^{a}$ & 5.0 & 26.0 & 5.0 & 29.0 & 8.3 \\
\hline Post-doctorates & 1.0 & 26.0 & 3.0 & 34.0 & 6.1 \\
\hline Technicians & 3.0 & 6.0 & 2.0 & 7.0 & 1.5 \\
\hline Animal care & - & - & 一 & - & - \\
\hline Total direct personnel & 9.0 & 58.0 & 10.0 & 70.0 & 15.9 \\
\hline Professional (adm.) & 0.5 & 0.5 & 0.5 & 1.5 & 0.5 \\
\hline Clerical, adm. support & 0.0 & 5.5 & 0.5 & 4.0 & 0.5 \\
\hline Maintenance & 1.4 & 1.4 & 一 & 1.0 & 0.5 \\
\hline Total indirect personnel & 1.9 & 7.4 & 1.0 & 6.5 & 1.5 \\
\hline Visiting scientists & - & 2.0 & 0.0 & 6.0 & 2.0 \\
\hline Graduate students & 10.0 & 32.0 & 13.0 & 36.0 & 8.8 \\
\hline Undergraduates & 9.0 & 17.0 & 1.0 & 31.0 & 9.0 \\
\hline
\end{tabular}

Information Transfer (OHER-Sponsored Research)

\section{FY 1993}

Journal articles (peer-reviewed)

Chapters, reviews

Books, proceedings (edited)

Reports/documents

Presentations at technical meetings

Meetings organized
37

FY 1994

31

-

$-$

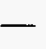

15
FY 1995

43

1

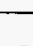

3

21

aNumber of OHER-sponsored scientific professionals by highest degree:

6.3 Ph.D

$2.0 \mathrm{MS} / \mathrm{BS}$ 


\section{Earth Sciences}

Personnel (FTE)

$$
\text { FY } 1994
$$

FY 1995

FY 1996

BER

(T)

BER

(T)

BER

Professional (scientific) ${ }^{a}$

3.7

3.7

4.5

4.5

1.5

1.5

Post-doctorates

$0.8 \quad 0.8$

1.0

1.0

$\begin{array}{ll}0.5 & 0.5\end{array}$

1.0

1.0

Technicians

Total direct personnel

$5.0 \quad 5.0$

6.5

6.5

1.5

1.5

Professional (adm.)

Clerical, adm. support

$\begin{array}{cccccc}- & - & - & - & - & - \\ 0.3 & 0.3 & 0.3 & 0.3 & 0.3 & 0.3 \\ - & - & - & - & - & -\end{array}$

Total indirect personnel

$0.3 \quad 0.3$

0.3

0.3

0.3

0.3

Visiting scientists

Graduate students

$0.2 \quad 0.2$

$1.25 \quad 1.25$

Undergraduates

$0.2 \quad 0.2$

0.3

3.0

0.5

0.3

3.0

$-$

1.0

0.5

$\begin{array}{ll}1.0 & 1.0 \\ -\quad-\end{array}$

Information Transfer (OHER-Sponsored Research)

\section{FY 1993}

FY 1994

FY 1995

Journal articles (peer-reviewed)

Chapters, reviews

3

0

0

Books, proceedings (edited)

Reports/documents

3

Presentations at technical meetings

Meetings organized

4

2

3
0
0
5
5
4

1

0

0

4

3

4

aNumber of OHER-sponsored scientific professionals by highest degree:

6.0 Ph.D.

4.0 MS/BS 


\section{Energy and Environment}

Personnel (FTE)

FY 1994

FY1995

FY 1996

BER

(T)

BER

(T)

BER

Professional (scientific)
Post-docttorates
Technicians
Animal care
$\quad$ Total direct personnel
Professional (adm.)
Clerical, adm. support
Maintenance
$\quad$ Total indirect personnel
Visiting scientists
Graduate students
Undergraduates

$5.2 \quad 118.0$

4.79

99.0

$6.53 \quad 59$

$1.1 \quad 11.0$

1.0

12.0

$1.5 \quad 11$

$1.3 \quad 71.0$

1.73

91.0

$2.6 \quad 60$

$7.6 \quad 200.0$

7.52

202.0

$10.63 \quad 130$

$0.2 \quad 11.0$

$0.26 \quad 11.0$

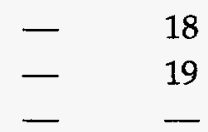

$1.3 \quad 20.0$

$\begin{array}{ll}1.26 & 20.0\end{array}$

$0.3 \quad 85.0$

$0.25 \quad 90.0$

- 11

$2.5 \quad 21.0$

$2.72 \quad 24.0$

$3.58 \quad 31$

Undergraduates

Information Transfer (OHER-Sponsored Research)

FY 1993

Journal articles (peer-reviewed)

Chapters, review

Books, proceedings (edited)

Reports/documents

Presentations at technical meetings

Meetings organized

\section{0}

2

18

6

29

FY 1994

FY1995

34

9

2

1

3

9

1

a Number of OHER-sponsored scientific professionals by highest degree:

3.0 Ph.D. 


\section{Engineering}

Personnel (FTE)

FY 1994

FY 1995

FY1996

BER

(T)

BER

(T)

BER

(T)

Professional (scientific) ${ }^{\mathrm{a}}$

$\begin{array}{cccccc}5.0 & 9.0 & 5.0 & 9.0 & 4 & 8 \\ - & - & 1.0 & 1.0 & 1 & 1 \\ 2.0 & 4.0 & 2.0 & 4.0 & 2 & 4 \\ - & - & - & - & - & -\end{array}$

Technicians

Animal care

Total direct personnel

$7.0 \quad 13.0$

8.0

14.0

7

13

Professional (adm.)

Clerical, adm. support

Maintenance

$\begin{array}{llllll}- & - & - & - & - & - \\ 1.0 & 1.0 & 1.0 & 1.0 & - & - \\ 0.5 & 0.5 & 0.5 & 0.5 & - & 0.2\end{array}$

Total indirect personnel

$1.5 \quad 1.5$

1.5

1.5

-

0.2

Visiting scientists

Graduate students

Undergraduates

$\begin{array}{cccccc}- & - & - & - & - & - \\ 1.0 & 1.0 & - & - & - & - \\ 1.0 & 1.0 & 2.0 & 2.0 & 1 & 2.75\end{array}$

Information Transfer (OHER Sponsored Research)

FY 1993

15

0

1

20

15

1
FY 1994

12

0

1

19

10

1
FY 1995

11
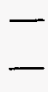

11

Meetings organized

$a_{\text {Number of OHER-sponsored scientific professionals by highest degree: }}$

3.0 Ph.D.

3.0 MS/BS 


\section{Information and Computing Sciences}

Personnel (FTE)

FY 1994

FY 1995

FY 1996

$\begin{array}{lllll}\text { BER } & (\mathrm{T}) & \text { BER } & (\mathrm{T}) & \text { BER }\end{array}$

(T)

Professional (scientific, Ph.D.) ${ }^{\mathrm{a}}$

$\begin{array}{lllllll}6.8 & 6.8 & 4.7 & 4.7 & 6.0 & 6.0 \\ - & - & - & - & - & - \\ - & - & - & - & - & - \\ - & - & - & - & - & -\end{array}$

Technicians

Animal care

Total direct personnel

6.8

6.8

4.7

4.7

6.0

6.0

Professional (adm.)

Clerical, adm. support

Maintenance

Total indirect personnel

Visiting scientists

Graduate students

Undergraduates

$\begin{array}{llllll}- & - & - & - & - & - \\ - & - & - & - & - & - \\ - & - & - & - & - & - \\ - & - & - & - & - & - \\ - & - & - & - & - & - \\ 0.6 & 0.6 & 0.3 & 0.3 & - & -\end{array}$

Information Transfer (OHER-Sponsored Research)

Journal articles (peer-reviewed)

Chapters, reviews

$\begin{array}{ll}- & - \\ - & 2 \\ - & 2 \\ - & 7 \\ - & 9 \\ - & 1\end{array}$

-
1
3
5
0

aNumber of OHER-sponsored scientific professionals by highest degree:

1.0 Ph.D.

2.0 MS/BS 


\section{Summary Total}

Personnel (FTE)

FY 1994

BER

$57.8 \quad 254.6$

$6.2 \quad 68.5$

$38.0 \cdot 172.8$

0.4

2.7

Animal care

Total direct personnel

Professional (adm.)

Clerical, adm. support

Maintenance

Total indirect personnel

Visiting scientists

Graduate students

Undergraduates $\begin{array}{llllll}102.4 & 498.6 & 103.62 & 514.1 & 139.83 & 457.1\end{array}$

$6.7 \quad 28.5$

$9.3 \quad 45.9$

$6.96 \quad 30.0$

$7.7 \quad 36.3$

$1.9 \quad 1.9$

10.46

45.1

$8.9 \quad 42.5$

$0.5 \quad 1.5$

$0.5 \quad 1.2$

$17.9 \quad 76.3$

$17.92 \quad 76.6$

$17.1 \quad 80.0$

$14.5 \quad 127.2$

$13.55 \quad 135.3$

$23.30 \quad 67.00$

$21.75 \quad 76.25$

$24.72 \quad 83.0$

$22.38 \quad 102.00$

$32.8 \quad 83.8$

$44.30 \quad 118.75$

Information Transfer (OHER-Sponsored Research0

$\underline{\text { FY } 1993}$

192

Journal articles (peer-reviewed)

Chapters, reviews

Books, proceedings (edited)

Reports/documents

Presentations at technical meetings

Meetings organized
FY 1994

182

20

15

48

147

8
FY 1995

276

35

35

39

277

16

a Number of OHER-sponsored scientific professionals by highest degree:

12.0 M.D.

66.0 Ph.D

1.0 D.V.M.

63.0 MS/BS 


\section{2/7.3}

Selected 1995-1996 Extramural Activities, Awards, Honors Editorships, \& Special Invited Lectures
Mina J. Bissell

- President Elect, American Society of Cell Biology, (1995 - 1997)

- AAAS Fellow

- Member HERAC; Chair, Subcommittee Subcommittee on Application of Genome and Structural Biology

- Member, Chicago University Advisory Board

- Member, Scientific Advisory Board, Canji (San Diego)

- Chair, Program Committee of the 6th International Congress on Cell Biology; Chair, 1996 Keystone Symposium on Breast and Prostate Cancer.

- ASCB Women in Cell Biology Career Recognition Award

- Member, Board of Directors, International Society of Differentiation

- Governing Board, Gordon Research Conferences

Editorial Boards:

- Molecular and Cellular Differentiation

- Molecular Carcinogenesis

- Developmental Biology

- Cancer Research 
- The Breast Journal

- Journal of Mammary Gland Biology

- Cell Structure and Function

- Cancer Research

- Molecular Carcinogenesis

- In Vitro Cellular and Developmental Biology

Keynote Speaker:

- Gordon Conference on Fibronectin, Integrins and Related Molecules (1995)

- Phillips Lectures, Haverford College, Haverford, PA (1995)

- Session Chair and Speaker, Nobel Conference on Cell Adhesion Molecules and Cell-Matrix in Veterbrate Tissues; Stockholm, Sweden (1995)

- Distinguished Lecture Series, Baylor College of Medicine, Houston, TX (1995)

- Chair, Keystone Meeting on Breast and Prostate Cancer, Taos, NM (1996)

- Member, U.S. Army Breast Cancer Research Program, Integration Panel (1995-1996).

Invited Lectures \& Symposia: (asterisk indicates plenary, symposium, and named lectures)

- University of Hawaii, Pacific Biomedical Research Center, Honolulu, Hawaii (January 1995)

- Breast Cancer Think Tank Symposium, Nassau, The Bahamas (January 1995)

- Thomas Jefferson University, Philadelphia, PA (March 1995)

- German Tissue Culture Society, Heidelberg, Germany (April 1995)

- European Cell Biology Organization, Heidelberg, Germany (April 1995)

- University of Tennessee, Memphis, TN (April 1995)

- Duke University, Durham, NC (April 1995)
- Purdue University, Purdue, IN (May 1995)

- Cleveland Clinic Foundation, Cleveland, OH (Distinguished Lecture Series) (May 1995)

- University of Iowa, Ames, Iowa (May 1995)

- University of California, San Diego, San Diego, CA (May 1995)

- Gordon Conference on Biological Structure and Gene Expression, New Port, RI (June 1995)

- Gordon Conference on Cancer, New London, NH (June 1995)

- Annual Meeting of the EndocrineSociety, Stevenson, WA (July 1995)

- Gordon Conference on Mammary Gland Biology, Newport, RI (August 1995)

- New England Medical Center, Boston, MA (August 1995)

- University of Copenhagen, Copenhagen, Denmark (August 1995)

- Annual Meeting of the Society of Developmental Biology, San Diego, CA (August 1995)

- Canji, Inc., San Diego, CA (September 1995)

- Workshop on Molecular Mechanisms Involved in Epithelial Cell Differentiation, Fundacion March, Madrid, Spain (October 1995)

- Genentech, Inc., San Francisco, CA (October 1995)

- Geneva Sayre Lecture, Russell Sage College, Troy, NY (October 1995)

- Universtiy of Alabama, Center for ECM Biology, Inaugral Seminar, Birmingham, Alabama (October 1995)

- Cell Biology Distinguished Lecture, Baylor Collegeof Medicine, Houston, TX (November 1995)

- Northwestern University Medical School, Chicago, IL (November 1995)

- Cutaneous Biology Research Center, Charleston, MA (November 1995) 
- Bay Area Scientific Mini-symposium, Clonetech,Palo Alto, CA (November 1995)

- Brown University, Providence, RI (December 1995)

- Women in Cell Biology Luncheon, 1995 American Society for Cell Biology Annual Meeting, Washington, D.C. (December 1995).

- Oregon Hills Science University, Portland, OR (February 1996)

Thomas F. Budinger

- Member, National Academy of Engineering

- 17th Annual Georg Charles de Hevesy Nuclear Medicine Pioneer Award issued by The Society of Nuclear Medicine

- Board of Trustees, Society of Nuclear Medicine

- Elected Fellow of the American Institute of Biomedical Engineering;

- Scientific Advisory Committee, Whitaker Foundation

\section{Judith Carnpisi}

- Member, Scientific Advisory Board, Alliance for Aging Research

- Board of Scientific Counselors, National Institute on Aging

- MERTT Award, National Institute on Aging

Editorial Boards:

- Molecular Biology Reports

- Journal of Cellular Physiology

- Experimental Cell Research

- Journal of Gerontology
Aloke Chatterjee

- Councilor (Physics), Radiation Research Society

- Member, Program Committee, Radiation Research Society

\section{Priscilla Cooper}

- Local organizer, Bay Area DNA Repair Discussions (BARDs) annual meeting, October 1995

- NRC Workshop participant, "New Approaches to a Biologically-Based Risk Model for Low-Dose/Low Dose-Rate, High LET Radiations", National Academy of Sciences, January 1996

- NIH DRG, Ad hoc reviewer Chemical Pathology Study Section, March 1996

- NCI Seattle Project Workshop discussion group leader, "Damage Response Pathways", Fred Hutchinson Cancer Research Center, March 1996

- Steering Committee member, NCI Seattle Project, Working Group on Damage Response Defects, April 1996

- Associate Editor, Radiation Research, 1996 - 2000

\section{Thomas Earnest}

- International Conference on Biophysics and Synchrotron Radiation, Grenoble, France, August, 1995

- International Workshop, Fukuyama, Japan, Novemberm 1995

- International Conference on the Crystallization of Biological Macromolecules, Hiroshima, Japan, November, 1995

- NIH Workshop on Synchrotron User Access Issues, Rockville, February, 1996

- UCLA course on Accelerator Physics, UCLA, January, 1996. "Design of Synchrotron Beamlines for Biological Crystallography" 
Robert M. Glaeser

- Elizabeth Roberts Cole Award, Biophysical Society

- Associate Editor, Journal of Structural Biology

Lois Swirsky Gold

- Member, Society of Toxicology

- Board Member, Harvard Center for Risk Analysis, Harvard Risk Management Reform Group

- Member, Editorial Board, Regulatory Toxicology and Pharmacology

Joe Gray

- President; International Society for Analytical Cytology, 1996-1998.

- Professor of Laboratory Medicine and Radiation Oncology; University of California, San Francisco

- Interim Director; UCSF Cancer Center

- Genetics Program Leader; UCSF Cancer Center.

- Chair; Externl Adcisory Comittee: National Flow Cytometry Resource (Los Alamos $\mathrm{N}$ a t i o $\mathrm{n}$ a 1 Laboratory)

Editorial boards:

- Cancer Research,

- Chromosome Research,

- Analytical Cellular Pathology

- Bioimaging

Invited lectures at major meetings in 1995-1996:

- Radiation Therapy Oncology Group Annual Meeting, San Francisco, California

- International Workshop for Biological Applications of Molecular Cytogenetics, Hilton Head Island, South Carolina
- Today and Tomorrow Symposium, Hiroshima, Japan

- Nakamura Lectureship: Scripps Clinic and Research Foundation, La Jolla, California

- Laboratory Medicine '95: 11th IFCC European Congress of Clinical Chemistry, Tampere, Finland

- Cancer Gordon Research Conference, Newport, Rhode Island

- Japan Dermatological Society in Morioka, Morioka Iwate, Japan

- AACR Special Conference: Cancer the Interface Between Basic \& Applied Research, Baltimore, Maryland

- Princess Takamatsu Symposium: Genetic Instability and Carcinogenesis, Tokyo, Japan

- Keystone Symposium, Breast and Prostate Cancer, Taos, New Mexico

Bing Jap

- Member, NIH Biophysical Study Section

Sung-Hou Kim

- HoAm Prize, The Samsung Foundation, Seoul, Korea

- Fellow, The American Academy of Arts and Sciences

- Member, The National Academy of Sciences

- Member, Editorial Board, Nucleic Acids Research

- Steering Committee, Structural Biology Synchrotron Users Organization

- Scientific Advisory Committee of the Cancer Research Fund of the Damon Runyon-Walter Winchell Foundation

- Member, Advisory Committee, National Science Foundation of Korea 
- Board of Scientific Councilors, National Center for Biotechnology Information, National Institutes of Health.

- Advisory Board, Molecules and Cells, Seoul, Korea

- Miller Research Professor, University of California, Berkeley (1996-97)

- Scientific Review Board, Howard Hughes Medical Institute Societies:

- American Society for Biochemistry and Molecular Biology

- American Chemical Society

- Biophysical Society

- American Crystallographic Association

- American Association for the Advancement of Science

- Korean Scientists and Engineers in America

- The Protein Society

Melvin P. Klein

- Chair, Advisory Committee to the Pittsburgh NMR Center for Biomedical Research, Carnegie-Mellon University and University of Pittsburgh

- Charter Council Member, International EPR Society

- Member, Advisory Committee, Biotechnology Research Resource, SSRL

- Member, Executive Committee, Users Organization, Advanced Light Source, LBNL

- Member, Advisory Committee,BioCAT, Advanced Photon Source, Argonne National Laboratory

\section{Ronald M. Krauss}

- Chair, Nominating Committee, Council on Arteriosclerosis, American Heart Association
- Member, Executive Committee, Council on Arteriosclerosis, American Heart Association

- Member, Nutrition Committee, American Heart Association

- Member, Data and Safety Monitoring Committee, Postmenopausal Estrogen-Progestin Intervention Study, NHLBI, NIH

Society Membership:

- American Association for the Advancement of Science

- American College of Physicians

- American Diabetes Association

- American Federation for Clinical Research

- American Heart Association

- American Institute of Nutrition

- American Society of Clinical Investigation

- American Society for Clinical Nutrition

- American Society for Human Genetics

- Federation of American Societies for Experimental Biology

Editorial Boards:

- Current Opinion in Lipidology (Section Editor)

- Current Opinion in Endocrinology and Metabolism (Section Editor)

- Journal of Lipid Research

- Menopausal Medicine

- Coronary Artery Disease: Index \& Reviews

- Endocrinology and Metabolism

Invited Lectures:

- LA Heart Association Review, Los Angeles, CA, January, 1995 
- AHA Representative, Hearings on U.S. Dietary Guidelines, San Francisco, CA, January, 1995

- Seminars in Medicine, Beth Israel Hospital, Boston, MA, February, 1995

- UCB-UCSF Joint Medical Program, Biochemical Correlates Course, Berkeley, CA, February, 1995

- UCSF Symposium, "Advances in Endocrinology and Metabolism," San Francisco, CA, March, 1995

- Plenary Lecture, 27th Annual Meeting of the Japan Atherosclerosis Society, Nagoya, Japan, March, 1995

- Children's Hospital Oakland, Oakland, CA, April 1995

- Symposium, "Dose and Formulation of Estrogen Therapy for the Prevention and Treatment of Postmenopausal Disease," Chicago, IL, April, 1995

- Symposium, Scientific Conference on the Efficacy of Hypocholesterolemic Dietary Interventions, San Antonio, TX, May, 1995 (Program Committee)

- National Live Stock \& Meat Board Symposium, Chicago, IL, May, 1995

- Plenary Lecture, The 21st Maine Biological and Medical Sciences Symposium, Mount Desert Island, ME, June, 1995

- Ninth Annual Symposium on the Long Term Effects of Estrogen Deprivation, Aspen, CO, July, 1995

- American College of Nutrition 36th Annual Meeting, Washington, DC, October, 1995

- AHA Conference on Hormonal, Metabolic and Cellular Influences on Cardiovascular Disease in Women, San Diego, CA, October, 1995

- American Dietetic Association 78th Annual Meeting, Chicago, IL, October, 1995

- XIIth International Symposium on Drugs Affecting Lipid Metabolism, Houston, TX, November, 1995

- Annual Clinical Lipidology Update, American Heart Association 68th Scientific Sessions, Anaheim, CA, November, 1995

- American Heart Association 68th Scientific Sessions,
Anaheim, CA, November, 1995

- DoxazosinInvestigatorsand Consultants Educational Exchange, Anaheim, CA, November, 1995

- Plenary Lecture, Norman Sharrer Symposium, Visalia, CA, November, 1995

- 1995 International Conference on the Diets of Asia, Oldways Preservation \& Exchange Trust, San Francisco, CA, December, 1995

- Roche Molecular Systems, Alameda, CA, December, 1995

- Coronary Heart Disease \& Atherosclerosis: A Preventable Condition, West Palm Beach, FL, Feb., 1996

Steven Lockett

- Invited Lecture: Iberian Society for Cytometry

Narla Mohandas

- Member, Editorial Board, Blood

- Member, Editorial Board, Blood Cells

- Member, Hematology Study Section, Division of Research Grants, NIH

- Member, Subcommittee on Red Cell and Hemoglobin, American Society of Hematology

Victor Markowitz

Invited Talks:

- "Data Management Tools for Genomic Applications", 2nd Conference on the Human GenomeProject: Commercial Implications, March 1995

- "Object-Oriented Interfaces for Genome Databases"

- 4th International Bioinformatics and Genome Research Conference, June 1995 
- "Coping with Data Modeling Diversity," CODATA Meeting on Biomolecular Databases, June 1995

- "OPM Data Management Tools" SmithKline Beecham, October 1995, Sequana, March 1996, Merck, March 1996

- "Exploring Heterogeneous Molecular Biology Databases in the Context of the Object-Protocol Model" International Symposium on Theoretical and Computational Genome Research, Heidelberg, Germany, March 1996

- "An Overview of OPM and OPM Data Management Tools", Workshop on Structuring Biological Information: Supplier and User Perspectives, Heidelberg, Germany, March 1996

Program Committees:

- 1995 SIGMOD Conference

- 1995 MIMBD Conference, Program Chair

\section{Maria Pallavicini}

- Councilor, International Society for Analytical Cytology (ISAC)

- Editorial Board, Cytometry

- Co-chair Scientific Program, Congress of the ISAC

- Member, Constitutional Committee, ISAC

- Member, Experimental Therapeutics Study Section, NIH

- Ad Hoc, Program Project Review NIH

Dan Pinkel

- Professor of Laboratory Medicine and Radiation Oncology, University of California San Francisco

- Acadennic Associate, Nichols Corning Institute

- Scientific Advisory Board (pending) Vysis Inc
Editorial boards:

- Cytogenetics and Cell Genetics, Cytometry

Invited Lectures:

- Washington University, St. Louis, MO, January 12, 1995

- International Workshop on Solid Tumors. Tucson AZ , Feb 19-21, 1995

- International Workshop for Biological Applications of Molecular Cytogenetics. Hilton Head SC , April 18-21, 1995

- Institut Gustave Roussy, Paris France, May 4, 1995

- French Cytometry Association: Fluorescence in situ Hybridization and Numerical Imaging. Paris, France May 5, 1995

- Molecular Biology Society of Japan, principal symposium speaker "New trends in genome exploring technologies". Nagoya Japan, December 6-9, 1995

- European Conference on Comparative Genomic Hybridization. Keynote Speaker. Semmering Austria, February 29 - March 2, 1996

- American College of Surgeons, October 8, 1996

Edward M. Rubin

- American Journal of Human Genetics, Ad hoc Reviewer

- Human Genetics, Ad hoc Reviewer

- Journal of Clinical Investigation, Ad hoc Reviewer

- Nature, Ad hoc Reviewer

- Science, Ad hoc Reviewer

- American Heart Association ScientificSessions Programs, Abstract Grader

- Nature Genetics, Ad hoc Reviewer

Meetings and Workshops:

- Red Cell Gordon Conference, Session Chairperson 
(1995)

- Session Chairperson of 1996 Science Biomedicine Conference and Plenary Session

- Genomics--Its Impact on Medicine, MAF Conference Organizer, Session Chair

Invited Lectures:

1995-International

- Genomic studies of $L p(a)$, European Lipoprotein Club Munich, Germany

- Molecular studies of HDL and Lp(a) in mice, International Symposia on the Genetics of Lipoprotein Metabolism; Lipoprotein Disorders in Atherosclerosis, Münster, Germany

- Keynote Address, Genomic and genetic studies of $\mathrm{Lp}(\mathrm{a})$ in mice, VIth Biolipid Shiraham Conference, Atami, Japan

- Genomic studies: Use of the mouse, MAF, Courcheval, France

- Keynote Address, Heart disease of mouse and man, International Society of Kidney Disease, Madrid, Spain

- Studies of cardiovascular disorders in mice, European Lipid Club, Munich, Germany

1996-International

- Plenary Address, Genomics and cardiovascular diseases, ANZA, Melbourne, Australia

- Prospecting for genes in $\mathbf{1 . 2} \mathrm{mb}$ of human genomic sequence, HUGO meeting, Heidelberg, Germany

- The mouse as a tool in genomics, March Atherosclerosis Forum, Megeve, France

1995-National

- Session Chair, Alpha-thalassemia Knockout Mice, Gordon Conference on Red Cells, Plymouth, NH

- Genomic approaches to cardiovascular diseases, National Institute of Heart, Lung and Blood, Bethesda, MD
- Genomic and genetic approaches to atherosclerosis, Cleveland Clinic, Department of Cell Biology, Cleveland, $\mathrm{OH}$

- Genes as the basis of heart disease, Department of Genetics,University of Michigan, Ann Arbor, MI

- Genetic studies of Lp(a) in mice, International Symposia on Endothelial Derived Factors and Vascular Protection, San Francisco, CA

- Genes at the heart of lipoprotein metabolism, Department of Genetics, University of Chicago, Chicago, IL

- Studies of lipoprotein in genetically engineered mice, DALM Conference Lipid Metabolism, Houston, TX

- Genomic studies in mice, Department of Statistics, University of California Berkeley, Berkeley, CA

1996-National

- Genetic approaches to lipoprotein disorder, Keystone Symposia, Keystone, $\mathrm{CO}$

- Prospecting genome databases for genes ,Laboratory Medicine Ground Rounds, University of CA San Francisco, San Francisco, CA

- Plenary Address, Prospecting for genes through the analysis of genomic databases, Science Biomedicine Conference, Washington, DC

- Prospecting the genome for genes, Beth Israel Hospital/Harvard, Boston, MA

- Use of the mouse as a tool in genomics, Department of Genetics, Baylor College of Medicine, Houston, TX

- The genetics of lipoprotein disorders, AHA Conference on Atherosclerosis, Thrombosis, and Vascular Biology, Salt Lake City, Utah; Lawrence Berkeley National Laboratory, Berkeley, CA

Peter G. Schultz

- Member, Editorial Advisory Board, Biocatalysis

- Member, Editorial Advisory Board, Bioconjugates

- Member, Honorary Advisory Board, Synlett 
- Member, Editorial Advisory Board, Accounts ofChemical Research, American Chemical Society

- Board of Consulting Editors, Bioorganic and Medicinal Chemistry

- Editorial Board, Perspectives in Drug Discovery and Design

- Editorial Board, Chemistry and Biology

- Editorial Advisory Board, Protein Science

- Editorilal Advisory Board, Molecular Medicine

- Chairman, Scientific Advisory Board, Affymax Research Institute

- Scientific Advisory Board, CV Therapeutics

- Advisory Board, Table Ronde Roussel UCLAF

- Advisory Board, Searle Scholars Program

Martha Stampfer

- Editorial Board, Cancer Research

Damir Sudar

- Invited Lecture: International Society for Analytical Cytometry, Rimini, Italy

Ignacio Tinoco

- 1996 Elisabeth Roberts Cole Award, Biophysical Society, "For broad-ranging, fundamental contributions to the molecular biophysics of nucleic acids."

Invited Lectures:

- January 15-21, 1995 - "Structural Elements in a Hairpin Ribozyme", Keystone Symposium on "Ribozymes: Basic Science and Therapeutic Applications", Breckenridge, $\mathrm{CO}$.
- February 12-16, 1995 - "Structural Elements in a Hairpin Ribozyme", 39th annual meeting of the Biophysical Society, San Francisco.

- August 20-25, 1995, "Structures and Frameshifting Efficiencies of RNA Pseudoknots", Frontiers in Biophysical Chemistry Symposium, 210th National American Chemical Society Meeting, Chicago, IL

- October 18-21, 1995, "Structural Elements of Ribozymes", At the Crossroads of Chemistry and Biology Symposium, Western Biotech Conference and 31st Western Regional ACS Meeting, San Diego, CA

- November 11-15, 1995, "RNA Structural Elements and Ribozymes", Mathematics and Molecular Biology IV, Santa Fe, NM

- February 17-21,1996, "Frameshifts, Retroviruses and Pseudoknots", Awards Symposium, 40th Biophysical Society Meeting, Baltimore, MD

Editorial Boards:

- Biopolymers, 1963 - present

- Biochemistry, 1973 - 1977; 1988 - present

- Biophysical Chemistry, 1975 - present

- Nucleic Acids Research, 1988 - present

- RNA, 1994 - present

- Journal of Molecular Biology, 1995-present

Henry VanBrocklin

- Ninth Annual Award for the Most Outstanding Scientific Poster 19th Western Regional Meeting of The Society of Nuclear Medicine

\section{Heinz-Ulrich Weier}

- Member, Executive Committee,UCSystemwide Biotechnology Research and Education Program

Invited Lectures: 
- American Society of Human Genetics, 45th Annual Meeting, Minneapolis, MN, Oct 24-28, 1995

- Genomic Analyses using Quantitative DNA Fiber Mapping (QDFM). Third Int. Conf. on Automation in Mapping and DNA Sequencing, Berkeley,CA, Nov 5-8, 1995

- DOE Contractor - Grantee Workshop V, DOE Human Genome Program, Santa Fe, New Mexico, Jan 28-Feb 1, 1996

- HGM'96, Heidelberg, Germany, March 22-24, 1996

\section{David Wemmer}

- Professor, Dept of Chemistry, University of California Berkeley 1992-present

- Assistant Dean, College of Chemistry, University of California Berkeley, 1992-96

- Director, National Tritium Labelling Facility (NIH Research Resource) 1990-present

- Member, NIH BBCA Study Section, 1993-97

- Member, Chancellor's Advisory Council on Biology, 1995-99

- Associate Editor, Biopolymers, 1990-present

- Editorial Boards of Concepts in Magnetic Resonance, 1989-94

- Macromolecular Structures (Current Biology), 1990present

- Journal of Biomolecular NMR 1990-present

- Journal of Magnetic Resonance 1992-present

- Journal of Structural Biology 1993-present

- Annual Reviews of Biophysics and Biomolecular Structure 1993-present

Advisory Committees:

- DOEHERAC Subcommittee, 1995 (Applications of Genome and Structural Biology Technologies to the OHER Mission)

- Advisory Committee, UCSF Molecular Graphics
Laboratory NIH Resource, 1995-present

- Advisory Committee, Stable Isotope Facility, Los Alamos National Lab, 1996

- H.C.Brown Lecturer, Purdue University, 1995

Other Invited lectures:

- Design and Characterization of Sequence Specific DNA Binding Ligands, NACON III, Sheffield UK, April 1995

- Structural Characterization of Chemically Modified DNA, NMR in Molecular Biology, Keystone, Apr 1995

- NMR Structural Studies of Modified DNAs, Workshop Magnetic Resonance and the Environment, PNL, Richland WA, April 1995

- Design and Characterization of Sequence Specific DNA Ligands, 36th Annual Buffalo Medicinal Chemistry Meeting, Buffalo NY, May 1995

- Design and Characterization of New Sequence Specific DNA Ligands, Western Biotech Conference, San Diego CA, October 1995

- PrP peptide structure determination with solid state NMR, Cold Spring Harbor Banbury Meeting, CSH NY, November 1995

- Solid State NMR as a Structural Tool, Protein Structure: Implications for Aging Brain Functions, Sattelite of the 25th Annual Meeting of the Society of Neuroscience, San Diego, CA, November 1995

- Characterization of Transcription Factors by Protein Dissection and NMR, 5th International Chemistry Conference, Hsin-chu, Taiwan, December 1995 


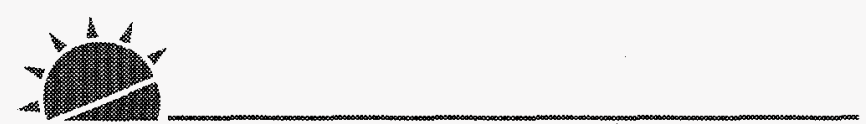

\subsection{OHER-Supported Publications}

\section{Analytical Technology}

Blankespoor, S.C., Derenzo, S.E., Moses, W.W., and Rossington, C.S. (1994) Characterization of a Pulsed XRay Source for Fluorescent Lifetime Measurements, IEEE Trans. Nucl. Sci., Vol. 41, No. 4, pp. 698 - 702.

Derhacobian, N., Fine, P., Walton, J.T., Wong, Y.K., Rossington, C.S., and Luke, P.N. (1994) Determination of Surface Recombination Velocity and Bulk Lifetime in Detector Grade Silicon and Germanium Crystals, IEEE Trans. Nucl. Sci., Vol. 41, No. 4, pp. 1026-1030, LBL-34022.

Derhacobian, N., Walton, J.T., Luke, P.N., Wong, Y.K., and Rossington, C.S. (1994) Proper Interpretation of Photoconductive Decay Transients in Semiconductors Having Finite Surface Recombination Velocity, J. Appl. Phys., Oct. 15.

Ludewigt, B., Jaklevic, J., Kipnis, I., Rossington, C., and Spieler, H. (1994) A High Rate, Low Noise X-Ray Silicon Strip Detector System, IEEE Trans. Nucl. Sci, Vol. 41, No. 4, pp. 1037-1041, LBL-34060.

Luke, P.N. (1995) Electrode Configuration and Energy Resolution in Gamma-Ray Detectors, presented at the 9th International Workshop on Room Temperature Semiconductor X and Gamma Ray Detectors, Associated Electronics and Applications, Grenoble, France, Sept. 18-22, 1995, to be published in Nucl. Inst. and Meth.

Luke, P.N. (1995), Unipolar Charge Sensing with Coplanar Electrodes - Application to Semiconductor Detectors, IEEE Trans. Nucl. Sci, Vol. 42, No. 4, p. 207.

Luke, P.N. and Eissler, E. E. (1995) Performance of CdZnTe Coplanar-Grid Gamma-Ray Detectors, presented at the IEEE Nuclear Science Symposium, San Francisco, Oct. 21-28, 1995, to be published in IEEE Trans. Nucl. Sci. 
Luke, P.N., Rossington, C.S., and Wesela, M.F. (1994) Low Energy X-Ray Response of Ge Detectors with Amorphous Ge Entrance Contacts, IEEE Trans. Nucl. Sci., Vol. 41, No. 4, pp.1074-1079, LBL-33980.

Rossington, C. S., Madden, N.W., and Chapman, K. (1994) High Energy Resolution X-Ray Spectrometer for High Count Rate XRF Applications, Advances in X-Ray Analysis, (J. Gilfrich, et al. eds.), Plenum Press, New York, Vol. 37, pp. 405-412.

Walton, J.T., Krieger, B., Krofcheck, D., O'Donnell, R., Odyniec, G., Partlan, M. and Wang, N.W. (1995) P-type Silicon Drift Detectors, presented at the $7^{\text {th }}$ European Conference on Semiconductor Radiation Detectors, Schloss Emau, Germany, May 7-10, 1995, to be published in Nucl. Inst. and Meth.

Wang, N.W., Krieger, B., Krofcheck, D., Lewak, D., O'Donnell, R., Odyniec, G., Partlan, M., Rudolph, H.W., Walton, J.T., and Wilson, W.K. (1995) P-type Silicon Drift Detectors: First Results, IEEE Trans. Nucl. Sc., Vol. 42, No. 4, p. 214.

Yu, K.M., Moll, A.J., Walukiewicz, W., Derhacobian, N., and Rossington, C. (1994) Amphoteric Substitutionality and Lattice Distortion of Ge in InP, Appl. Phys. Lett., Vol. 64, No. 12, pp. 1543-1545, LBL-34723.

\section{Health Effects}

Ames, B.N., and Gold, L.S. (1996) The causes and prevention of cancer: Gaining perspectives on management of risk, in Improving Risk Management: From Science to Policy (R. W. Hahn,ed.), Oxford University Press, pp. 445.

Ames, B.N., and Gold, L.S. (1995) The causes and prevention of cancer: The role of environment, in The True State of the Planet (R. Bailey, ed.), Washington, DC, Free Press, pp. 141-175.

Ames, B.N., and Gold, L.S. (1996) Cell division and DNA lesions are key factors in mutagenesis, carcinogenesis, and cancer prevention, in Encyclopedia of Cancer (Joseph R. Bertino, ed.), Orlando: Academic Press, Inc., in press.

Ames, B.N., and Gold, L.S. (1996) The prevention of cancer, Environ. Health Perspect., in press.

Ames, B.N., and Gold, L.S. (1996) Reply to Farber (Letter to Editor): Cell division and cancer causation, Cancer Research, in press.
Ames, B.N., and Gold, L.S. (1996) The rodent high-dose cancer test is limited at best: When cell division is ignored, then risk assessment will be flawed, BELLE Newsletter, in press.

Ames, B.N., Gold, L.S., and Willett, W.C. (1995) The causes and prevention of cancer, in Istituto della Enciclopedia Italiana: Enciclopedia del Novecento.

Ames, B.N., Gold, L.S., and Willett, W.C. (1995) The causes and prevention of cancer, Proc. Natl. Acad. Sci. USA, Vol. 92, pp. 5258-5265.

Ashkenas, J., Damsky, C.H., Bissell, M.J., and Werb, Z. (1994) Integrins, signaling, and the remodeling of the extracellular matrix, The Integrins (D. Cheresh and $R$. Mecham, eds.) Academic Press, pp 79-109.

Bissell, M.J., and Werb, Z. (1995) Eds. Basic science aspects of breast cancer, Seminars in Cancer Biology, Vol. 6, pp. 117-118.

Blaschke, R.J., Howlett, A.R., Desprez, P.Y., Petersen, O.W., and Bissell, M.J. (1994) Cell differentiation by extracellular matrix components, to be published in Extracellular Matrix Components: Methods in Enzymology (E. Ruoslahti and E. Engvall, volume eds.) Academic Press, Vol. 245, pp. 535-569.

Boudreau, N., Myers, C., and Bissell, M.J. (1995) From laminin to lamin: regulation of tissue-specific gene expression by the ECM, Trends in Cell Biology, Vol.5, pp. 14.

Boudreau, N., Reddy, S.T., Stoker, A.W., Fairman, C., and Bissell, M.J. (1996) The embryonic environment and the extracellular matrix suppress oncogenic transformation by Rous sarcoma virus in the chick embryo, Molecular and Cellular Differentiation, Vol. 3, pp. 261-274.

Boudreau, N., Sympson, C.J., Werb, Z., and Bissell, M.J. (1995) Suppression of ICE and apoptosis in mammary epithelial cells by extracellular matrix, Science, Vol. 267, pp. 891-893.

Boudreau, N., Werb, Z., and Bissell, M.J. (1996) Suppression of apoptosis by basement membrane requires threedimensional tissue organization and withdrawal from the cell cycle, Proc. Natl Academey of Sciences, in press.

Chasis, J.A., Coulombel, L., McGee, S., Lee, G., Tchernia, G., Conboy, J., and Mohandas, N. (1996) Differential utilization of Protein 4.1 translational initiation sites during erythropoiesis: Implications for a mutation in- 
duced stage-specific deficiency of Protein 4.1 during erythroid development, Blood, in press .

Chen, H., Weaver, V.M., Petersen, O.W., and Bissell, M.J. (1996) Extracellular matrix as a central regulation of function, growth and programmed cell death in breast cells of both mice and men: Implications for therapy, Proc. of the Pexcoller Foundation, in press.

Cooper, P.K., and Leadon, S. A. (1994) Defective Repair of Ionizing Radiation Damage in Cockayne's Syndrome and Xeroderma Pigmentosum Group G., Ann. New York Acad. Sci., Vol. 726, pp. 330-332

Cooper, P.K., and Leadon, S.A. (1996) Defects in Transcription-Coupled Repair of Ionizing Radiation-Induced DNA Base Damage in RadiosensitiveXP-Gand Cockayne Syndrome Human Cells, in Radiation Research 18951995, Proceedings of the X International Congress of Radiation Research, in press.

Cynober, Tr., Mohandas, N., and Tchernia, G. (1996) Red Cell abnormalities in Hereditary Spherocytosis - Relevance to diagnosis and for understanding the variable expression of clinical severity, J Lab Clin Med, in press.

Dairkee, S.H., Deng, G., Stampfer, M.R., Waldman, F.M., Smith, H.S. (1995) Selective Cell Culture of Primary Breast Carcinoma, Cancer Res., Vol. 55, pp. 2516-1519.

Desprez, P.Y., Hara, E., Bissell, M.J., and Campisi, J. (1995) Suppression of mammary epithelial cell differentiation by the Helix-Loop-Helix Protein, Id-1, Molecular Cell Biology, Vol. 15, pp. 3398-3404.

Discher, D.E., Winardi, R., Schischmanoff, P.O., Parra, M., Conboy, J.G., and Mohandas, N. (1995) Mechanochemistry of Protein 4.1's Spectrin-Actin Binding Domain: Ternary ComplexInteractions, Membrane Binding, Network Integration, Structural Strengthening, $J$ Cell Biology, Vol. 130, pp. 897-907.

Edman, C.F., George, S.E., Means, A.R., Schulman, H., and Yaswen, P. (1994) Selective activation and inhibition of calmodulin dependent enzymes by a calmodulinlike protein found in human epithelial cells, Eur. J. Biochem., Vol. 226, pp. 725-730.

Freedman, D., Gold, L.S., and Lin, T. (1996) Concordance between rats and mice in bioassays for carcinogenesis, Reg. Tox. Pharmacol., in press.

Frittitta, L., Vigneri, R., Stampfer, M.R., and Goldfine, I.D. (1995) Insulin receptor overexpression in 184B5 human mammary epithelial cells induces a ligand-dependent transformed phenotype, J. Cell. Biochem., Vol. 57, pp. 666-669.

Gallagher, P.G., Weed, S.A., Tse, W.T., Morrow, J.S., Marchesi, S.L., Mohandas, N., and Forget, B.G. (1995) Recurrent fatal hydrops fetalis associated with an amino acid substitution in the $C$-terminus of erythrocyte $b$ Spectrin, J. Clin. Invest., Vol. 95, pp. 1174-1182.

Gaylor, D.W., and Gold, L.S. (1995) Quick estimate of the regulatory virtually safe dose based on the maximum tolerated dose for rodent bioassays, Reg. Toxicol. Pharmacol., Vol. 22, pp. 57-63.

Gold, L.S., Manley, N.B., Slone, T.H., Garfinkel, G.B., Ames, B.N., Rohrbach, L., Stern, B.R., and Chow, K. (1995) Sixth plot of the Carcinogenic Potency Database: Results of animal bioassays published in the general literature 1989-1990 and by the National Toxicology Program 1990-1993, Environ. Health Perspect., Vol. 103, Suppl. 8, pp. 3-122.

Gold, L.S., and Slone, T.H. (1995) The mouse liver in perspective: Comparison of target organs of carcinogenicity for mutagens and nonmutagens in chronic bioassays, in Fifth Workshop on Mouse Liver Tumors: Summary Report, Washington, DC: International Life Sciences Institute, pp. 2-3.

Gold, L.S., Slone, T.H., and Ames, B.N. (1996) Prioritization of possible carcinogenic hazards in food, in Food Chemical Risk Analysis (David Tennant, ed.), London: Chapman and Hall, in press.

Guthridge,C.J., Stampfer, M.R., Clark, M.A., and Steiner, M.R. (1994) Characterization and comparison of phospholipase A2 in ras-transformed and immortalized human mammary epithelial cells, Cancer Lett., Vol. 86, pp. 11-21.

Hara, E., AkifUzman,J.,Dimri, G.P.,Nehlin, J.O., Testori, A. and Campisi, J. (1996) The Helix-Loop-Helix Protein Id-1 and a Retinoblastoma Protein Binding Mutant of SV40 T Antigen Synergize to Reactivate DNA Synthesis in Senescent Human Fibroblasts, Developmental Genetics, Vol. 18, pp. 161-172.

Harris, E., Yaswen, P., and Thorner J. (1995) Gain-offunction mutations in a human calmodulin-like protein identify residues critical for calmodulin action in yeast, Mol. Gen. Genetics, Vol. 247, pp. 137-147.

Hemming, N.J., Anstee, D.J., Staricoff, M.A., Tanner, 
M.J.A., and Mohandas, N. (1995) Identification of the Membrane Attachment Sites for Protein 4.1 in the Human Erythrocyte, J Biol Chem., Vol. 270, pp. 5360-5366.

Henle, E.S., Roots, R., Holley, W.R., and Chatterjee, A. (1995) DNA Strand Breakage is Correlated with Unaltered Base Release after Gamma Irradiation, Rad. Res., Vol. 143, pp. 144-150.

Howlett, A.R., Bailey, N., Damsky, C., Petersen, O.W., and Bissell, M.J. (1995) Cellular growth and survival are mediated by B-1 integrins in normal human breast epithelium but not in breast carcinoma, Journal of Cell Science, Vol. 108, pp. 1945-1957.

Howlett, A.R., Petersen, O.W., Steeg, P.S., and Bissell, M.J. (1994) A novel function for nm23: overexpression in human breast carcinoma cells leads to the formation of basement membrane and growth arrest, Journal of the National Cancer Institute, Vol. 86, pp.1838-1844.

Imam, S.A., Stampfer, M.R., Yilmaz, A., and Taylor, C.R. (1994) Identification of a cell-surface glycoprotein associated with normal mammary and extramammary epithelial cells, Br. J. Cancer, Vol. 69, pp. 439-444.

Jones, P.L., Boudreau, N., Meyers, C.A., Erickston, H.P., and Bissell, M.J. (1995) A novel function for tenascin: transcriptional regulation of beta-casein gene expression, Journal of Cell Science, Vol. 108, pp. 519-527.

Leadon, S.A., and Cooper, P.K. (1996) TranscriptionCoupled Repair of Radiation Damage in Human Cells, in Radiation Research 1895-1995, Proceedings of the $\mathrm{X}$ International Congress of Radiation Research, in press.

Lelievre, S., Weaver, V.M., and Bissell, M.J. (1996) Extracellular matrix signalling from the cellular membrane skeleton to the nuclear skeleton: A model of gene regulation, Recent Progress in Hormone Research, in press.

Lew, V.L., Raftos, J.E., Sorette, M., Bookchin, R.M., and Mohandas. N. (1995) Generation of normal human red cell volume, hemoglobin content and membrane area distributions, by "birth" or regulation? Blood, Vol. 86, pp. 334-341.

Lin, C.Q., Dempsey, P., Coffey, C., and Bissell, M.J. (1995) Extracellular matrix regulates whey acidic protein gene expression by suppression of TGF-a in mouse mammary epithelial cells: studies in culture and in transgenic mice, Journal of Cell Biology, Vol. 129, No. 4, pp. 1115-1126.
Lin, T., Gold, L.S., and Freedman, D. (1996) Bias in qualitative measures of concordance for rodent carcinogenicity tests, Statistical Science, in press.

Löbrich, M., Rydberg, B., and Cooper, P.K. (1996) Assays for Determining Double-Strand Break Induction and Rejoining Quality in Specific Genomic Locations, in Radiation Research 1895-1995, Proceedings of the XInternational Congress of Radiation Research, in press.

Löbrich, M., Rydberg, B., and Cooper, P.K. (1994) DNA Double-Strand Breaks Induced by High-Energy Ne and Fe Ions in Human Fibroblasts. II. Probing Individual NotI Fragments by Hybridization, Radiat. Res., Vol. 139, pp. 142-151.

Löbrich, M., Rydberg, B., and Cooper, P.K. (1996) Random-Breakage Mapping Method Applied to Human DNA Sequences, Nucl. Acids Res.,in press.

Löbrich, M., Rydberg, B., and Cooper, P.K. (1995) Repair of X-Ray-Induced DNA Double-Strand Breaks in Specific Not I Restriction Fragments in Human Fibroblasts: Joining of Correct and Incorrect Ends, Proc. Natl. Acad. Sci. USA, Vol. 92, pp. 12050 12054.

Lochter, A., and Bissell, M.J. (1995) Involvement of extracellular matrix constituents in breast cancer, Seminars in Cancer Biology, Vol. 6, No. 3, pp. 165-174.

Lund, L., Romer, J., Thomasset, N., Solberg, H., Pyke, C., Bissell, M.J., Dano, K., and Werb, Z. (1996) Two distinct phases of apoptosis in mammary gland involution: proteinase-independent and -dependent pathways, Development, in press.

Magowan, C., Coppel, R.S., Lau, A.O.T., Moronne, M.M., Tchernia, G., and Mohandas, N. (1995) Role of the Plasmodium falciparum Mature-Parasite-Infected Erythrocyte Surface Antigen (MESA/PfEMP-2) in Malarial Infection of Erythrocytes, Blood, Vol. 86, pp. 3196-3204.

Manno, S., Takakuwa, Y., Nagao, K., and Mohandas. N. (1995) Modulation of erythrocyte membrane mechanical function by b-spectrin phosphorylation and dephosphorylation, J Biol Chem., Vol. 270, pp. 5659-5665.

Martins-Green, M., and Bissell, M.J. (1995) Cell-ECM interactions in development, Seminars in Developmental Biology, Vol. 6, pp. 149-159.

Martins-Green, M., Boudreau, N., and Bissell M.J. (1994) Inflammation is responsible for the development of wound-induced tumors in chickens infected with rous 
sarcoma virus, Cancer Research, Vol. 54, pp. 4334-4341.

Mathai, J.C., Mori, S., Smith, B.L., Preston, G.M., Mohandas, N., Collins, M., van Zijl, P.C.M., Zeidel, M.L., and Agre, P. (1996) Functional analysis of Aquaporin-1 deficient red cells: the Colton-null phenotype, J Biol Chem., Vol. 271, pp. 1309-1313.

Oldenburg, C., Benson, S., Pruess, K., Daisey, J., Brown, N., Gold, L. S., and Macfarlane, J. (1995) The SELECT environmental remedy selection tool: A platform for T2VOC multiphase transport modeling, AIChE Symposium, Series 91, No. 306, pp. 38-43.

Paszty, C., Mohandas, N., Stevens, M.E., Loring, J.F., Liebhaber, S.A., Brion, C.M., and Rubin, E.M. (1995) Lethal a-thalassemia created by gene targeting in mice and its genetic rescue, Nature Genetics, Vol.11, pp.33-39.

Petersen, O.W., Rønnov-Jessen, L., and Bissell, M.J. (1995) The microenvironment of the breast: The overall roles of the stroma and the extracellular matrix in function and dysfunction, The Breast Journal, Vol. 1, No.1, pp. 22-35.

Rønnov-Jessen, L., Petersen, O.W., and Bissell, M.J. (1996) Cellular changes involved in conversion of normal to malignant breast: The importance of the stromal reaction, Physiological Reviews, in press.

Rønnov-Jessen, L., Petersen, O.W., Kotelianski, V., and Bissell, M.J. (1995) The origin of the myofibroblasts in breast: recapitulation of tumor environment in culture unravels heterogeneity and implicates fibroblasts and vascular smooth muscle cells but not pericytes in conversion, Journal of Clinical Investigation, Vol. 95, pp. 859873.

Roskelley, C.D., Desprez, P.Y., and Bissell, M.J. (1994) Extracellular matrix-dependent, tissue-specific gene expression requires both physical and biochemical signal transduction, Proc. of the National Academy of Science, Vol. 91, pp. 12378-12382.

Roskelley, C.D., Srebrow, A., and Bissell, M.J. (1995) A hierarchy of ECM-mediated signalling regulates tissuespecific gene expression, Current Opinion in Cell Biology, Vol. 7, pp. 736-747.

Rydberg, B. (1996) Clusters of DNA Damage Induced by Ionizing Radiation: Formation of Short DNA Fragments. II. Experimental Detection, Radiat. Res., Vol. 145, pp. 200-209.

Rydberg, B., Holley, W.R., and Chatterjee, A. (1995)
Regionally Multiply Damaged Sites: Theoretical and Experimental Evidence, in Radiation Damage in DNA: Structure/Function Relationships at Early Times, eds. A.F. Fuciarelli and J.D. Zimbrick. (Batelle Press, Columbus), pp. 55-63.

Rydberg, B., Löbrich, M., and Cooper, P.K. (1994) DNA Double-Strand Breaks Induced by High-Energy Ne and Fe Ions in Human Fibroblasts. I. Pulsed Field Gel Electrophoresis Method, Radiat. Res., Vol. 139, pp. 133-141.

Schischmanoff, P.O., Winardi, R., Discher, D.E., Parra, M.K., Bicknese, S.E., Witkowska, H.E., Conboy, J.G., and Mohandas. N. (1995) Defining of the minimal domain of Protein 4.1 involved in Spectrin-Actin binding, J Biol Chem., Vol. 270, pp. 21243-21250.

Schmidhauser, C., Casperson, G.F., and Bissell, M.J. (1994) Transcriptional activation by viral enhancers is critically dependent on extracellular matrix - cell interactions in mammary epithelial cells, Molecular Carcinogenesis, Vol. 10, pp. 66-71.

Shapiro, D.B., Esquerra, R.M., Goldbeck, R.A., Ballas, S.K., Mohandas, N., and Kliger, D.S. (1995) Carbon monoxide religation kinetics to Hemoglobin S polymers following ligand photolysis, J Biol Chem., Vol. 270, pp. 26078-26085.

Shapiro, D.B., Esquerra, R.M., Goldbeck, R.A., Ballas, S.K., Mohandas, N. and Kliger, D.S. (1996) A study of the mechanisms of slow religation to sickle cell hemoglobin polymers following laser photolysis, J Molecular Biology, in press.

Sieweke, M., and Bissell, M.J. (1994) Tumor promoting effect of wounding: a possible role for TGF-b in stromal alterations, Critical Rev. in Oncogen, Vol. 5, No. 2\&3, pp. 297-311.

Slingerland, J.M., Hengst, L., Pan, C-H., Alexander, D., Stampfer, M.R., and Reed, S.I. (1994) A novelinhibitor of cyclin/cdk activity detected in TGF-b arrested cell, Molecular Cell Biology, Vol. 14, pp. 3683-3694.

Stampfer, M.R., and Yaswen, P. (1994) Culture Systems for Study of Human Mammary Epithelial Cell Proliferation, Differentiation and Transformation, Cancer Surveys, Vol. 18, pp. 7-34.

Streuli, C.H., Schmidhauser, C., Bailey, N., Yurchenco, P., Skubitz, A., and Bissell, M.J. (1995) A domain within laminin that mediates tissue-specific gene expression in mammary epithelia, J. Cell Biol., Vol. 120, pp. 253-260. 
Sympson, C.J., Bissell, M.J., and Werb, Z. (1995) Mammary gland tumor formation in transgenic mice overexpressing stromelysin-1, Seminars in Cancer Biology, Vol. 6, pp. 159-163.

Sympson, C.J., Talhouk, R.S., Alexander, C.M., Chin, J.R., Bissell, M.J., and Werb, Z. (1994) Targeted expression of stromelysin to the mouse mammary gland provides evidence for a role of proteinases in branching morphogenesis and the requirement for an intact basement membrane for tissue-specific gene expression, J. of Cell. Biol., Vol. 125, pp. 681-693.

Taylor, I.C.A., Roy, S., Yaswen, P., Stampfer, M.R., and Varmus, H.E. (1995) Mouse mammary tumors express elevated levels of RNA encoding the murine homolog of SKY, a putative receptor tyrosine kinase, J. Biol. Chem., Vol. 270, pp. 6872-6880.

Thompson, E.W., Torri, J., Sabol, M., Sommers, C.L., Byers, S., Paik, S., Martin, G.R., Lippman, M.E., Valverius, E., Stampfer, M.R., and Dickson, R.B. (1994) Oncogeneinduced basement membrane invasiveness in human mammary epithelial cells, Clin. Exp. Metast., Vol. 12, pp. 181-194.

Weaver, V.M., Howlett, A.R., Langston-Weber, B., Petersen, O.W., and Bissell, M.J. (1995) The development of a functionally relevant cell culture model of progressive human breast cancer, Seminars in Cancer Biology, Vol. 6, pp. 175-184.

Werb, Z., Sympson, C.J., Alexander, C.M., Thomasset, N., Lund, L., MacAuley, A., Ashkenas, J., and Bissell, M.J. (1996) Extracellular matrix remodeling and the regulation of epithelial-stromal interactions during differentiation and involution, Kidney International ,In press.

Winardi, R., Discher, D., Kelley, C., Zon, L., Mays, K., Mohandas, N., and Conboy. G. (1995) Evolutionary conserved alternative pre-mRNA splicing regulates structure and function of the spectrin-actin binding domain of erythroid protein 4.1., Blood, Vol. 86, pp. 43154322.

\section{Resource for Molecular Cytogenetics}

Balazs, M., Matsumura, K., Moore, D., Pinkel, D., Gray, J.W., and Waldman, F.M. (1995) Karyotypic heterogeneity and its relation to labeling index in interphase breast tumor cells, Cytometry, Vol. 20, pp.62-73.

Brzoska,P.M., Levin, N.A., Fu, K.K., Kaplan, M.J., Singer, M.I., Gray, J.W., and Christman, M.F. (1995) Frequent novel DNA copy number increase in squamous cell head and neck tumors, Cancer Research, Vol.55, pp.30553059.
Donehower, L.A., Godley, L.A., Aldaz, C.M., Pyle, R., Shi, Y.P.,Pinkel,D., Gray, J., Bradley, A., Medina, D., and Varmus, H.E. (1995) Deficiency of p53 accelerates mammary tumorigenesis in Wnt-1 transgenic mice and promotes chromosomal instability, Genes and Development, Vol. 9, pp. 882-895.

Du Manoir, S., Kallioniemi, O.P., Lichter, P., Piper, J., Benedetti, P.A., Carothers, A.D., Fantes, J.A., GarciaSagredo, J.M., Gerdes, T., Giollant, M., Hemery, B., Isola, J., Maahr, J., Morrison, H., Peery, P., Stark, M., Sudar, D., van Vliet, L.J, Verwoerd, N., and Vrolijk, J. (1995) Hardware and software requirements for quantitative analysis of Comparative Genomic Hybridization, Cytometry, Vol. 19, pp. 4-9.

Feuerstein, B.G., and Mohapatra, G. (1995) Molecular cytogenetic quantitation of gains and losses of genetic material from human gliomas, Journal of Neuro-Oncology, Vol. 24, pp. 47-55.

Goodarzi, M.O., Lee, T.H., Pallavicini, M.G., Donegan, E.A., and Busch, M.P. (1995) Unusual kinetics of white cell clearance in transfused mice, Transfusion, Vol. 35, pp. 145-149.

Gray, J.W., Collins, C., Henderson, I.C., Isola, J., Kallioniemi, A., Kallioniemi, O., Nakamura, H., Pinkel, D., Stokke, T., Tanner, M., and Waldman, F. (1996) Molecular cytogenetics of human breast cancer, Cold Spring Harbor Symposia on Quantitative Biology LIX, in press.

Gray,J.W., Lockett, S., Mascio, L., Mullikin, J., Pinkel, D., Piper, J., Sudar, D., and Thompson, C. (1995) Digital Imaging Microscopy for Molecular Cytogenetics, Proc. Micros. Soc. Am. 52nd Ann. Mtg., G.W. Bailey and A.J. Garratt-Reed, eds., pp. 82-88.

Gray, J.W., Moore, D., Piper, J., and Jensen, R. (1995) Molecular cytogenetic approaches to the development of biomarkers, in Biomarkers and Occupational Health: Progress and Perspective, (Mendelson, M., Peeters, J., Normandy, M., eds.) Joseph Henry Press, pp. 194-215.

Isola, J.J., Kallioniemi, O.P., Chu, L.W., Fuqua, S.A., Hilsenbeck, S.G., Osborne, C.K., and Waldman, F.M. (1995) Genetic aberrations detected by comparative genomic hybridization predict outcome in node-negative breast cancer, American Journal of Pathology, Vol. 147, pp. 905-911.

Iwabuchi, H., Sakamoto, M., Sakunaga, H., Ma, Y.Y., Carcangiu, M.L., Pinkel, D., Yang-Feng, T.L., and Gray, J.W. (1995) Genetic analysis of benign, low-grade, and high-grade ovarian tumors, Cancer Research, Vol. 55, pp. 6172-6180. 
Jossart, G.H., Greulich, K.M., Siperstein, A.E., Duh, Q., Clark, O.H., and Weier, H.-U.G. (1995) Molecular and cytogenetic characterization of a $t(1 ; 10 ; 21)$ translocation in the human papillary thyroid cancer cell line TPC-1 expressing the ret/H4 chimeric transcript, SURGERY, Vol. 118, pp. 1018-1023.

Kallionienni, A., Kallioniemi, O.P., Citro, G., Sauter, G., DeVries, S., Kerschmann, R., Caroll, P., and Waldman, F. (1995) Identification of gains and losses of DNA sequences in primary bladder cancer by comparative genomic hybridization, Genes, Chromosomes and Cancer, Vol. 12, pp. 213-219.

Kim, D.H., Mohapatra, G., Bollen, A., Waldman, F.M., and Feuerstein, BG. (1995) Chromosomal abnormalities in glioblastoma multiforme tumors and glioma cell lines detected by comparative genomic hybridization, International Journal of Cancer, Vol. 60, pp.812-819.

Kuo, W.L., Stafford, D.W., Cruces, J., Gray, J., and Solera, J. (1995) Chromosomal localization of the gammaglutamyl carboxylase gene at 2p12, Genomics, Vol. 25, pp. 746-748.

Levin, N.A., Brzoska, P.M., Warnock, M.L., Gray, J.W., and Christman, M.F. (1995) Identification of novel regions of altered DNA copy number in small cell lung tumors, Genes Chromosomes Cancer, Vol. 13, pp. 175-185.

Liang, X.H., Mungal, S., Ayscue, A., Meissner, J.D., Wodnicki,P., Hockenberry, D., Lockett, S.J., and Herman, B. (1995) Bcl-2 Protooncogene Expression in Cervical Carcinoma Cell Lines Containing Inactive p53, J. Cell. Biochem., Vol. 57, pp. 509-521.

Litle, V., Bowers, E., Lockett, S.J., and Pallavicini, M.G. (1996) Slide-based approaches for genotype/phenotype analyses of low frequency tumor cells using computerized image microscopy, Cytometry, in press.

Lockett, S.J., Thompson, C., Sudar, D., Mullikin, J.,Hyun, B., Kharvari, R., Pinkel, D., and Gray, J.W. (1996) Interactive Algorithms for Rapid Chromosome Copy Number Enumeration of Individual Whole Cell Nuclei Inside Intact Tissue Specimens, Proc. SPIE, in press.

Marstaller, J.E., and Zorn, M,D. (1995) An Electronic Laboratory Notebook Based on HTML Forms, Software Documentation and Developers Manual, LBL Technical Report LBL-37809.

Marstaller, J.E., and Zorn, M.D. (1995) An Electronic Laboratory Notebook Based on the World Wide Web, in
Proc. Pacific Symposium on Biocomputing 1996(L. Hunter, and T. E. Klein, eds.), pp. 730-731.

Marstaller, J.E., and Zorn, M.D. (1995) An Electronic Laboratory Notebook Based on the World Wide Web, LBL Technical Report LBL-37808.

Mascio, L.N., Verbeek, P., Sudar, D., Kuo, W.L., and Gray, J.W. (1995) Semiautomated DNA probe mapping using digital imaging microscopy: I. System Development, Cytometry, Vol. 19, pp. 51-59.

Mehrotra, B., George, T.I., Kavanau, K., Avet-Loiseau, H., Moore, D. 2nd, Willman, C.L. Slovak, M.L., Atwater,S., Head, D.R., and Pallavicini, M.G. (1995) Cytogenetically aberrant cells in the stem cell compartment (CD34+lin-) in acute myeloid leukemia, Blood, Vol. 86, pp. 1139-1147.

Mohapatra, G., Kim, D.H., and Feuerstein, B.G. (1995) Detection of multiple gains and losses of genetic material in ten glioma cell lines by comparative genomic hybridization, Genes, Chromosomes and Cancer, Vol. 13, pp. 86-93.

Munné, S., Dailey, T., Finkelstein, M., and Weier, H-U.G. (1996) Reduction in overlaps and missing signals in interphase-FISH, Journal of Assisted Reproduction and Genetics, in press.

Munné, S., Sultan, K.M., Weier, H.U., Grifo, J.A., Cohen, J., and Rosenwaks, Z. (1995) Assessment of numeric abnormalities of $X, Y, 18$, and 16 chromosomes in preimplantation human embryos before transfer, American Journal of Obstetrics and Gynecology, Vol. 172, pp. 11911201.

Nguyen, B.T., Lazzari, K., Abebe, J., Mac, I., Lin, J.B., Chang, A., Wydner, K. L., Lawrence, J.B., Cram, L.S., Weier, H.U., Weaver, J.C., and Bradley, D.W. (1995) In situ hybridization to chromosomes stabilized in gel microdrops, Cytometry, Vol. 21, pp. 111-119.

Park, S.H., Maeda, T., Mohapatra, G., Waldman, F.M., Davi, R.L., and Feuerstein, B.G. (1995) Heterogeneity, polyploidy, aneusomy, and $9 \mathrm{p}$ deletion in human glioblastoma multiforme, Cancer Genetics and Cytogenetics, Vol. 83, pp. 127-135.

Piper, J., Rutovitz, D., Sudar, D., Kallioniemi, A., Kallioniemi, O., Waldman, F., Gray, J.W., and Pinkel, D. (1995) Computer image analysis of comparative genomic hybridization, Cytometry, Vol. 19, pp. 10-26. 
Ramshaw, H.S., Rao, S.S, Crittenden, R.B., Peters, S.O, Weier, H-U., and Quesenberry, P.J. (1995) Engraftment of bone marrow cells into normal, unprepared hosts: effects of 5-fluorouracil and cell cycle status, Blood, Vol. 86, pp. 924-929.

Robbins, W.A., Baulch,J., Moore, D., Weier,H.-U., Blakey, D., and Wyrobek, A.J. (1996) Three-probe fluorescence in situ hybridization to assess chromosome $X, Y$, and 8 aneuploidy in sperm of 14 men from two heal thy groups: evidence for a paternal age effect on sperm aneuploidy, Reprod. Fertility and Development, in press.

Sakamoto, M., Pinkel, D., Mascion, L., Sudar, D., Peters, D., Kuo, W.L., Yamakawa, K., Nakamura ,Y., Drabkin, H., Jericevic, Z., Smith, L, and Gray, J.W. (1995) Semiautomated DNA probe mapping using digital imaging microscopy: II. System performance, Cytometry, Vol. 19, pp. 60-69.

Sauter, G., Carroll,P., Moch, H., Kallioniemi, A., Kerschmann, R., Narayan, P., Mihatsch, M.J., and Waldman, F.M. (1995) c-myc copy number gains in bladder cancer detected by fluorescence in situ hybridization, American Journal of Pathology, Vol. 146, pp. 11311139.

Stokke, T., Collins, C., Kuo, W.L., Kowbel, D., Shadravan, F., Tanner, M., Kallioniemi, A., Kallioniemi, O.P., Pinkel, D., Deaven, L., and Gray. J.W. (1995) A physical map of chromosome 20 established using fluorescence in situ hybridization and digital image analysis, Genomics, Vol. 26, pp. 134-137.

Szöllösi, J., Balázs, M., Feuerstein, B.G., Benz, C.C., and Waldman, F.M. (1995) ERBB-2 (HER2/neu) gene copy number, p185HER-2 overexpression, and intratumor heterogeneity in human breast cancer, Cancer Research, Vol. 55, pp. 5400-5407.

Szöllösi, J., Lockett, S.J., Balázs, M., and Waldman, F.M. (1995) Correction of autofluorescence in digital images of fluorescence in situ hybridization, Cytometry, Vol. 20, pp. 356-361.

Tanner, M.M., Tirkkonen, M., Kallioniemi, A., Holli, K., Collins, C., Gray, J., Kallioniemi, O.P., and Isola, J. (1995) Amplification of chromosomal region 20q13 in invasive breast cancer - prognostic implications, Clinical Cancer Research, Vol. 1, pp. 1455-1461.

Waldman, F., Sauter, G., Isola, J., Kallioniemi, O., and Kallioniemi, A. (1996) Molecular cytogenetics of solid tumor progression, in Hormonal Carcinogenesis, in press.

Weier, H-U.G., Greulich, K.M., and Young, D.M. (1995) Dual temperature in situ hybridization, BioTechniques, Vol. 19, pp. 364-366.
Weier, H-U., Pinkel, D., and Gray, J. (1995) WholeChromosome Complementary Probe Fluorescence Staining, Molecular Biology and Biotechnology, R.A. Meyers (ed.), VCH Verlagsgesellschaft, Weinheim, Germany, pp. 965-968.

Weier, H-U., Pinkel, D., and Gray, J. (1995) WholeChromosomeComplementary ProbeFluorescence Staining, Encyclopedia of Molecular Biology and Molecular Medicine, Verlag Chemie, in press.

Weier, H-U.G., George, C. X., Greulich, K. M., and Samuel, C.E. (1995) The interferon-inducible, doublestranded RNA-specific adenosine deaminase gene (DSRAD) maps to human chromosome 1q21.1-21.2, Genomics, Vol. 30, pp. 372-375.

Weier, H-U.G., Wang, M., Mullikin, J.C., Zhu, Y., Cheng, J-F., Greulich, K.M., Bensimon, A., and Gray, J.W. (1995) Quantitative DNA fiber mapping, Hum. Mol. Genetics, Vol. 4, pp. 1903-1910.

Weier, H-U.G., Rhein, A.P., Shadravan, F., Collins, C., and Polikoff, D. (1995) Rapid physical mapping of the human trk proto-oncogene (NTRK1) gene to human chromosome 1q21-22 by P1 clone selection, fluorescence in situ hybridization (FISH) and computer-assisted microscopy, Genomics, Vol. 26, pp. 390-393.

Wyrobek, A., Lowe, X., Pinkel, D., and Bishop, J. (1995) Aneuploidy in late-step spermatids of mice detected by two-chromosome fluorescence in situ hybridization, Molecular Reproduction and Development, pp. 40259-266.

Zitzelsberger, H.F., Szücs, S., Weier, H.-U., Höfler, H., and Bauchinger, M. (1996) Cytogenetic analyses of primary cultures of 48 untreated human prostate carcinomas, Genes, Chromosomes and Cancer, in press.

Zorn, M. D. (1995) SubmitData - User Manual. LBL Report PUB-3126.

\section{Data Management Tools For Scientific Databases}

Chen, I.A., and Markowitz, V.M. (1995) Modeling Scientific Experiments with an Object Data Model, Proc. of the 11th Int. Conference on Data Engineering.

Chen, I.A., and Markowitz, V.M. (1995) An Overview of the Object-Protocol Model (OPM) and OPM Data Management Tools, Information Systems, Vol. 20, No. 5.

Chen, I.A., Kosky, A., Markowitz, V.M., Szeto, E. (1995) OPM*QS: The Object-Protocol Model Multidatabase Query System, Technical Report LBL-38181.

Chen, I.A., and Markowitz, V.M. (1995) Mapping OPM Schemas into Relational Database Schemas and Procedures, Technical Report LBL-33048 (revised). 
Chen, I.A., and Markowitz,V.M. (1995) The Object-Protocol Model (Version 4), Technical Report LBL-32738 (revised).

Chen, I.A., and Markowitz,V.M. (1995) OPM Schema Translator (OPMVersion 4), Technical Report LBL-35582 (revised).

Chen, I.A., Markowitz, V.M., and Szeto, E. (1995) OPM Query Translator, Technical Report LBL-38180.

Markowitz, V.M. (1995) Coping with Data Modeling Diversity, presented at the 2nd Meeting on Interconnection of Molecular Biology Databases.

Markowitz, V.M., Chen, I.A., Kosky, A. (1996) Exploring Heterogeneous Molecular Biology Databases in the Context of the Object-Protocol Model, in Theoretical and Computational Genome Research, S. Suhai (ed.), Plenum.

Markowitz, V.M., Chen, I.A., Letovsky, S., Li, P., and Fasman, K. (1996) Version Management for Scientific Databases, Proc. of the Int. Conference on Extending Database Technology (EDBT'96).

Markowitz, V.M., and Ritter, O. (1995) Characterizing Heterogeneous Molecular Biology Database Systems, Journal of Computational Biology, Vol. 2, No. 4.

\section{General Life Sciences}

\section{Structural Biology}

Baeyens, K. J., De Bondt, H., Pardi, A., and Holbrook, S. R. (1996) A curved RNA helix incorporating an internal loop with G-A and A-A non-Watson-Crick base pairing, in press.

Baeyens, K. J., DeBondt, H. L., and Holbrook, S. R. (1995) Structure of an RNA Double Helix including UracilUracil Base Pairs in an Internal Loop, Nature Str. Biol., Vol. 2, pp. 56-62.

Baeyens, K. J., Jancarik, J., and Holbrook, S. R. (1994) Use of low-molecular-weight polyethylene glycol in the crystallization of RNA oligomers, Acta Cryst., D50, pp. 764767.

Baldwin, M.A., Zhang, H., Bekker, T., Zhou, S., Nguyen, J., Kolbert, A.C., Heller, J., James, T.L., Wemmer, D.E., Pines, A., Cohen, F.E., and Prusiner, S.B. (1996) Synthetic Peptides model a-helix-b-sheet conformational changes in the prion protein, in Peptides: Chemistry, Structure and Biology, ESCOM, Leiden, in press.

Braun, J., Limbach, H.-H., Wemmer, D.E., Morimoto, H., and Williams, P.G. (1996) Observation of Kinetic Tritium Isotope Effects by Dynamic NMR. Example: The
Tautomerism of Porphyrin, J.A.C.S., in press.

Chen, J., Luecke, H., Bui, J., Song, M., Yaswen, P., and Jap, B.K. (1995) Crystallographic studies of a calmodulinlike protein, presented at the Annual American Crystallographic Association Meeting, Montréal, Québec, July 1995.

Cho, H.S., Liu, C.W., Damberger, F.F., Pelton, J.G., Nelson, H.C.M., and Wemmer, D.E. (1996) Yeast Heat Shock Transcription Factor Activation Domains are Unstructured as Probed by Heteronuclear NMR Spectroscopy, Protein Science, Vol. 5, pp. 262-269.

Damberger, F.D., Pelton, J.G., Liu, C., Cho, H., Harrison, C.J., Nelson, H.C.M., and Wemmer, D.E. (1995) Refined Solution Structure of the DNA-binding Domain of the Heat Shock Factor from Kluyveromyces lactis, J. Molec. Biol., Vol. 254, pp. 704.

Earnest, T.N., "A 2D Smart Pixel Detector for Time Resolved Protein Crystallography", IEEE Proceedings, 1995.

Earnest, T.N., "A Macromolecular Crystallography Facility at the Advanced Light Source" ,J. Crystal Growth, in press.

Fagan, P.A., Fàbrega, C., Eritja, R., Goodman, M.F., and Wemmer, D.E. (1996) An NMR Study of the Conformation of the 2-Aminopurine: Cytosine Mismatch in DNA, Biochem., Vol. 35, pp. 4026-4033.

Fagan,P.A., Spielmann, H.P., Sigurdsson, S.Th., Hopkins, P.B., and Wemmer, D.E. (1996) An NMR Study of [d(CGCGAATTCGCG) $]_{2}$ containing an Interstrand Cross-Link Derived from a Distamycin Pyrrole Conjugate, Nuc. Acids Res., Vol. 24, pp. 1566-73.

Geierstanger, B.H., and Wemmer, D.E. (1995) Complexes of the Minor Groove of DNA, Ann. Rev. Biophysics \& Biomolec. Structure, Vol. 24, pp. 463-493.

Geierstanger, B.H., Mrksich, M., Dervan, P.B., and Wemmer, D.E. (1996) Extending the Recognition Site of Designed Minor Groove Binding Molecules, Nature Structural Biology, Vol. 3, pp. 321-324.

Gustedt, W.v., Chan, M., Nikaido, H., and Jap, B.K. (1995) Large scale purification of an ABC-type protein complex, the maltose transporter of $E$. coli and preliminary crystallization results, presented at the 40th Annual Biophysical Society Meeting, Kansas City, MO, August 1995.

Heller, J., Kolbert, A.C., Larsen, R., Ernst, M., Livshitz, T., Baldwin, M., Prusiner, S.G., Pines, A., and Wemmer, D.E. (1996) Solid-State NMR Studies of the Prion Protein H1 Fragment, Prot. Science, in press. 
Heller, J., Larsen, R., Ernst, M., Kolbert, A.C., Baldwin, M., Prusiner, S.B., Wemmer, D.E., and Pines, A. (1996) Application of Rotational Resonance to Inhomogeneously Broadened Systems, Chem. Phys. Lett., Vol. 251, pp. 223-9.

Jacobsen, J.P., Pedersin, J.B., Hansen, L.F., and Wemmer, D.E. (1995) Site selective bis-intercalation of a homodimeric thiazole orange dye in DNA oligonucleotides, Nuc. Acids Res., Vol. 23, pp. 753.

Jaiswal, D.K., Morimoto, H., Trump, E.L., Williams, P.G., and Wemmer, D.E. (1996) Synthesis of High Specific Activity Tritium Labelled [2-3 $\mathrm{H}]$-Adenosine-5'Triphosphate, J. Labelled Cmpd. Radiopharm., in press.

Jap, B.K. (1995) Structural design of osmo-regulated $\mathrm{H} 2 \mathrm{O}$-channel inferred from the projection map at $3.5 \AA$ resolution, presented at the $1995 \mathrm{UCI}$ Symposium in Cancer Research, April 1995.

Jap, B.K. (1995) Structural studies of water channels, presented at NIH, Bethesda, MD, Sept. 1995.

Jap, B.K., and Li, H. (1995) Structure design of osmoregulated $\mathrm{H}_{2} \mathrm{O}$-channel inferred from high resolution projection map obtained by electron crystallography, presented at Microscopy Society of America, Feb. 1995.

Jap, B.K., and Li, H. (1995) Structure of osmo-regulated $\mathrm{H}_{2} \mathrm{O}$-channel AQP-CHIP, in projection at $3.5 \AA$ resolution, J. Mol. Biol., Vol. 251, pp. $413-420$.

Jap, B.K., and Walian, P.J. (1996) Structure and Functional Mechanism of Porins. Physiologal Reviews, in press.

Kanaar, R., Lee, A.L., Rudner, D.Z., Wemmer, D.E., and Rio, D.C. (1995) Interaction of the Sex-lethal RNA binding domains with RNA, EMBO Journal, Vol. 14,pp. 4530.

Kubinec, M.G., Culf, A.S., Cho, H., Lee, D.C., Burkham, J., Morimoto, H., Williams, P.G., and Wemmer, D.E. (1996) Applications of Tritium NMR to Macromoleucles: A Study of Two Nucleic Acid Molecules, J. of Biomol. $N M R$, in press.

Lee, J.W., Chan, M., Law, T.V., Kwon, H.J., and Jap, B.K. (1995) Preliminary cryocrystallographic study of the mitochondrial cytochrome bc1 complex: improved crystallization and flash-cooling of a large membrane protein, J. Mol. Biol., Vol. 252, pp. 15 - 19.

Lee, J.W., Law, T.V., and Jap, B.K. (1995) Improved crystallization, flash-cooling and sustained diffraction of membrane cytochrome bc1 complex, presented at the Annual American Crystallographic Association Meeting, Montréal, Québec, July 1995.

Liu, H., Spielmann, H.P., Ulyanov, N.A., Wemmer, D.E., and James, T.L. (1995) Interproton Distance Bounds from 2D-NOE Intensities: Effect of Experimental Noise and Peak Integration Errors, J.Biomol. NMR., Vol. 6, pp. 390.

Löwe, J., Stock, D., Jap, B., Zwickl, P., Baumeister, W., and Huber, R. (1995) The crystal structure of the $20 \mathrm{~S}$ proteasome from the archaeon T. acidophilum at $3.4 \AA$ resolution, Science, Vol. 268, pp. 533-539.

Magowan, C., Coppel, R.L., Lau, A.O.T., Moronne, M.M., Tchernia, G., and Mohandas, N. (1995) Role of the Plasmodium falciparum mature-parasite-Infected erythrocyte surface antigen (MESA/PfEMP-2) in malarial infection of erythrocytes, Blood, Vol. 86, pp.3196-3204.

Mannuzzu, L.M.,Moronne, M.M., and Isacoff, E.Y.(1996) Direct Measure of Conformational Rearrangement Underlying Potassium Channel Gating, Science, Vol. 271, pp. 213-216.

Meyer-Ilse, W., Medecki, H., Jochum, L., Anderson, E., Attwood, D., Magowan, C., Balhorn, R., Moronne, M. (1995) New High-Resolution Zone-Plate Microscope at Beamline 6.1 of the ALS, Synchrotron Radiation News, Vol. 8, pp. 29-33.

Moronne, M.M., Larabell, C., Meyer-Ilse, W., and von Brenndorff, A.I. (1995). Development of specific luminescent probes for biological $x$-ray microscopy, Proceedings of the 5th International Conference on Biophysics and Synchrotron Radiation, Grenoble, France.

Moronne, M.M., Larabell, C., Selvin, P.R ., and von Brendorff A.I.(1994) Development of fluorescent probes for X-ray microscopy, Microscopy Society of America, Vol. 52, pp. 48-49.

Pelton, J.G., and Wemmer, D.E. (1995) NMR Pulse Sequence Optimization for Biomolecular Studies, Ann. Rev. Phys. Chemistry, Vol. 46, pp. 139-167.

Rentzeperis, D., Marky, L.A., Dwyer, T.J., Geierstanger, B.H., Pelton, J.G., and Wemmer, D.E. (1995) Interaction of Minor Groove Ligands to an AAATT/TTTAA Site: Correlation of Thermodynamic Characterization and Solution Structure, Biochemistry, Vol. 34, pp. 2937.

Spielmann, H.P., Dwyer, T. J., Hearst, J.E., and Wemmer, D.E. (1995) The Solution Structures of Psoralen Monoadducted and Crosslinked DNA Oligomers by NMR Spectroscopy and Restrained Molecular Dynamics, Biochem., Vol. 34, pp. 12937.

Spielmann, H.P., Fagan, P.A., Bregant, T.M., Little, R.D., and Wemmer, D.E. (1995) The Binding Modes of a Rationally Designed Photoactivated DNA Nuclease Determined by NMR, Nuc. Acids Res., Vol. 23, pp. 1576.

Spielmann, H.P., Wemmer, D.E., and Jacobsen,J.P. (1995) The Solution Structure of a DNA Complex with the 
Fluorescent bis-intercalator TOTO determined by NMR Spectroscopy, Biochemistry, Vol. 34, pp. 8542.

Spielmann, P.H., Dwyer, T.J., Sastry, S., Hearst, J.E., and Wemmer, D.E. (1995) DNA Structural Reorganization Upon Conversion of a Psoralen Furanside Monoadduct to an Interstrand Cross-Link: Implications for DNA Repair, Proc. Natl. Acad. Sci., Vol. 92, pp. 2345.

Volkman, B.F., Nohaile, M.J., Amy, N., Kustu, S., and Wemmer, D.E. (1995) Three-Dimensional Solution Structure of the N-Terminal Receiver Domain of NTRC, Biochemistry, Vol. 34, pp. 1413.

Wemmer, D.E. (1996) A, B and ZDNA, in Encyclopedia of NMR, D.M.Grant and R.K.Harris, Eds., J.Wiley and Sons, NY, in press.

Wemmer, D.E. (1996) Design and Characterization of New Sequence Specific DNA Ligands, in Proceedings of the International Biological NMR Symposium, Oxford University Press, in press.

Wemmer, D.E. (1996) New Features in RNA Recognition: A Tat-TAR Complex, Chemistry \& Biology, Vol. 3, pp. 17-19.

\section{Human Genome Center}

Denefle P., Hughes S., Desurmont C., Vigne E, Bassinet L., Verstuyft J., Perricaudet M., Benoit P., Rubin E.M. (1995) Towards gene therapy targeting HDL. Athero 10:501-505.

Frazer K.A., Narla G., Zhang J., Rubin E.M. (1995) The apolipoprotein(a) gene is regulated by sex hormones and acute phase inducers in YAC transgenic mice. Nat Gen 9:424-431

Kimmerly, W.J., Kyle, A.L., Lustre, V.M., Martin, C.H., and Palazzolo, M.J. (1995) Direct Sequencing of Terminal Regions of Genomic P1 Clones, in press.

Martin, C.H., Mayeda, C.A., Davis, C.A., Ericsson, C.L., Knafels, J.D., Mathog, D.R., Celniker, S.E., Lewis, E.B., and Palazzolo, M.J. (1995) Complete sequence of the bithorax complex of Drosophila, Proc. Natl. Acad. Scie. USA, Vol. 92, pp. 8398-8402.

Martin, C.H., Mayeda, C.A., Davis, C.A., Strathmann, M.P., and Palazzolo, M.J. (1994) Transponson-facilitated Sequencing: an Effectice Set of Procedures to Sequence DNA Fragments Smaller than $4 \mathrm{~kb}$, in Automated DNA Sequencing and Analysis, Adams, M.D., Fields, C. and Venter, J.C., eds., Academic Press, London, pp 60-64.

Rubin E.M., Smith D.J., Atheroslerosis in mice: Getting to the heart of a polygenic disorder. (1994) Trends in
Genetics 10:199-203.

Smith D.J., Zhu Y., Zhang J.-L., Cheng J.-F., Rubin E.M. (1995) Construction of a contiguous $2 \mathrm{Mb} Y A C / P 1$ library of human chromosome 21q22.2 in transgenic mice. Genomics 27:425-434

Smoller, D.A., Kimmerly, W.J., Hubbard, O., Ericsson, C., Martin, C.H., and Palazzolo, M.J. (1994) A role for the P1Cloning System in Genome Analysis. Automated DNA Sequencing and Analysis, Adams, M.D., Fields, C. and Venter, J.C. eds., Academic Press, London, pp. 88-95.

Van Gelder, R.N., Bae, Helen, Palazzolo, M.J., and Krasnow, M.A. (1995) Extent and character of circadian gene expression in Drosophila melanogaster: identification of twenty oscillating mRNAs in the fly head, Current Biology, Vol. 5, No. 12.

Veklerov, E.,Martin, C.H., and Theil,E.H. (1995) TRAMP: a software package for generating transposon maps, Cabios, pp. 173-179.

\section{Medical Applications}

Campos, H., Dreon, D.M., and Krauss, R.M. (1995) Associations of hepatic and lipoprotein lipase activities with changes in dietary intake and low density lipoprotein subclasses, J. Lipid Res., Vol. 36, pp. 462-472.

Campos, H., Roederer, G.O., Lussier-Cacan, S., Davignon, J., and Krauss, R.M. (1995) Predominance of large LDL and reduced $\mathrm{HDL}_{2}$ cholesterol in normolipidemic men with coronary artery disease, Arterioscler. Thromb. Vasc. Biol., Vol. 15, pp. 1043-1048.

Krauss, R.M. (1995) Genetic influences on lipoprotein responses to dietary fat and cholesterol, Am. J. Clin. Nutr., Vol. 62, No. 2, (Suppl.), p. 457S.

Krauss, R.M. (1995) Nutrient-gene interactions in carbohydrate and lipid metabolism: unraveling the tangled web, Commentary. Curr. Op. Endocrinol., Vol. 2, pp.511512.

Krauss, R.M. (1995) Plasma lipids and lipoproteins, in Hormone Replacement Therapy and The Cardiovascular System: Recent Advances, Cardiovascular Workshop, Basle, Switzerland, November 26, 1994; The Medicine Group (Journals) Ltd., Publishing House, pp.12-14.

Krauss, R.M., Chait, A., and Stone, N.J. (1995) Soy protein and serum lipids, Letter to the Editor. N. Engl. J. Med., Vol. 333, p. 1715.

Krauss, R.M., and Dreon, D.M. (1995) Low density lipoprotein subclasses and response to a low-fat diet in healthy men, Am. J. Clin. Nutr., Vol. 62, No. 2 (Suppl.) pp. 478S-487S. 
Krauss, R.M., and Kesaniemi, Y. A. (1995) Dyslipidemic syndromes and atherosclerosis: recent advances and challenges for the future, Editorial Comment. Curr. Op. Lipidol., Vol. 6, pp. 187-189.

Krauss, R.M., Rotter, J.I., and Lusis, A.J. (1995) Genetic and metabolic influences on LDL subclasses, in Atherosclerosis X. Proceedings of the 10th International Symposium on Atherosclerosis, Montreal, October 9-14, 1994. (F.P. Woodford, J. Davignon and A. Sniderman, eds.) Elsevier Science Publishers, pp. 980-998.

Mack, W.J., R.M. Krauss, H.N. Hodis. Lipoprotein subclasses in the monitored atherosclerosis regression study (MARS):Treatment effects and relation to angiographic progression. Arterioscler. Thromb. Vasc. Biol. 16:697704, 1996.

Rotter, J.I., Bu, X., Cantor, R. M., Warden, C.H., Brown, J., Gray, R. J., Blanche, P.J., Krauss, R.M., and Lusis, A.J. (1996) Multilocus genetic determinants of LDL particle size in coronary artery disease families, Am J. Hum. Genet., Vol. 58, No. 3, pp. 585-594.

Rutledge, J.C., Curry, F.E., Blanche, P., and Krauss, R.M. (1995) Solvent drag of LDL across mammalian endothelial barriers with increased permeability, Am. J. Physiol., Vol. 268, pp. H1982-H1991.

Tribble, D.L., Krauss, R.M., Lansberg, M.G., Thiel, P., and van den Berg, J.J.M. (1995) Greater oxidative susceptibility of the surface monolayer in small, dense LDL contributes to differences in copper-induced oxidation among LDL density subfractions, J. Lipid. Res., Vol. 36, pp. 662-671.

Tribble, D.L., Thiel, P.M., van den Berg, J.J.M., and Krauss, R.M. (1995) Differing a-tocopherol oxidative lability and ascorbic acid sparing effects in buoyant and dense LDL, Arterioscler. Thromb. Vasc. Biol., Vol. 15, pp. 2025-2031.

Williams, P.T., Dreon, D.M., and Krauss, R.M. (1995) Effects of dietary fat on high-density- lipoprotein subclasses are influenced by both apolipoprotein $\mathrm{E}$ isoforms and low-density-lipoprotein subclass patterns, Am. J. Clin. Nutr., Vol. 61, pp. 1234-1240.

\section{The Center for Functional Imaging}

Albert, M.S., Schepkin, V.D., and Budinger, T.F. (1995) 129Xe T1 in blood to explore the feasibility of hyperpolarized 129Xe MRI, Journal of Computer Assisted Tomography, Vol. 19, No. 6, pp. 975-981.

Budinger, T.F. (1995) Health and safety aspects of human magnetic resonance studies. Encyclopedia of Nuclear Magnetic Resonance, John Wiley \& Sons Ltd., Vol. 4, pp.

\section{8-2273.}

Budinger, T.F. (1996) Medical imaging, in Introduction to Bioengineering, Williams \& Wilkins, in print.

Budinger, T.F. (1995) New approaches to targeting arthritis with radiopharmaceuticals, Journal of Rheumatology, Vol. 22, No. 1, Supp 43.

Budinger, T.F. (1995) PET instrumentation, in Biomedical Engineering Handbook, CRC Press, Vol. 69.2, pp. 11341139.

Budinger, T.F. (1996) Single photon emission computed tomography, in Diagnostic Nuclear Medicine, 3rd Ed., MP Sandler, RE Coleman, FJTh Wackers, JA Patton, A Gottschalk and PB Hoffer, eds., Williams \& Wilkins, Baltimore, MD, Vol. I, pp. 121-138.

Budinger, T.F., and VanBrocklin, H.F. (1995) Radiopharmaceuticals, in Biomedical Engineering Handbook, CRC Press, Vol. 69.1, pp. 1140-1150.

Coxson, P.G., Brennan, K.M., Huesman, R.H., Lim, S., and Budinger, T.F. (1995) Variability and reproducibility of rubidium-82 kinetic parameters in the myocardium of the anesthetized canine, Journal of Nuclear Medicine, Vol. 36., No. 2, pp. 287-296.

Coxson, P.G., Huesman, R.H., Lim, S., Klein, G.J., Reutter, B.W., and Budinger, T.F. (1995) Comparison of kinetic models for data from a positron emission tomograph, Proceedings of SPIE, San Diego, CA.

Eberling, J.L., Nordahl, T.E., Kusubov, N., Reed, B.R., Budinger, T.F., and Jagust. W.J. (1995) Reduced temporal lobe glucose metabolism in aging, Journal of Neuroimaging, Vol. 5, No. 3, pp. 178-182.

Huesman, R.H., Klein, G.J., Reutter, B.W., Coxson, P.G., Botvinick, E.H., and Budinger, T.F. (1995) Strategies for Extraction of Quantitative Data from Volumetric Dynamic Cardiac PET Data, submitted to Cardiology, in press, LBL Report No. LBL-37775, UC-408.

Moses, W.W., Derenzo, S.E., and Budinger, T.F. (1994) PET detector modules based on novel detector technologies, Nuclear Instruments and Methods in Physics Research, Vol. 353, pp. 189-194.

Wanna, F.S., Young, J.N., Budinger, T.F., and DeCampli, W.M. (1995) Effects of singlet oxygen and its scavenger (tryptophan) on bioenergetics and the recovery of the ischemic myocardium, Proceedings of 81st Annual Clinical Congress of American College of Surgeons. 


\section{Appendix 7.5}

Selected Research Highlights

The titles of the following brief narratives describe significant research highlights of OHER-sponsored research at LBNL during FY 1995-1996.

* Quantitative Image Processing System (Quips ${ }^{\mathrm{TM}}$ ): A new multi-color digital fluorescence microscopy workstation for molecular cytogenetic applications.

- Radiation Resistant Fluorescent Probes.

* The Biomedical Isotope Facility-Comes On Line.

* The Center for Environmental Biotechnology.

* New Human Genome Laboratory Takes Shape; Five Million Base Pair Sequencing Milestone Surpassed; Palazzolo Named Genome Center Director. 


\section{Quips $^{\mathrm{TM}}$ : \\ Quantitative Image Processing System}

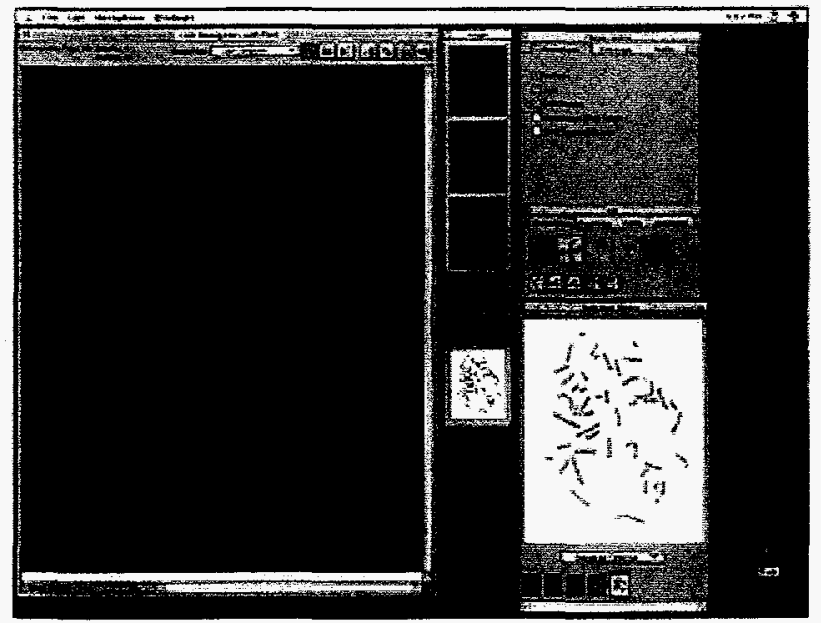

CGH application full screen view

The Resource for Molecular Cytogentics has developed a new multi-color digital fluorescence microscopy workstation for molecular cytogenetic applications, including probe mapping, genotypic and phenotypic analysis of individual cells, and comparative genomic hybridization $(\mathrm{CGH})$

Computer assisted fluorescence microscopy offers several advantages in molecular cytogenetic studies including increased sensitivity (a camera can be equipped with a light intensifier or can integrate the signal), improved visualization (image processing can be used to enhance contrast or bring out important features), reduced bleaching problems (once captured the image can be viewed without bleaching any more), quantitative analysis (quantitation of geometric features or intensities) and automation (the microscope can be equipped with automated stage, filterwheels, shutters, etc.). Both conventional microscopy and confocal microscopy have been applied to acquisition of multi-color images of cells stained using FISH (Fluorescence In Situ Hybridization).

High resolution multi-color images are acquired using a computer controlled research fluorescent microscope equipped with a high resolution $C C D$ camera and an intensified CCD (ICCD). The video frame rate ICCD is used for manual roam and focus and the slower high resolution $C C D$ is used for image acquisition. The acquisition is connected to a network of UNIX workstations which are used for data storage and analysis. Decoupling of the data acquisition and analysis allows a better use of the acquisition equipment.

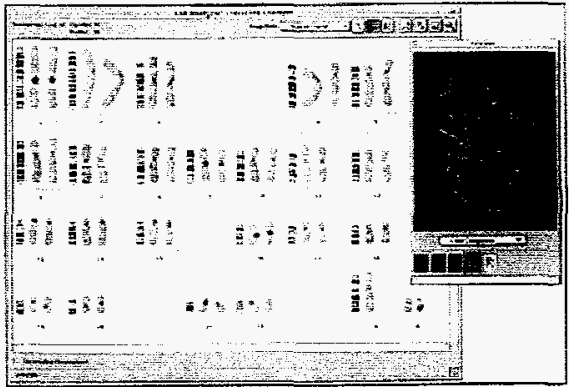

DAPI-banded karotype and color metphase

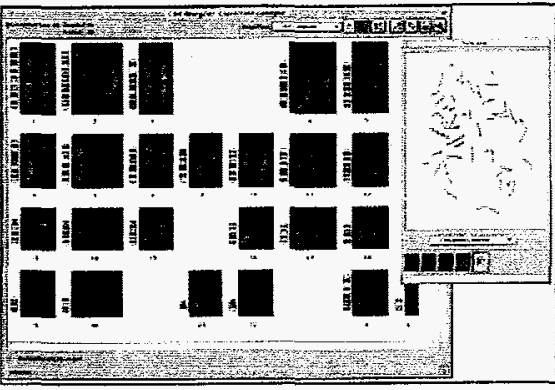

Color karotype and DAPI metphase

Computer assisted microscopy has already been applied in a variety of molecular cytogenetic studies including a) quantitative analysis of hybridization intensity (e.g. to allow classification of probes according the ratio of fluorescence intensities in two or more spectral ranges or as required for $\mathrm{CGH}$ analysis), b) for probe mapping and c) for hybridization domain enumeration. However, the true utility of this technology is only beginning to be realized. In seems likely that work in this area of the next few years will result in almost completeautomation of probe mapping, gene copy number analysis, translocation detection in interphase and metaphase and residual or metastatic disease detection. In addition, this technology should also allow analysis of the correlation between genotype and phenotype as needed to understand the biological consequences of genetic aberrations. QUIPS ${ }^{\mathrm{TM}}$ enables geneticists, cytogeneticists, pathologists, molecular biologists, and other healthcare professionals to clearly see genetic aberrations associated with disease. Its speed and imageenhancement capabilities set it apart from other genetics software. The QUIPS ${ }^{\mathrm{TM}}$ technology is licensed to and marketed by Vysis, Inc., a Illinois-based diagnostics company which is driving the development of disease management with molecular techniques through innovation and commercialization of genomic assessment products (many of these innovations, such as fluorescent probes for cancer detection, have been developed by The Resource-a Berkeley Lab partnership with the Cancer Center at UCSF).

Contact:

Damir Sudar, (510) 486-5359

e-mail:damir@white.lbl.gov

website: http://rmc-www.lbl.gov/ 


\section{Radiation Resistant Fluorescent Probes for High Resolution Soft $X$-ray Microscopy}

The specific aim of this project is to develop radiation resistant fluorescent probes uniquely suited for applications in $x$-ray microscopy. In particular, these compounds will make it possible to take advantage of the high resolution capabilities (5-10 times better than light microscopy) of scanning $x$-ray microscopes based on third generation soft $x$-rays sources such as the Advanced Light Source (ALS). In addition, the radiation tolerance of these probes will also make them suitable for use with cathodoluminesence that depends on electron beam excitation. Most scanning electron microscopes (SEM) are capable of being used for cathodoluminescence, especially with the new photodetectors being developed by Oxford Instruments and others. Since SEMs are ubiquitous in biology and material science, this could represent a sizable commercial market.

$X$-ray microscopy and cathodoluminescence are complementary in that the former can be used with intact biological structures up to $10 \mu \mathrm{m}$ thick, whereas the latter is capable of very high resolution but primarily for shallow surface features. At present, no proven biological labeling strategies exist for these technologies; the main difficulty is that conventional organic dyes used for light microscopy, which have revolutionized cell biology in the last two decades, are readily destroyed by energetic $x$-rays and electrons. The lanthanide probes we are developing, remain stable even with very large doses of radiation and have the potential of being of great practical utility for scanning $x$-ray and electron microscopy.

We have recently demonstrated that lanthanide conjugated probe molecules including DNA, avidin, secondary antibodies, and biotinylated polychelates produce useful luminescence under $x$-ray excitation. A consistent observation regardless of the specific lanthanide compound studied is that useful luminescence is obtained at doses well above $10^{10}$ rads. Calculations based on this data show that our reagents are sufficiently bright to visualize microtubules at $50 \mathrm{~nm}$ resolution. This latter figure is (the confocal microscopy), but at 4 to 5 times better resolution. Images of lanthanide labeled specimens of actin stress fibers in mouse 3 T 3 cells were obtained and microtubule assemblies were isolated confirming that these probes can be used for high resolution $x$-ray excited luminescence microscopy in actual biological samples.

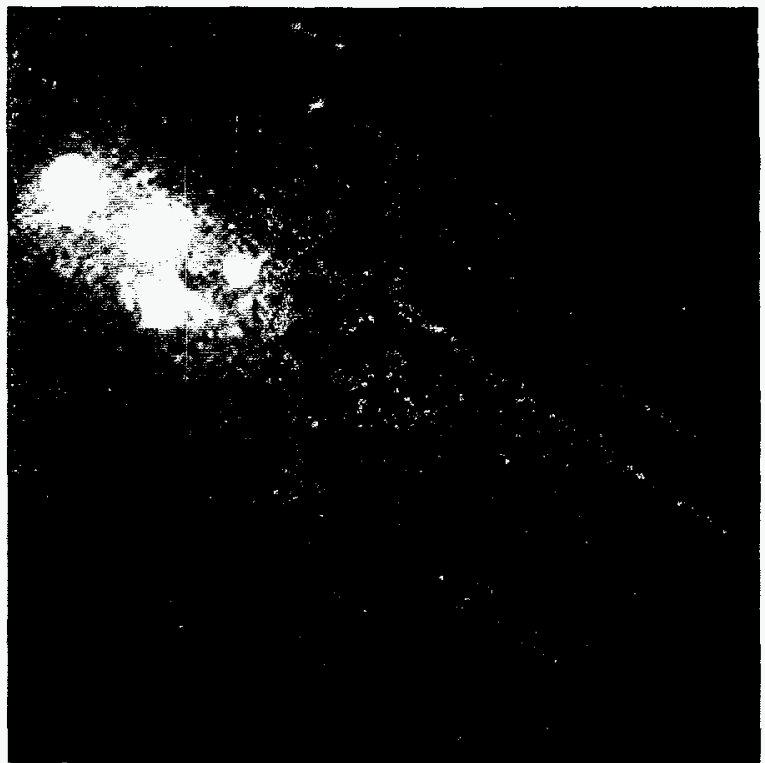

X-ray nanoprobe-excited Terbium luminescence image.

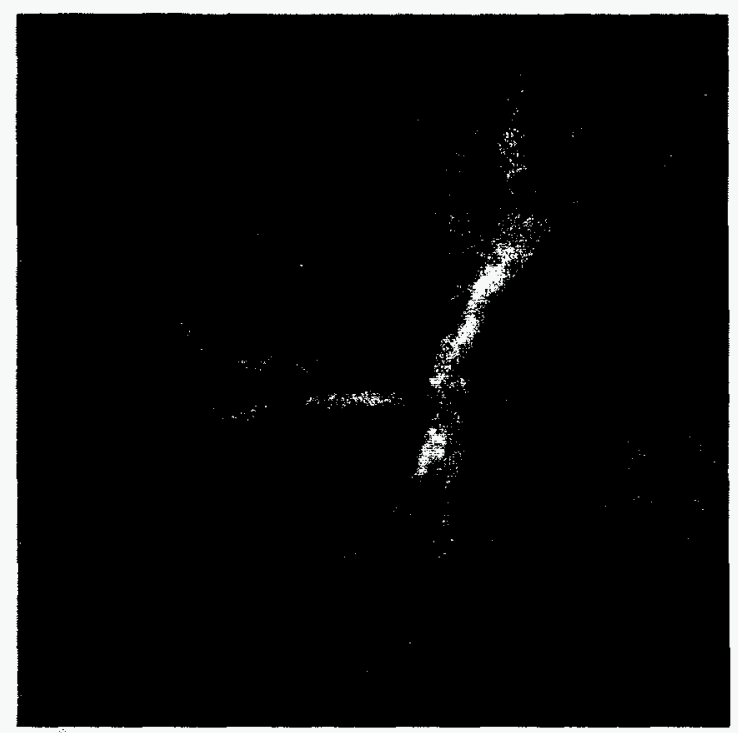

In vitro polymerized tubulin Terbium luminescence.

Contact:

Mario Moronne, (510) 486-4236

e-mail: mario@csa.lbl.gov 


\section{The Biomedical Isotope Facility- comes on line}

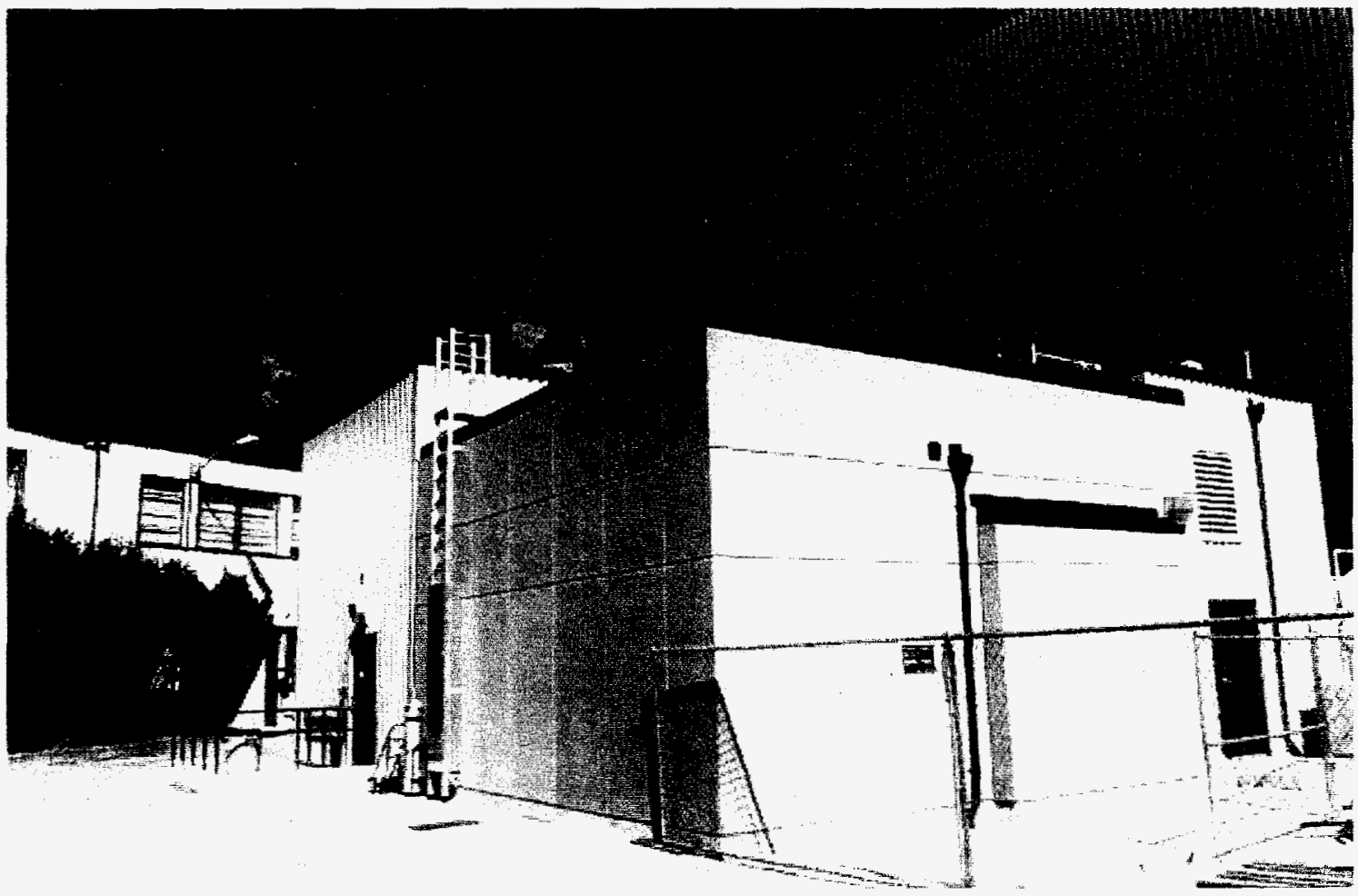

On July 5th, 1995 a new cyclotron was installed at the Biomedical Isotope Facility, building 56 on the Berkeley Lab campus. On August 17th the first beam on target was achieved. The first batch of radioisotope was produced in early September. This $10 \mathrm{MeV}$ proton machine is capable of producing Curie quantities of Fluorine-18, Carbon-11, Nitrogen-13 and Oxygen-15, positron emitters that can be incorporated into radioactive tracers for medical imaging with positron emission tomography. The first patientdose of FDG ([F-18] fluorodeoxyglucose) was produced in early January 1996 with [F-18]fluorometa-tyrosine and [N-13] ammonia produced in mid February. These compounds and new radiotracers, combined with the high resolution instrumentation and computational methods developed at the Center for Functional Imaging are blazing new trails toward a better understanding of cardiovascular disease and such neurodegenerative diseases as Parkinson's and Alzheimer's. A formal dedication of the new Biomedical Isotope Facility is scheduled for the end of August, 1996.

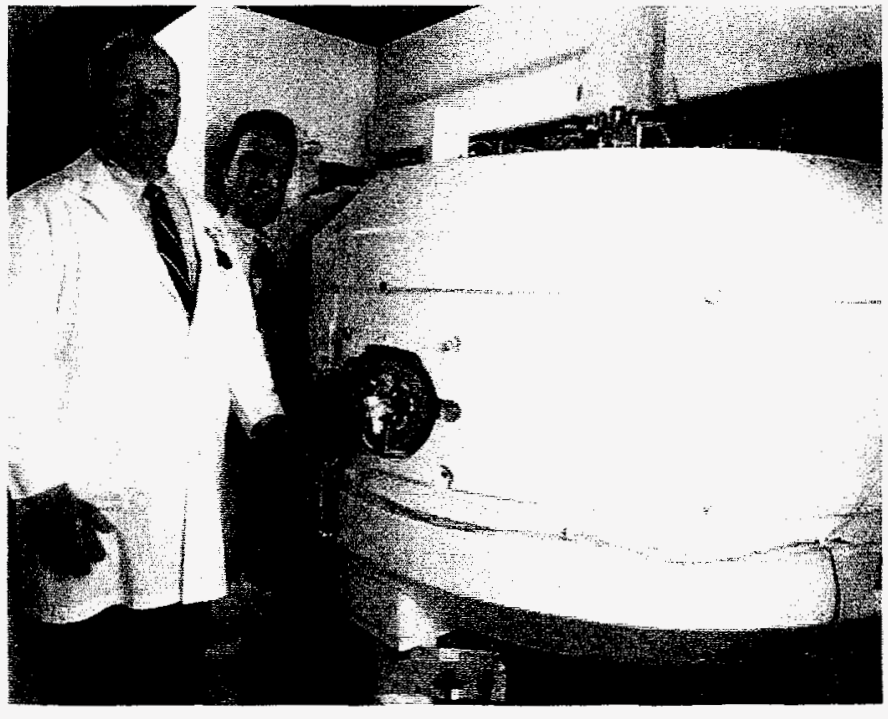

Contact:

Henry VanBrocklin, (510) 486-4083

e-mail: hfvanbrocklin@lbl.gov

website: http://cfi.lbl.gool 


\section{The Center for Environmental Biotechnology}

The Center for Environmental Biotechnology (CEB) was founded in 1995 to coordinate and implement interdisciplinary, multidivisional research in environmental biotechnology. CEB focuses on such environmental issues as: mixed contamination at DOE defense labs, defense base closures, petroleum refining and exploration, computer/metal electroplating industries, ore mining and processing, ground water/sewage, agriculture, aquaculture and forest-related wastes, as well as marine, wetland/marshland/sediment pollution. Both basic and applied research programs are being established under six key focus areas:

- Molecular evolution of microorganisms in damaged environments

- Monitoring of in situ and ex situ bioremediation

- Natural augmentation of bioremedial activity

- Structure-function relationships of in situ and ex situ bioremediation

- Health-riskassessmentof potentially hazardous materials

- Ecotoxicity assessment of bioavailability

These focus areas bring together the existing capabilities at Berkeley Lab and the University of California at Berkeley and link them with outside capabilities within academia, industry, government agencies and research institutions. The strengths and capabilities Berkeley Lab has developed over the years in the environmental area, such as sutrurface imaging, fiber optics, site characterization, and monitoring of bioremediation using stable isotope chemistry, have been successfully applied to environmental problems in the field. The Center links biotechnology to technologies for environmental applications developed at the Advanced Light Source, the National Center for Electron Microscopy, and the Human Genome Center. The Center also manages wideranging programs, such as the Bioremediation, Education, Science and Technology (BEST) program, an HBCUand minority-institutions-targeted special environmental education project, coordinates for Berkeley Lab the

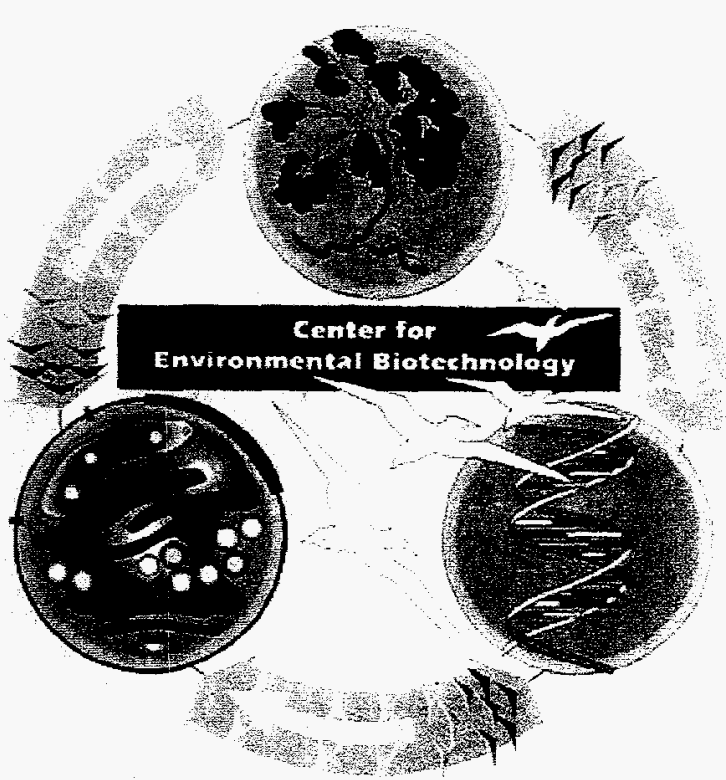

Alameda Naval Air Station base closure clean-up program, and participates in the daily operation of the home office for the Natural and Accelerated Bioremediation Research (NABIR) program for DOE/ER. The biweekly Center Forums present outstanding scientists with interdisciplinary research interests and attract a wide audience.

It is CEB's vision to establish research programs that will result in technology transfer and have immediate spinoffs for both DOE and non-DOE projects, statewide and across the nation. CEB's goal is to build bridges and enhance synergy among scientists, disciplines, and institutions.

Contact:

Jennie Hunter-Cevera, (510) 486-7359

e-mail: JCHunter-Cevera@lbl.gov

website: http://www.lbl.gov/ julie/CEB/ 
New Human Genome Laboratory Takes Shape

\section{Million Base Pair} Sequencing Milestone Surpassed

\section{Palazzolo Named}

\section{Genome Center Director}

The groundbreaking for the new Human Genome Laboratory took place on August 15, 1995. When completed, at the end of 1997 , the facility will bring together under one roof the many research teams that make up LBNL's Human Genome Center. Inside the new Laboratory will be space for mapping, sequencing, and cloning activities; biochemistry studies; data processing facilities; cell and tissue culture facilities; equipment and instrumentation rooms; and controlled environmental chambers.

The structure, located on the hillside above Bldg. 74, will be three stories high with 44,000 square feet of space and is expected to cost $\$ 24.7$ million.

By June, 1996, The Human Genome Center surpassed the five million base pair milestone, placing it in the top two or three genome centers in the world in terms of sequence generated and efficiency. The rate of sequence generation is currently at 500,000 base pairs a month and increasing steadily (compared to 80,000 a month in 1994). Cost per base pair is currently at 38 cents direct, 56 cents total. Current total (June 21) is 1,926,541 of human sequence, and $3,521,024$ of Drosophila, for a total of $5,447,565$ finished, double-stranded sequence, $3,000,000$ of which has been submitted to the Genome Sequence Data Base (GSDB) with an error rate of only 1 in 5000 (compared with 1:2500 in 1994).

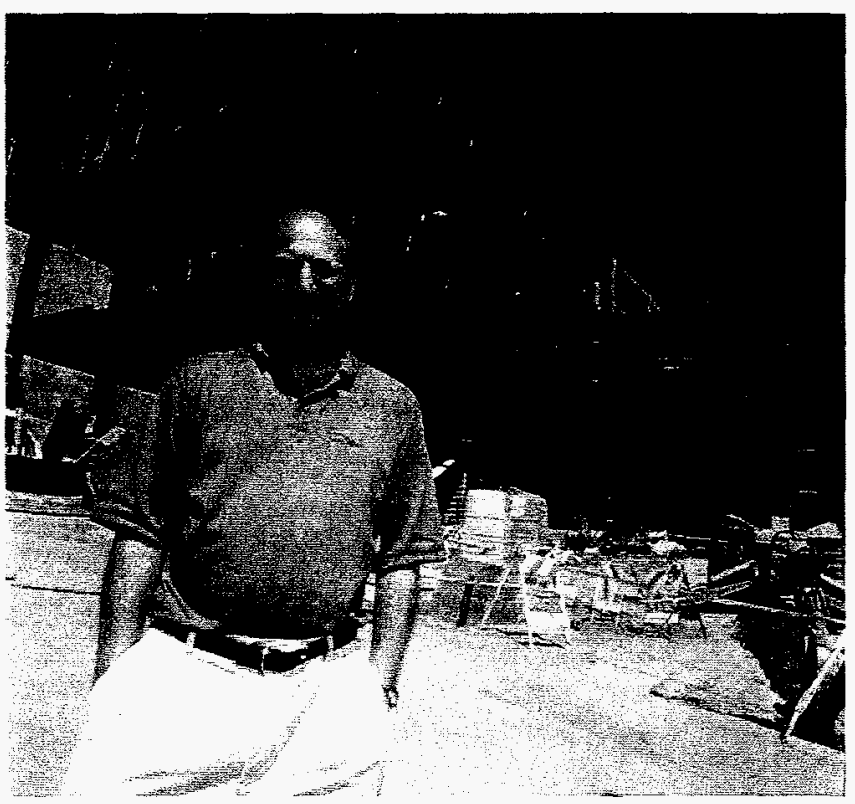

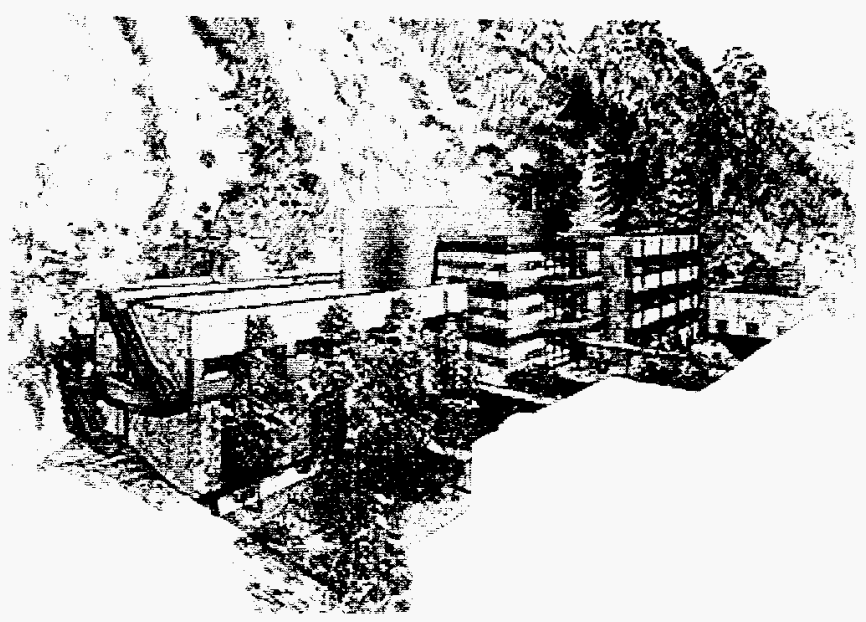

Also in June, 1996, Michael J. Palazzolo was appointed Director of the Human Genome Center at Berkeley Lab.A Phi Beta Kappa graduate of Columbia University, Palazzolo, 41, earned his B.A. in chemistry, and the M.D./Ph.D. in Medicine/Physiology. He conducted his doctoral research with James $\mathrm{H}$. Schwartz from the Center for Neurobiology and Behavior and with Richard Axel at the Institute for Cancer Research, both at Columbia. From 1985 to 1990 , he did postdoctoral research at Caltech and in 1990-91 was a research assistant professor with the Department of Genetics at Washington University School of Medicine, St. Louis.

Palazzolo cited two things that mark the strength of the Genome Center -- "the group leaders, Chris Martin, Joe Jaklevic, Frank Eeckman, and Eddy Rubin, with their talents and abilities to work together, and the others at the center who make the work happen."

Palazzolo succeeds Mohan Narla, who served as acting director since January of 1994 and will assume leadership of a new department in the Life Sciences Division that will combine studies of membrane proteins with innovative microscopies.

The Berkeley Lab Human Genome Center, established in 1988, has an 80-person staff and a current annual budget of about $\$ 16$ million. It combines expertise in biology, industrial automation and computing sciences through research and technology to help decipher the blueprint for man - the human genome.

The Center is also engaged in a major collaborative effort with the Berkeley campus and Carnegie Institution of Washington to map, sequence and characterize the genome of the fruit fly - Drosophila melanogaster. The National Institutes of Health (NIH) currently provides $\$ 5$ million per year to support this project.

Contact:

Michael Palazzolo, (510) 486-6932

e-mail: MJPalazzolo@lbl.gov

website: http://www-hgc.lbl.gov/GenomeHome.html 